\title{
Competitive Aggressiveness, Anger, and the Experience of Provocation in Collegiate Athletes
}

\author{
Michael E. Berrebi
}

Follow this and additional works at: https://researchrepository.wvu.edu/etd

\section{Recommended Citation}

Berrebi, Michael E., "Competitive Aggressiveness, Anger, and the Experience of Provocation in Collegiate Athletes" (2018). Graduate Theses, Dissertations, and Problem Reports. 5194.

https://researchrepository.wvu.edu/etd/5194

This Dissertation is protected by copyright and/or related rights. It has been brought to you by the The Research Repository @ WVU with permission from the rights-holder(s). You are free to use this Dissertation in any way that is permitted by the copyright and related rights legislation that applies to your use. For other uses you must obtain permission from the rights-holder(s) directly, unless additional rights are indicated by a Creative Commons license in the record and/ or on the work itself. This Dissertation has been accepted for inclusion in WVU Graduate Theses, Dissertations, and Problem Reports collection by an authorized administrator of The Research Repository @ WVU.

For more information, please contact researchrepository@mail.wvu.edu. 
Competitive Aggressiveness, Anger, and the Experience of Provocation in Collegiate Athletes

Michael E. Berrebi, M.S.

Dissertation submitted to the College of Physical Activity and Sport Sciences at West Virginia University

in partial fulfillment of the requirements for the degree of

Doctor of Philosophy in

Sport \& Exercise Psychology

Edward Etzel, Ed.D., Chair

Jack Watson II, Ph.D.

Scott Barnicle, Ph.D.

David Mitchell, Ph.D.

Department of Sport Sciences

Morgantown, West Virginia

2018

Keywords: anger, aggression, aggressiveness, provocation, college athletes

(C) 2018 Michael E. Berrebi 


\begin{abstract}
Competitive Aggressiveness, Anger, and the Experience of Provocation in Collegiate Athletes

Michael E. Berrebi

In sport, aggressive behavior is a potentially harmful byproduct of uncontrolled anger. In addition, it is known that provocation can lead to both anger and aggressive retaliation. However, despite the potential consequences of aggressive behavior, little is known about levels of competitive anger and aggressiveness in athletes, and it is unclear if differences exist by gender or type of sport. Little research has also explored intervention approaches to help athletes better manage anger and aggression. Therefore, the purpose of this study was to explore competitive aggressiveness, anger, and the experience of provocation among collegiate athletes. Participants were 243 male and female contact or collision sport athletes competing at NCAA Division I, II, and III universities across the country. Participants filled out questionnaires assessing both competitive aggressiveness and anger and the experience of provocation. Overall, it was found that male athletes scored significantly higher than female athletes on competitive aggressiveness, as well as experiencing more frequent provocative behavior and more negative and intense responses to provocation. Collision sport athletes were also found to be higher in competitive aggressiveness and anger, regardless of gender. Division I and II athletes were found to be significantly higher than Division III athletes in competitive aggressiveness and anger.
\end{abstract}




\section{TABLE OF CONTENTS}

Page \#

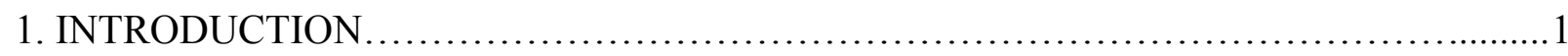

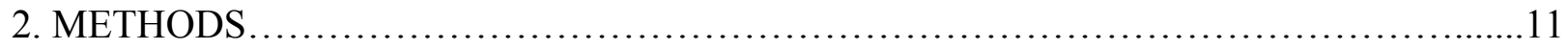

2.1. Participants......................................................... 11

2.2. Research Design and Sampling.........................................11

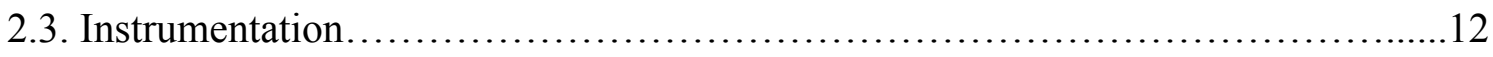

2.3.1. Demographic questionnaire.................................... 12

2.3.2. Competitive aggressiveness and anger...........................12

2.3.3. Provocation................................................. 14

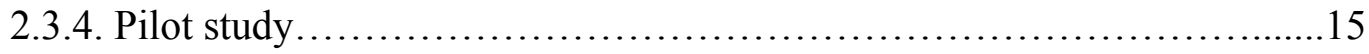

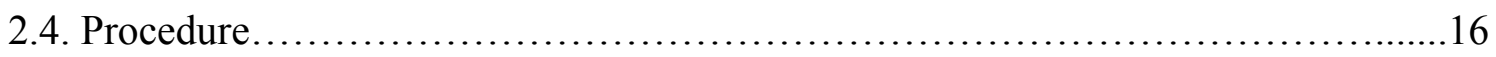

2.5. Data Analysis......................................................... 17

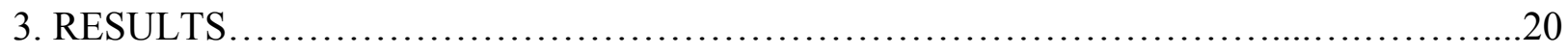

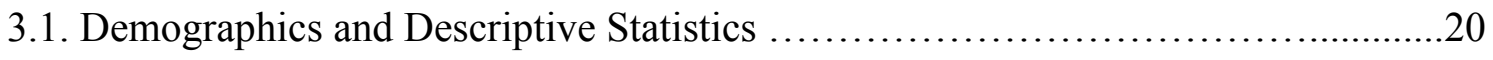

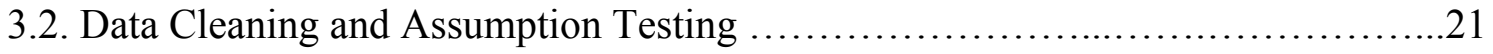

3.3. Bivariate Statistics.................................................22

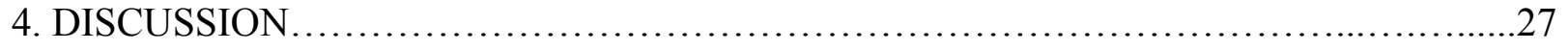

4.1. Competitive Aggressiveness and Anger....................................27

4.1.1. Gender comparisons...........................................27

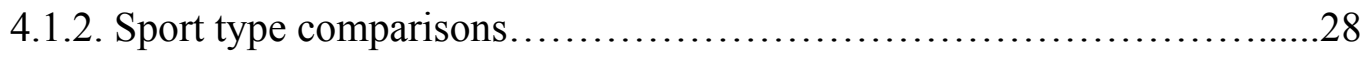

4.1.3. Division level comparisons.................................... 32

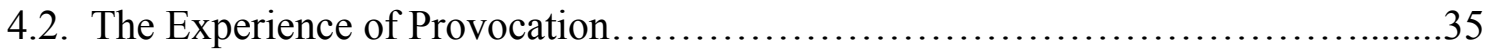


4.2.1. Gender comparisons........................................... 35

4.2.2. Sport type comparisons......................................36

4.2.3. Division level comparisons......................................... 38

4.3. Future Research and Directions..............................................

4.3. Study Strengths and Limitations........................................42

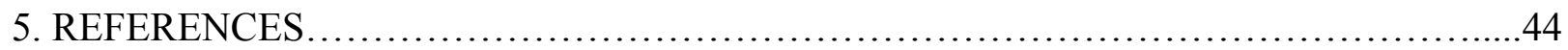

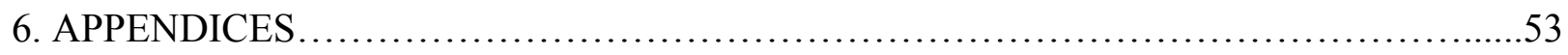

6.1. Appendix A: Data Tables.............................................53

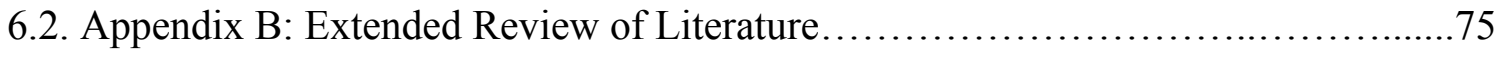

6.2.1. Part I: Competitive Anger in Sport................................ 75

6.2.2. Part II: Aggressive Behavior in Sport..............................88

6.2.3. Part III: Managing Anger and Aggressive Behavior in Sport..............107

6.2.4. Significance of Study ......................................... 115

6.2.5. References.................................................. 121

6.3. Appendix C: Assistant and Head Coach Recruitment Letter.....................139

6.4. Appendix D: Participant Cover Page...........................................140

6.5. Appendix E: Demographic Questionnaire................................... 141

6.6. Appendix F: Competitive Aggressiveness and Anger Scale.....................142

6.7. Appendix G: Sport Provocation Questionnaire.............................143

6.8. Appendix H: SPQ Pilot Data and Feedback................................ 146 


\section{Introduction}

In sport, there is sufficient anecdotal and empirical evidence that suggests being able to manage one's emotions is a key factor in influencing performance (e.g., Hanin, 2010; Lane, 2007; Woodcock, Cumming, Duda, \& Sharp, 2012). In addition to athletic ability, teamwork, and strategy, sport performance also hinges upon the ability of the athlete to regulate emotions. Throughout a competition, athletes experience a variety of positive and negative emotions that can influence motivation and change both physical and cognitive performance (Botterill \& Brown, 2002). More recently, it has been suggested that being able to regulate emotions in sport is an important determinant of performance outcomes both for individual athletes (e.g., Lane, Beedie, Jones, Uphill, \& Devonport, 2012) and teams (Wagstaff \& Weston, 2014).

Anger has been described as "an emotional state that consists of feelings that vary in intensity, with associated activation or arousal of the autonomic nervous system" (Spielberger \& Reheiser, 2009, p. 281). A key component of this definition is the lack of judgment regarding whether anger is a "good" or "bad" thing, but rather a normal, human emotion. In fact, experiencing anger is somewhat unavoidable, especially in high-stress, pressure-packed environments that competitive sports embody. Whether an athlete's anger becomes problematic appears to be less about the fact that it is present and more about the nature and severity of behavioral outcomes (Kassinove \& Tafrate, 2002). In fact, researchers who have explored whether anger helps or hurts performance in sport have presented mixed results (e.g., Robazza \& Bortoli, 2007; Ruiz \& Hanin, 2011). It seems the most important factor is how anger is interpreted and managed by athletes (Hanin \& Syrja, 1995).

Despite a growing body of research focused on exploring emotions in sport, anger has not been thoroughly investigated. This is in spite of the knowledge that anger is one of the most 
common emotions that athletes experience during competitive play (Sofia \& Cruz, 2016). While anger is an emotion expressed by a high percentage of athletes, researchers suggest gender, competition level, and type of sport may play a factor in the level of anger experienced by athletes (Maxwell, Visek, \& Moores, 2009). Some findings suggest the possibility that athletes with a perfectionist orientation are at a greater risk for experiencing anger when the pressure is on (Vallance, Dunn, \& Dunn, 2006). It has also been identified that male and female athletes may cope with anger in similar ways (Bolgar, Janelle, \& Giacobbi, 2008). Overall, the nature and degree of differences among gender and level/type of sport is still largely unknown.

Anger has been associated with a number of negative performance outcomes such as misuse of energy, a decrease in achievement and motivation, and the possibility of violent behavior (Robazza et al., 2006). The fact that uncontrolled anger can lead to aggressive or violent behavior has been known for decades (e.g., Berkowitz, 1993; Feindler \& Ecton, 1994). However, few studies have been published in the years since that explore the relationship between competitive anger levels and aggressive behavior. Maxwell (2004) found that simply ruminating about past experiences that have caused anger could increase the possibility of aggression. In addition, being provoked and having thoughts of revenge have been found to be significantly related to self-reported aggression (Maxwell, Moores, \& Chow, 2007).

Unfortunately, it remains difficult to assess competitive anger, which is required to provide a more clear understanding of how it impacts aggression. Part of the problem stems from how to accurately assess anger and aggressive behavior. Outside of sport, instruments such as the State Trait Anger Expression Inventory (STAXI; Spielberger, 1988) have been constructed to help assess the experience, expression, and control of anger. However, nearly thirty years since the introduction of the STAXI, it still has not been normed on athletes or become a standard form 
of measurement in sport psychology research. There currently exists no standard method to assess anger or aggressive acts in sport. Being able to utilize trained observers to identify aggression would be ideal. This would help identify what led to the aggressive act, the act itself, and the resulting consequences. This is unfortunately a time-consuming and potentially expensive process. In addition, aggressive behavior may not always be noticeable on a game-togame basis (Maxwell \& Moores, 2007).

The Competitive Aggressiveness and Anger Scale (CAAS) is a notable instrument used to assess both competitive anger and aggressiveness, or the tolerance of aggressive behavior and inclination to aggress. The CAAS (Maxwell \& Moores, 2007) is a 12-item instrument that assesses anger (e.g., frustration from missed calls from referees) and aggressiveness in a sport setting. While aggressiveness is a trait rather than a behavior (like aggression), it is one of the better ways to assess the probability of aggressive behavior in a proactive way (i.e., before it actually happens). Few researchers have utilized the CAAS since its inception (e.g., Visek Maxwell, \& Hurst, 2011), but it appears to be an efficient and promising instrument for use in the exploration of anger and aggressiveness in athletes.

Another consideration in the study of aggression is the lack of a clear consensus on how to define and differentiate assertive and aggressive behavior, and also what constitutes "violence" (Abrams, 2010; Kirker, Tenenbaum, \& Mattson, 2000). Currently, one of the more common methods to help understand aggression is to split these types of behaviors into instrumental and hostile types (Husman \& Silva, 1984). The major difference is the distinction that instrumental aggression may cause harm, but has the overarching goal of pursuing a nonaggressive goal (such as scoring points). Hostile aggression suggests a primary intent of injuring another person physically or psychologically. Abrams (2010) suggested that violence 
can be spontaneous or planned, with the end goal to hurt another person. Spontaneous violence seems to be a result of being provoked, while planned violence is intentional and a "complete system failure" (p. 6). Abrams went on to suggest that athletes displaying this type of behavior should be immediately removed from the playing field and, in extreme instances, even prosecuted.

With these definitions as resources, hostile and planned violence are the most dangerous. What must happen for athletes to feel it necessary to display these types of behaviors? There is no doubt that feeling frustrated and angry are important factors in understanding aggressive behavior (Berkowitz, 1993; Feindler \& Ecton, 1994; Robazza et al., 2006;). However, simply feeling angry does not automatically cause one to lash out aggressively. What other factors come into play?

To help answer this question, a number of theories have been put forth to help understand the potential causes of aggression. Examples include the instinct theory, frustration aggression theory (Dollard, Doob, Miller, Mowrer, \& Sears, 1939), social learning theory (Bandura, 1973), theory of moral reasoning (Bredemeier, 1994), and revised frustration-aggression theory (Berkowitz, 1965; 1993). Instinct theory suggests aggression is an innate human instinct that builds up until it must be expressed either directly or cathartically (through sports for example). Based on Albert Bandura's seminal work, social learning theory predicts aggression is learned by observation, and aggression that is reinforced is likely to reoccur if not penalized. The theory of moral reasoning postulates that how likely a person is to aggress is based on their level of moral development. One of the more widely held views, Berkowitz's revised frustration-aggression theory suggests frustration only leads to aggression when an individual encompasses the social cues that indicate aggression is appropriate in a particular instance. This theory is important in 
understanding how frustration in competition can play an important factor in determining aggressive behavior, based on the individual and his/her environment.

One of the least understood experiences related to being frustrated and taking it out aggressively, is the act of provocation. According to Maxwell, Moores, and Chow (2007), provocation is "any behavior [of another person or persons] that is judged by the victim as aversive or unpleasant, normally with intent on the part of the perpetrator implicitly assumed, and rousing feelings of anger, frustration, or fear" (p. 11). This definition suggests that provocation is assumed to involve intent by the perpetrator. This is a key distinction, as it should not be considered provocation if an athlete, simply by competing hard and without harmful intent, frustrates or angers an opponent to the point of him/her lashing out.

In his work on revised frustration-aggression hypothesis, Berkowitz (1989) suggested that provocation, along with frustration and aversive stimuli, could lead to aggression through the generation of negative affect that is interpreted by the individual as anger. Provocation is one of the clearest antecedents of aggression in both non-sporting (e.g., Harris, 1993) and sporting (e.g., Huang, Cherek, \& Lane, 1999) environments. Outside of sport, researchers have suggested that provocation may cancel out any inhibitory effects that empathy can have on aggressive behavior (Phillips \& Giancola, 2007; Stranger, Kavusannu, McIntyre, \& Ring 2016). Other research suggests that provocation itself is frequently interpreted as offensive and has been linked to increases in overall anger levels (Mohr et al., 2007).

Maxwell (2004) was one of the first researchers to focus on understanding the experience and consequences of provocation in athletics. He reported that provocation might be positively associated with aggression in athletes. This mirrored similar findings of research on normbreaking behaviors in sport, in which Kirker, Tenenbaum, and Matteson (2000) observed that 
mild aggressive acts often followed provocation acts in a vengeful manner. In the worst cases, this sometimes resulted in more severely violent aggression. Maxwell (2004) claimed athletes from team sports report greater frequency of provocation than athletes who compete in individual sports. A few years later, Maxwell and Moores (2007) suggested that males experience provocation at a greater frequency than females, suggesting that males may perceive more incidences as provoking in sport. Maxwell, Visek, and Moores (2009) found that athletes who competed in high contact team sports tended to experience higher provocation while playing sport. Findings of this study suggested that provocation can be seen as a justification for retaliatory aggression, but not always between the original combatants, at least in team sports. Importantly, it has also been suggested that individuals with high trait anger are more likely to feel more readily provoked and endorse aggressive acts as a result (Maxwell, Visek, \& Moores, 2009). This hypothesis was originally put forth by Spielberger (1988), who suggested in his state-trait anger theory that high trait anger individuals experience anger more frequently and longer than low trait anger individuals. In addition, these people are more likely to express this anger in an aggressive or harmful manner. Unfortunately, this theory has not been explored in the realm of athletics, and little knowledge exists regarding the characteristics of athletes that are more or less likely to have high trait anger (or respond aggressively when triggered or provoked).

Clearly, some research exists that suggests provocation is an important factor in determining anger and aggressive behavior (e.g., Maxwell, Visek, \& Moores, 2009; Stranger et al., 2016). However, assessing provocation is difficult since ideally (as with aggressive behavior), provocation is assessed by observation. However, this method is timely and unpredictable, in addition to somewhat subjective. An act perceived as provocative to one athlete may not necessarily be perceived the same way by others. Furthermore, sometimes provocation 
is verbal, which can be difficult to assess by outside observers. Currently, neither observer assessment or provocation nor adequate self-report measures have been documented in the literature.

Maxwell and Moores (2006) attempted to meet the need of a self-report assessment in sport by crafting the Provocation in Sport Questionnaire (PSQ), a six-item self-report questionnaire that inquires about incidences of provocation common in many sports. These statements were scored by athletes on a five-point Likert-type scale to help understand the frequency of each provocation type and the corresponding intensity of anger. Unfortunately, this scale is no longer available and no other known instrument exists in which to assess the experience of provocation in sport. Since provocation seems to be a key factor in understanding anger and aggressive behavior in sports, a novel assessment of provocation is needed to help develop this area of sport psychology research.

Therefore, the purpose of this study was to explore the relationship between self-reported competitive aggressiveness, anger, and provocation in collegiate male and female contact and collision sport athletes. Contact and collision sport athletes are an important population to investigate because they are frequently in close proximity with opponents during competition and are therefore more likely to engage in aggressive behavior. Non-contact sport athletes were not included in this investigation.

Based on the modest amount of research available on anger, aggression, and provocative behavior in sport, this study explored these variables while controlling for gender and type of sport (i.e., contact vs. collision). It has been suggested that gender and type of sport have significant competitive anger and aggression differences based on previous research (e.g., Maxwell, Visek, \& Moores, 2009). For example, some studies have suggested that male athletes 
are more aggressive than their female counterparts, both on and off the field (e.g., Burton \& Marshall, 2005; Coulomb-Cabagno \& Rascle, 2006). Male athletes have also been found to perceive aggression as more legitimate than females (e.g., Bredemeier, 1985; Gardner \& Janelle, 2002; Tucker \& Parks, 2001). Other research has disputed these findings (e.g., Bolgar, Janelle, \& Giacobbi, 2008; Keeler, 2007). Ultimately, aggression studies that focused on gender have revealed conflicting findings, with no significant differences being reported between males and females (Kimble et al., 2010).

With this knowledge in mind, the first major research question in the study was: "Does competitive anger, aggressiveness, and experience of provocation vary between male and female college athletes?” The second major research question was: "Does competitive anger, aggressiveness, and provocation vary between contact and collision sport college athletes?"

Based on prior research, there were two main hypotheses in this study. The first was that male athletes would score higher on the CAAS anger and aggressiveness subscales, in addition to experiencing (and responding negatively to) more provocation than female athletes. The second was that collision sport athletes would score higher on the CAAS anger and aggressiveness subscales, in addition to experiencing more provocation and more frequently responding to provocation than contact athletes.

There were a number of assumptions made by the researcher in this study. For example, although prior research was ambiguous (e.g., Coulomb-Cabagno \& Rascle, 2006, Keeler, 2007), it was assumed that gender does play a significant role in the relationship between anger, aggressiveness, and provocation. It was also assumed that contact and collision sport athletes differed in aggressiveness, anger, and/or experiences of provocation. Closely related to that is the assumption that provocation played a significant role in determining one's level of competitive 
anger and aggressiveness. Finally, it was assumed that the original sport provocation questionnaire being used in this study adequately assessed the experience of provocation in collegiate sport.

There is currently a major gap in the understanding of how anger, aggressive behavior, and provocation interact in sport settings. There exists no valid assessment tool for the experience of provocation in sport. In order to develop interventions to mitigate anger responses to provocation, a more clear understanding of the interaction of aggression, anger and provocation is required. Understanding the characteristics of athletes who are prone to high anger levels, aggressiveness, and experiencing provocation will help in the development of more focused interventions for these individuals. Male athletes may not actually be more aggressive than female athletes, despite popular perception, and therefore interventions for one gender could be utilized effectively for the other. However, anger levels and aggressiveness may be significantly different, in which case gender-specific programming and interventions may be required.

While the current study is largely exploratory, increasing the understanding of provocation can be helpful for athletes, coaches, sport psychology consultants, and even referees. Being able to understand how frequent provocative behavior occurs, how it is being displayed, how it affects athletes, and how often it is reciprocated is valuable both theoretically and practically. Team sport contact and collision athletes can better understand what to expect in competition and coaches may be able to better prepare athletes for provocative behavior. Coaches of certain types of teams (e.g., male teams or collision sports) need better information, education, and programming to help promote an environment more conducive to safe, sanctioned play. 
It is vital to understand who the at-risk athletes may be so they can be provided better education and emotional regulation resources, as it is possible high trait anger athletes are more likely to be involved in aggressive on-field acts (Maxwell, Visek, \& Moores, 2009). Similarly, coaches and sport psychology consultants can use the findings to better understand aggression and where and why it is likely to occur. Referees could foster a better sense of how to officiate sport to eliminate provocative behavior before it turns into dangerous reciprocation. Nearly all stakeholders involved in collegiate sport could benefit from the findings of this study, as a better understanding of the relationship between provocation and competitive anger and aggression in sport is necessary. 


\section{Methods}

\section{Participants}

Participants were $243(\mathrm{M}=124)$ male and female athletes from NCAA Division I, II, and III universities throughout the continental United States. The age range of participants was between 18-23 years. Participants were sampled from both contact and collision team sports. To be considered a contact sport, in-game contact is allowed, but extreme contact or direct collisions are not implicit or required by the rules of the sport (Keeler, 2007; Silva, 1983). For the purposes of this study, men's and women's basketball, field hockey, women's lacrosse, and men's and women's soccer were all considered contact sports. For collision sports, collisions are necessary and integral, and they are also considered a predesigned aspect of appropriate goal-directed behavior in that sport (Keeler, 2007; Silva, 1983). Collision sports sampled for this study included football, men's lacrosse, men's and women's rugby, and men's and women's ice hockey.

\section{Research Design and Sampling}

This study employed a quantitative, survey-based approach to investigate the relationships between three phenomena of interest: 1) competitive anger, 2) aggressiveness, and 3) provocation in collegiate sport. The researcher used purposive sampling to select participants who met the inclusion criteria for the study (Creswell, 2014). This criterion was being a current NCAA Division I, II, or III athlete and competing in selected contact or collision sports. This was also a sample of convenience due to the researcher using personal contacts at various universities to gain access to athletes competing at those universities. Sampling began during the 2017 summer "off-season" period and ended in October of the Fall 2017 competitive season. After the initial sampling period, additional attempts at recruiting participants were implemented 
every two weeks. This entailed follow-up email reminders to coaches requesting that they pass along the survey link to their athletes.

\section{Instrumentation}

Coaches were contacted via email and asked to forward the survey link to athletes on their team (see Appendix C). If participants were willing to partake, they clicked on the survey link to find an informational cover page (see Appendix D), followed by the online survey that consisted of a short demographics questionnaire, a sports-based competitive anger and aggressiveness assessment, and a provocation questionnaire. The order of the questionnaires was randomized for participants to help reduce the possibility of an order effect (Creswell, 2014). The provocation assessment was an original questionnaire that focused on the participant's experience of provocation during athletic competition. It was detailed in the participant cover page that consent was implied by completing the online survey. All three sections of the online survey was predicted to take approximately fifteen minutes to fill out.

Demographic questionnaire. The researcher used a demographic survey to gather the following seven variables of interest: 1) age, 2) gender, 3) race/ethnicity, 4) year in school, 5) type of sport, 6) name of university, and 7) NCAA division level. While some identifying information such as school of enrollment was collected, all information was kept confidential and secured online using password-protected software. Once downloaded, study data was stored in encrypted files on the researcher's personal computer. Demographic information was also collected at the beginning of the survey, which has been shown to increase item response rate for participants who begin the survey (Teclaw, Price, \& Osatuke, 2011). (See Appendix E)

Competitive aggressiveness and anger. The Competitive Aggressiveness and Anger Scale (CAAS; Maxwell \& Moores, 2007) is a 12-item self-report questionnaire designed to 
assess competitive anger and aggressiveness, or the tolerance of aggression and inclination to aggress, in sport settings. The CAAS is divided into two subscales: a) anger, and b) aggressiveness subscales, with six items in each subscale rated on a five-point Likert type scale from $1=$ almost never to $5=$ almost always. A sample item from the anger subscale is: "I find it difficult to control my temper during a match". A sample item from the aggressiveness subscale is: "It is acceptable to use illegal physical force to gain an advantage".

Using confirmatory factor analysis (CFA), the authors reported good internal consistencies for each subscale and the total scale score. These Cronbach alphas include: anger $(\alpha=.78)$, aggressiveness $(\alpha=.84)$, and total $(\alpha=.87$; Maxwell $\&$ Moores, 2007). These values all fall within the generally accepted reliability levels as determined by Nunnally and Bernstein (1994). Concurrent validity was established with subscales of the Buss-Perry Aggression Questionnaire (BPAQ; Buss \& Perry, 1992). In addition, the authors found adequate one-month test-retest statistics for the subscales and total scale score. Discriminant validity was established using peer perception of aggressive orientation. The anger and aggressiveness subscales were also found to be moderately correlated to each other (e.g., $\alpha=.59$ and .60$)$, suggesting that they are related but not too similar in nature. This is in agreement with literature that suggests a relationship exists between anger and aggression (e.g., Buss \& Perry, 1992; Maxwell, 2004), in addition to a clear link with aggressiveness.

When crafting and examining the psychometric properties of the scale, the authors found differences in gender and type of sport, with males and contact sport athletes reporting a higher tendency to aggress than females and non-contact athletes (Maxwell \& Moores, 2007). The CAAS is one of the only known sport-specific scales to assess competitive anger and aggressiveness in athletes. However, the factor structure of the CAAS has been found to be 
replicable with both Americans and English-speaking Chinese athletes. It has been identified as an appropriate way of assessing athletes most likely to display acts of aggression (Visek, Maxwell, Watson, \& Hurst, 2011). The CAAS was intended to be a trait measure, so it does not take into account fluctuations in state anger and aggressiveness throughout an athletic competition. Other limitations include that it lacks a social desirability check and was constructed using a non-elite sample of athletes. (See Appendix F)

Provocation. To assess participants' experience of provocation during competition, an original questionnaire was utilized in this study. This questionnaire is based on the Provocation in Sport Questionnaire (PSQ; Maxwell \& Moores, 2006), which was a scale that contained six short statements representing incidences of provocation that are common in sports. In the only confirmed published study utilizing it, the PSQ was translated to use in Chinese (Maxwell, Moores, \& Visek, 2009). The scale measured the frequency at which respondents experienced various types of perceived provocation and the corresponding self-reported intensity of associated anger on five-point Likert type scales. The PSQ was the only known instrument to study the experience of provocation in sport.

Unfortunately, the full version of the PSQ is no longer available for use as it cannot be located. Instead, a new provocation questionnaire was created to assess the experience and response of various incidences of provocation (i.e., verbal, gestures, and physical). The Sport Provocation Questionnaire was constructed using the original PSQ by Maxwell and Moores (2006) as a foundation, in addition to information collected from current and former athletes about their experiences. The author's own experiences and observations of athletic competition also factored into the construction of the questionnaire. Specifically, the items assess the 
frequency of experienced provocation, the frequency of one's response to provocation, the level of anger felt by provocation, and the intensity of one's response to being provoked.

For each item, scores range from 1 (lowest) to 5 (highest). Higher scores represent greater frequency of provocation and response to provocation, as well as more intense anger felt by provocation. The intensity of provocation is assessed as ordinal data and will be analyzed separately from the other categories of the questionnaire. An example of an item assessing frequency of provocation is: "In competitive sports, how likely do you experience the following types of verbal provocation? a) the use of curse words or verbal abuse; b) the use of racial/ethnic slurs; c) the use of violent threats". An example of an item assessing anger level from provocation is: "In competitive sports, what is your level anger when an opponent: a) aggressively or inappropriately touches you; b) purposefully shoves or trips you; c) punches or kicks you; d) purposefully strikes you with an instrument (like a helmet or stick)". (See Appendix G).

Pilot study. After obtaining IRB approval, the sport provocation questionnaire was piloted with a sample of twenty-two former high school and collegiate athletes. The mean age for all participants was $25.23(\mathrm{SD}=4.33) ; 7$ participants were male. Nearly half $(45.5 \%)$ of all pilot participants played at the NCAA collegiate level, while the remaining played high school sports. Just over two-thirds of participants (68.2\%) played contact sports, while the second biggest group (18.2\%) played collision sports. The majority (63.4\%) of participants played soccer, while the rest played a variety of contact or collision team sports such as basketball, hockey, or football.

All participants filled out the questionnaire based on their prior sport experiences involving provocation. Open-ended feedback obtained from the pilot research was used to 
improve the content and structure of the questionnaire and can be found in Appendix $\mathrm{H}$. The four provocation scales were found to have adequate internal reliability, and the scales were moderate-highly correlated to each other (Field, 2009). These values suggest the scales are related to each other but still assessing different concepts in the experience of provocation. This information, in addition to the descriptive and correlational data obtained from the pilot study, can also be found in the tables in Appendix H. At this time, no standardized assessment of provocation in sport exists. With adequate internal reliability and sufficient face validity, it is expected that this new questionnaire will help build the foundation for future research to explore this important phenomenon.

\section{Procedure}

IRB approval was obtained before data collection began. Both assistant and head coaches from selected sport teams were contacted via email to explain the study and request participation from the athletes on their teams. As a small incentive, coaches were informed that participation in the study would grant them access to a general summary of the study findings once the researcher has compiled and analyzed all data. If they chose to participate, coaches were asked to forward the Qualtrics survey link to all of the athletes on their team.

After the initial introductory email, all assistant and head coaches were contacted every two weeks with follow-up emails requesting their athletes participate in the study. Towards the end of the data collection period, a small number of other university athletic department personnel (e.g., athletic director or sport psychology consultant) were contacted at some schools to try to increase the sample size and generate adequate statistical power.

All participants who opened the survey link first saw an informative cover letter detailing the purpose of the study and an explanation of participant rights (i.e., confidentiality, right to 
withdraw at any time). There was also an option to print a copy of the cover letter for personal records. If participants agreed to continue, they were then asked to enter basic demographic information. Participants were then presented with online versions of both the CAAS and the sport provocation questionnaire. Successful completion of the demographic information and two surveys was predicted to take approximately fifteen minutes. Finally, the participants received the primary investigator's contact information so that participants could communicate with the researcher about any issues related to the collection procedures, their data, or any other studyrelated concerns.

Data collection began during the summer off-season period but continued into the competitive Fall 2017 season. The off-season was decided as the best time to sample since most athletes were not as busy with school and training obligations. Collecting data at this time may also have helped avoid any bias due to abnormally high or low frustration or anger being experienced by athletes in the middle of the competitive season (for example, after a particularly disappointing or successful game or overall season).

\section{Data Analysis}

A G*Power 3.1 analysis (Faul, Erdfelder, Lang, \& Buchner, 2007) revealed approximately 120 total participants would be the minimum sample size required to see a significant gender effect at the 95\% level. After an adequate sample was collected, data analysis included both descriptive (e.g., frequencies, correlations, measures of central tendency, and standard deviations) and inferential statistical tests (e.g., internal reliability analyses and ANOVAs) to investigate the study hypotheses. All collected data was cleaned in Microsoft Excel and entered into the IBM Statistical Package for Social Sciences version 24 (SPSS, 2016). 
The independent variables in this study included gender and type of sport. These were assessed on the demographic page. There are three dependent variables in the study:

1) competitive anger, 2) aggressiveness, and 3) provocation. These variables were assessed using the CAAS and sport provocation online questionnaires. Frequencies, means, standard deviations, and other descriptive data were calculated for demographic information such as age, gender, race/ethnicity, school, division, and type of sport. Overall means and standard deviations were calculated for all CAAS and provocation subscales. Standard bivariate correlations were also calculated among gender, type of sport, and the competitive anger, aggression, and provocation data.

There were two primary research questions in this study. The first was: "How does competitive anger, aggressiveness, and experience of provocation vary among male and female athletes?" The second primary research question was: "How does competitive anger, aggressiveness, and provocation vary among contact and collision sport athletes?" These primary research questions were examined using a general linear model (GLM) to run multiple one-way analysis of variance (ANOVAs). To investigate the possibility of an interaction between the independent variables of gender and type of sport, two-way ANOVAs was used. Two-way ANOVAs helped answer the question of how scores on the dependent variables of CAAS or sport provocation questionnaire scores differed by gender and type of sport.

For correlations, anger and aggressiveness subscale scores from the CAAS and provocation subscale scores were run together in a correlational matrix to examine the strength of the relationship between the variables. This was completed for the male and female data, as well as type of sport, to compare correlation strengths among the different variables. 
Additional ad hoc analyses were completed to assess other study variables such as NCAA Division level or year in school. For example, differences in anger, aggressiveness, and experience of provocation were examined between NCAA Division I and Division III athletes. No current research suggests there are anger or aggressiveness differences among NCAA Division levels, but it is possible that at higher competitive levels, more competitive anger and aggressive behavior is produced due to the rising stakes, pressure, and fanfare. 


\section{Results}

\section{Demographics and Descriptive Statistics}

A total of 243 NCAA athletes from 18 universities participated in the current study. From the final data aggregate, any participants who completed less than $40 \%$ of the survey questionnaire items were excluded from the final data analyses. The mean participant age was $19.53(\mathrm{SD}=1.36)$. Participants were composed of 124 males and 119 females. At the time of data collection, they were playing one of ten different male or female team sports that included basketball, soccer, lacrosse, hockey, football, and rugby. Approximately $38 \%$ of participants were freshmen, with $20 \%$ sophomores, $21 \%$ juniors, and $15 \%$ seniors. In addition, $5 \%$ of participants identified as fifth-year seniors or graduate students. Over one-fourth $(26 \%)$ of participants were enrolled in NCAA Division I universities, with 29\% attending Division II schools and the remaining 44\% attending Division III schools. Just over half (53\%) of all participants played contact sports, while the rest (47\%) were involved in collision sports. This demographic information is summarized in Table A1.

Subsequent to data collection, Cronbach's alpha analyses of internal consistency were calculated for the four provocation and CAAS scales (see Table B1). Review of these analyses revealed that all four provocation scales had adequate internal consistency, and were moderatehighly correlated to each other (Field, 2009). These Cronbach's alphas coefficients provided evidence to support the interpretation that the scales are appropriately related to each other but addressing different parts of the experience of provocation in collegiate sport. Internal reliability analysis was also utilized for the six-item Anger and Aggressiveness subscales of the CAAS, which were found to have moderate-high correlations. 


\section{Data Cleaning and Assumption Testing}

The following adjustments were made on the data in SPSS to ensure the ensuing bivariate analyses were accurate. The first change was to code an additional "6" Likert-type response (i.e., N/A or have not experienced) as a discrete missing variable. This ensured that these responses were not included in the standard scaled data for the provocation items. The second adjustment was to multiply all of the CAAS scores by the proper mean intensity of each item (following the procedures outlined by Maxwell \& Moores, 2007). The authors conducted this step during the development of the CAAS because individual items on the two subscales are not equally weighted, with some impacting the anger or aggressiveness score more than other items. Finally, a total score variable was created for both the CAAS and SPQ instruments. The CAAS total score was created by summing the six-item Anger and Aggressiveness subscales. The provocation total score was calculated as the average of the four provocation scales, using data from participants who filled out at least three out of four mean responses. This decision was made to ensure the anger level provocation subscale data was included despite having to code for the "6" missing data choice. Overall, this resulted in a total of 18 participants being removed from the final database before final analyses were conducted.

Before conducting inferential statistical analyses, the data were examined using SPSS to ensure that it met the appropriate assumptions needed for valid two-way ANOVA results. The assumptions of a continuous dependent variable, independence of observations, and independent variables with categorical groups were all satisfied based on random sampling and the type of variables (e.g., continuous, ordinal) utilized in the study. Using box and whisker plots (Field, 2009), only one outlier was identified from the CAAS Anger subscale data and five from the CAAS Aggressiveness subscale data. These were not considered extreme outliers, (i.e., over 
three times the Interquartile Range) so they were retained in the database. Up to three outliers were identified for the four different provocation subscales, but these were also included in the final data aggregate since they did not constitute extreme outliers that would likely have a significant detrimental effect on the analyses.

The normality of the data was examined using kurtosis/skewness values as well as histograms and Q-Q plots. Overall, the data for nearly all of the subscales followed a normal distribution, with only slight departures from normality found on the CAAS Aggressiveness and negative response to provocation subscale data. These departures consisted of slight floor effects, meaning the subscales had a clear lower limit of possible participant's responses. This caused a larger than usual number of scores to congregate near this limit. However, ANOVA is known to be particularly robust to violations of normality, so the analyses were carried out despite these aforementioned slight departures. Levene's test, as well as assessing the data spread vs. Q-Q plots, was utilized to test the homogeneity of variances (Field, 2009). While the CAAS aggressiveness and negative response to provocation subscales varied more than expected in normally distributed data, the standard deviation spread was not large compared to the mean differences. This suggested that running the ANOVA using the data would not be overly problematic, and it would be unnecessary to run non-parametric tests of ANOVA.

\section{Bivariate Statistics}

The first primary research question in this study was: How does competitive anger, aggressiveness, and the experience of provocation vary among male and female athletes? To answer this question, a one-way between subjects ANOVA was conducted to compare scores on the CAAS among male and female athletes (see Table C1). For all ANOVAs, SPSS was used to calculate effect size, represented as partial eta square $\left(\eta^{2}\right)$. To compare magnitude of effect 
sizes, rule of thumb values ( small $=.01$, medium $=.06$, and large $=0.14$ ) were used based on recommendations set forth by Vacha-Haase and Thompson (2004). There was a statistically significant effect of total CAAS score among gender $\left[F(1,237)=23.68, p<0.001, \eta^{2}=.091\right]$, with males $(M=55.79, \mathrm{SD}=19.41)$ scoring significantly higher than females $(\mathrm{M}=45.52, \mathrm{SD}=$ 12.12).

Additional one-way between subjects ANOVAs were conducted to compare scores on the CAAS Anger and Aggressiveness subscales by gender. There was no statistically significant effect of CAAS Anger scores among gender $\left[F(1,241)=1.35, p=0.247, \eta^{2}=.006\right]$, although males $(M=26.43, \mathrm{SD}=8.59)$ scored non-significantly higher than females $(\mathrm{M}=25.23, \mathrm{SD}=$ 7.47) (see Table C2). There was, however, a significant effect for CAAS Aggressiveness subscale scores among gender $\left[\mathrm{F}(1,237)=46.27, \mathrm{p}<0.001, \eta^{2}=.163\right]$, with males $(\mathrm{M}=29.36$, $\mathrm{SD}=12.60)$ scoring significantly higher than females $(\mathrm{M}=20.29, \mathrm{SD}=7.02)($ see Table $\mathrm{C} 3)$.

There was not a statistically significant effect of total SPQ score among gender $[\mathrm{F}(1,217)$ $\left.=2.49, \mathrm{p}=0.12, \eta^{2}=.011\right]$, although males $(\mathrm{M}=2.38, \mathrm{SD}=0.68)$ scored slightly higher than females $(\mathrm{M}=2.24, \mathrm{SD}=0.55)$ (see Table $\mathrm{C} 4)$. However, when separated into the four provocation subscales, statistically significant differences were found among all four provocation subscales between male and female athletes. Specifically, males scored significantly higher than females on frequency of provocation experienced, frequency of negative response to provocation, and intensity of response to provocation. Females scored significantly higher than males on anger felt from provocation (see Table C5).

The second primary research question in this study was: How does competitive anger, aggressiveness, and the experience of provocation vary among contact and collision sport athletes? To answer this question, a one-way between subjects ANOVA was conducted to 
compare scores on the CAAS among type of sport (see Table C6). There was a statistically significant effect for total CAAS score among type of sport $\left[F(1,237)=31.17, p<0.001, \eta^{2}=\right.$ $.116]$, with collision sport athletes $(\mathrm{M}=56.98, \mathrm{SD}=18.85)$ scoring significantly higher than contact sport athletes $(\mathrm{M}=45.35, \mathrm{SD}=13.13)$.

Additional one-way between subjects ANOVAs were conducted to compare scores on the CAAS Anger and Aggressiveness subscales by type of sport. There was a statistically significant effect for CAAS Anger subscale scores among type of sport $[\mathrm{F}(1,241)=4.04, \mathrm{p}=$ $\left..046, \eta^{2}=.016\right]$, with collision sport athletes $(\mathrm{M}=26.95, \mathrm{SD}=8.35)$ scoring significantly higher than contact sport athletes $(M=24.88, S D=7.72)($ see Table $C 7)$. There was also a significant effect for CAAS Aggressiveness subscale scores among type of sport $[F(1,237)=52.25, \mathrm{p}<$ $\left.0.001, \eta^{2}=.181\right]$, with collision sport athletes $(\mathrm{M}=30.03, \mathrm{SD}=12.30)$ scoring significantly higher than contact sport athletes $(\mathrm{M}=20.48, \mathrm{SD}=7.84)$ (see Table $\mathrm{C} 8$ ).

There was also a statistically significant effect for total SPQ score among type of sport $\left[F(1,217)=7.39, \mathrm{p}=.007, \eta^{2}=.033\right]$, with collision sport athletes $(\mathrm{M}=2.43, \mathrm{SD}=0.65)$ scoring significantly higher than contact sport athletes $(\mathrm{M}=2.21, \mathrm{SD}=0.57)($ see Table $\mathrm{C} 9)$. To better understand what aspects of provocation were significantly different, one-way ANOVAs were run for each of the four subscales of the SPQ. The results of these analyses can be found in Table C10. Specifically, collision sport athletes scored significantly higher than contact sport athletes on the frequency of provocation experienced and frequency of negative response to provocation.

A two-way ANOVA was conducted to examine the effect of gender and type of sport on total CAAS scores (see Table C11). The results of the two-way ANOVA provided evidence to indicate there was no statistically significant interaction effect between gender and type of sport. 
This suggests that any total CAAS score differences between contact and collision sport athletes were not dependent upon the gender identified with by the participants and that any total CAAS score differences between females and males were not dependent upon which type of sport they played.

A separate two-way ANOVA was conducted to examine the effect of gender and type of sport on total SPQ scores (see Table C12). The results of the two-way ANOVA provided evidence to support the notion that there was no significant interaction effect between gender and type of sport. This indicates that any total SPQ score differences between contact and collision sport athletes were not dependent on the gender identified with by the participants, and any total SPQ score differences between male and female athletes were not dependent upon which type of sport they played.

Statistical analyses regarding the division level of participants were not part of the researcher's original research questions. However, since data was collected from athletes in all three NCAA division levels, additional statistical analyses were conducted to explore possible differences among the dependent variables. There was a statistically significant effect of total CAAS score among NCAA Division level $\left[F(2,236)=4.96, p=.008, \eta^{2}=.040\right]$ (see Table D1). Post hoc comparisons using the Tukey HSD test provided evidence to suggest that the mean total CAAS score for Division I athletes $(\mathrm{M}=54.74, \mathrm{SD}=19.21)$ was significantly higher than Division III athletes $(\mathrm{M}=47.11, \mathrm{SD}=14.36)$, but not Division II $(\mathrm{M}=53.13, \mathrm{SD}=17.94)$ athletes (see Table D2).

One-way, between subjects ANOVAs were conducted to compare scores on the CAAS Anger and Aggressiveness subscales among NCAA Division level. There was a statistically significant effect of CAAS Anger subscale scores among NCAA Division level $[\mathrm{F}(2,240)=$ 
$\left.5.48, \mathrm{p}=.005, \eta^{2}=.044\right]$ (see Table D3). Post hoc comparisons were conducted using Tukey's HSD test (Field, 2009). The results of this analysis provided support for the interpretation that the mean CAAS Anger subscale score for Division I athletes $(\mathrm{M}=27.68, \mathrm{SD}=8.66)$ was significantly higher than Division III athletes $(\mathrm{M}=23.98, \mathrm{SD}=6.94)$, but not statistically different from Division II $(\mathrm{M}=27.01, \mathrm{SD}=8.60)$ athletes. Division II athletes were also found to score significantly higher than Division III athletes on CAAS Anger subscale scores (see Table D4). There was also a statistically significant effect for CAAS Aggressiveness subscale scores among NCAA Division level $\left[\mathrm{F}(2,236)=3.12, \mathrm{p}=.046, \eta^{2}=.026\right]$ (see Table D5). Post hoc comparisons using Fisher's LSD test (Field, 2009) indicated that Division I athletes (M= 27.16, $\mathrm{SD}=12.50)$ scored significantly higher than Division III athletes $(\mathrm{M}=23.05, \mathrm{SD}=9.79)$, but not Division II $(\mathrm{M}=26.05, \mathrm{SD}=11.80)$ athletes (see Table D6).

There were no statistically significant differences in total SPQ scores between NCAA division levels $\left[F(1,216)=.574, p=.564, \eta^{2}=.005\right]$ (see Table D7). One-way between subjects ANOVAs were conducted for all four provocation subscales to look for differences by NCAA division level. As displayed in Table D8, no significant differences were found by division level among any of the four provocation subscales. 


\section{Discussion}

The primary goal of this study was to investigate and better understand competitive aggressiveness, anger, and the experience of provocation in collegiate sport athletes. In particular, it was important to understand if these variables differed among male and female contact and collision sport athletes, and if any further differences occurred among NCAA division level. Both male and female collegiate athletes participating in contact and collision sports were surveyed electronically using questionnaires that assessed the variables of competitive aggressiveness and anger, and the experience of provocation. The two hypotheses proposed at the beginning of the study were that: 1) male athletes would score higher on the CAAS anger and aggressiveness subscales, and would report experiencing (and responding negatively to) more provocation than female athletes; and 2) collision sport athletes would score higher on the CAAS anger and aggressiveness subscales, and would report experiencing more provocation and more frequently responding to provocation than contact athletes.

\section{Competitive Aggressiveness and Anger}

Gender comparison. Based on the results of the current study, the first hypothesis was partially supported. Male collegiate athletes scored significantly higher overall on the CAAS than female athletes, and they were significantly more likely to tolerate aggressiveness and be inclined to aggress in an athletic setting. However, while male athletes scored slightly higher on competitive anger, this difference was not statistically significant. These findings point to the notion that the amount of anger felt during competitive sports was not significantly different based on gender. Some researchers have suggested that males are more prone to anger than females (e.g., Maxwell \& Moores, 2007; Maxwell, Visek, \& Moores, 2009). However, the results of the current study suggest that the female athletes in these types of sports may simply be 
less likely to act on anger than male athletes. For example, female athletes were found to have significantly higher anger levels from provocation by opponents, but males had more negative and intense responses to the same types of provocative behavior. This finding seems to be in disagreement with some previous research on high school tennis athletes who reported that male and females tended to cope with anger in similar ways (Bolgar, Janelle, \& Giacobbi, 2008).

The notion that male athletes are, in general, more inclined to aggress than female athletes has been suggested in previous literature (e.g., Bredemeier, 1978; Coulomb-Cabagno \& Rascle, 2005; Maxwell, 2004). Even at the middle school level, some male athletes displayed significantly more aggression off the field than female athletes, with participation in sport being a risk factor for antisocial behavior (Burton \& Marshall, 2005). Further, during the development of the CAAS questionnaire, the authors found that male CAAS scores were higher than female scores on both the Anger and Aggressiveness subscales (Maxwell \& Moores, 2007). This result was consistent for both contact and non-contact sport athletes. On the other hand, not all researchers have found evidence to support the classic aggressive male athlete stereotype. For example, Keeler (2007) found that males and females did not differ in hostile or instrumental sport aggression, and this finding was consistent among non-contact, contact, and collision sport athletes. However, males did score higher on questions assessing life assertion and assault aggression. Overall, the finding that male athletes (regardless of sport type) displayed more competitive aggressiveness is in agreement with most of the previous research on gender differences in aggressive behavior.

The results of the current study parallel a number of findings from previous research studies (Burton \& Marshall, 2005; Coulomb-Cabagno \& Rascle, 2006; Gardner \& Janelle, 2002). One example is males reporting that they were more inclined to aggress than female athletes, 
regardless of what type of sport they played. However, unlike research conducted in the creation of the CAAS (Maxwell \& Moores, 2007), the current findings support the idea that male and female college athletes are not significantly different in the amount of anger experienced in competitive environments. It should be noted that Maxwell and Moores (2007) also utilized participants from non-contact sports. Therefore, the current study is unique in that it is the first known study to explore competitive aggressiveness and anger differences between only contact and collision sport athletes. It is important to differentiate these types of sports from non-contact ones, since contact and collision sport athletes compete as members of teams, in environments that produce consistent physical contact with opponents.

The finding that males participating in contact and collision sports reported higher competitive aggressiveness could have important implications for educational programs, such as ones that focus on anger management skills. Aggression has been shown numerous times to be a possible byproduct of anger, especially when anger is unable to be controlled (e.g., Feindler \& Ecton, 1994; Maxwell, Visek, \& Moores, 2009; Robazza et al., 2006). While the male and female athletes in the current study experienced similar levels of anger during competition, males said that they would be more inclined to justify aggressive behavior as a means of dealing with that anger. It appears that male athletes might benefit more from resources intended to teach athletes other ways to deal with competitive anger, especially under the stressful conditions seen in sport competition.

Sport type comparison. The second hypothesis was supported based on the findings of the current study. Collision sport athletes were found to have significantly higher competitive aggressiveness and anger than contact sport athletes. This finding was consistent irrespective of gender. What seems to be one of the clearest predictors of competitive aggressiveness and anger 
is the type of sport an athlete plays. Although all sports involved in the current study featured contact between opponents, the key difference between collision and contact sports is that the latter allows in-game contact, but extreme contact or direct collisions are not implicit (or required) by the written rules of the sport (Keeler, 2007; Silva, 1983). In contrast, collision sports generally involve high-speed collisions as an integral part of the sport. Simply put, they are necessary to achieve appropriate goals needed for success.

A few previous studies have produced findings that are relevant to the sport type differences found in the current study. In particular, lower moral reasoning and an emphasis on winning are possible features of collision sport environments that help explain the preponderance of aggressive behaviors. Bredemeier and colleagues (1986) conducted some of the seminal research on moral reasoning in sport and found that more experience in high-contact sports could lead to lower moral reasoning (i.e., more inclination to aggress or perceive aggressive behavior as appropriate). Other research has pointed to coaches emphasizing winning as a primary factor leading to low moral reasoning for athletes (e.g., Miller, Roberts, \& Ommundsen, 2005). Therefore, it is possible that the culture created by collision sport coaches is more conducive to facilitating low moral reasoning in athletes, increasing the chances of dangerous aggression being produced on the field.

Previous research findings have supported the notion that collision sport athletes tend to perceive aggressive behavior as more legitimate than non-contact sport athletes (Tucker \& Parks, 2001). In addition, contact sport athletes may be more inclined to aggress than non-contact sport athletes (Maxwell, Visek \& Moores, 2009). Further, Maxwell and Moores (2007) found that contact sport athletes scored significantly higher on the CAAS Aggressiveness subscale than non-contact sport athletes (but not the CAAS Anger subscale). 
Other research has produced findings that suggest type of sport is not a significant factor when exploring differences in aggression. For example, Gardner and Janelle (2002) found no significant differences by contact level for athletes' legitimacy ratings of viewing video clips of aggressive sporting behavior. Similarly, Keeler (2007) found no significant differences in athletic instrumental or hostile aggression by gender or by athletes in collision, contact, or noncontact sports. Unfortunately, neither of these studies involved directly comparing collision and contact sport athletes, nor were they investigating the distinct variables of competitive aggressiveness and anger. The findings of the current study point to more pronounced differences between collision and contact sport athletes in regards to competitive aggressiveness and anger. It appears that collision sport athletes, regardless of NCAA division level, report higher levels of competitive aggressiveness and anger.

It appears from the results of the current study that in collegiate sport, the type of sport played may be the most critical factor in determining competitive aggressiveness and anger levels within athletes. A non-significant interaction effect when adding the variable of gender provided further evidence for this observation. It appears that as sports increase in physical contact and amount of collisions allowed, competitive anger and aggressiveness increases for both men and women. One study by Huang, Cheek, and Lane (1999) looked at nonsporting aggression in high school athletes in response to perceived provocation. They found athletes participating in high-contact sports to be more likely to emit aggression than those participating in low-contact sports. The authors suggested that high-contact sport athletes might be more sensitive to provocative behavior and more likely to aggress when provoked because high contact sport athletes may have learned the behavior from the coach, as well as possibly being naturally more aggressive (Huang, et al., 1999). 
It is challenging to answer the question of whether sport creates angry and/or aggressive individuals or if individuals inclined to be more angry and/or aggressive enter into specific sports. It is likely the answer lies somewhere in the middle, with more angry and/or aggressive individuals being drawn to the physical contact found in collision sports, but the nature of the sports themselves also provoking a higher inclination to aggress. Research has revealed that expressing aggression does not act as a catharsis (as once believed), but instead can promote further feelings of aggression and aggressive acts (Bushman, 2002). With regard to provocation, this would suggest that collision sports provide more natural opportunities for conflict to occur because athletes are constantly hitting each other (in both hostile or instrumentally aggressive ways).

It seems likely based on the current study's findings that collision sport athletes are the most at-risk for participating in harmful aggression, especially when provocation occurs. In an effort to proactively prevent aggressive and harmful behavior occurring on the playing field, it is important that athletic departments, especially at the highest division of NCAA sport, allocate the most education and funding for resources to help collision sport athletes better manage anger. One suggestion is to require all first-year collision sport athletes to undergo mandatory anger management classes. These could begin in the pre-season and might consist of a series of educational workshops focused on how to recognize anger, in addition to learning and applying appropriate strategies to cope with the emotion in competitive environments.

Division level comparison. Based on analysis by NCAA division level, NCAA Division I athletes scored higher than Division III athletes on competitive aggressiveness and anger. Division I athletes did not score significantly different in either of these variables from Division II athletes, but Division II athletes did score significantly higher than Division III athletes on 
competitive anger. These results lend credence to the notion that at the Division I and II levels of collegiate sport, more competitive aggressiveness and anger exists. Few studies have investigated anger or aggression differences by skill or competition level. Maxwell and colleagues (2009) observed that anger and aggressiveness decreased as experience in sport increased, but only for contact and non-contact sport athletes. The authors suggested that in collision sports, aggressive behavior may be more critical for success, and athletes in collision sports may not possess other appropriate strategies to cope with these emotions. It was also proposed that these athletes may find that the benefit of aggression simply outweighs the potential consequences during competitive play.

After thorough investigation, no empirical evidence was discovered to help explain the differences in competitive aggressiveness and anger found between NCAA division levels. Anecdotally, it seems that differences between Division I and Division III athletes might arise because of the increased pressure and stakes found at the NCAA Division I level of sport. NCAA Division I contact and collision sport athletes are more likely to be scholarship athletes, putting more pressure on them to win. Division I sports are also much more in the public eye and often times are televised nationally. This is especially true in the revenue-producing sports such as football and basketball. Increased pressure and scrutiny could lead to heightened stress and emotions, which if not properly managed might lead to aggressive behavior.

Unfortunately, little research has investigated anger or aggression disparities among athletes of different NCAA division levels. Simpson and Newby (1994) conducted a study looking at the POMS (McNair, Lorr, \& Droppelman, 1971) profiles of football players at nonscholarship versus scholarship schools. They found that even though the scholarship school was small and not "elite", athletes on scholarship scored better in terms of general mood state and 
lower on anger. This would suggest that having a scholarship actually has a positive influence on mood and decreases anger, conclusions that are inconsistent with the findings of the current study.

Greene, Sears, and Clark (1993) conducted a similar study using the STAXI to compare anger levels among football players on a university varsity team and intramural flag football teams. The researchers found similar levels of trait anger, but varsity athletes reported lower scores on the anger-in, anger-out, and anger-control subscales of the STAXI. One reason put forth to explain this finding was that athletes may be more likely to excel if they do not act on anger and are able to re-focus on the tasks at hand (Greene, Sears, \& Clark, 1993). It is possible that varsity athletes benefit more from sanctioned on-field aggression, because it may buffer him/her from anger turning into other forms of aggressive behavior, such as lashing out at officials or harming opponents.

Robazza and Bertoli (2006) found an athlete's skill level was an important factor that can moderate an athlete's interpretation of how his/her anger influences performance. Higher skill athletes were able to find anger as more facilitative to performance than lower skill athletes. For example, higher skilled athletes might seek out anger as a way to raise arousal levels, delay feelings of fatigue, or produce extra energy when effort is beginning to wane (Robazza \& Bertoli, 2006). It should be noted this research was conducted with Italian professional athletes and not with athletes of different NCAA divisions. The findings that highly skilled athletes can potentially benefit more from anger suggests that at the Division I and II levels of NCAA sport, athletes might have higher competitive anger but also simultaneously feel more able to use it in an advantageous way. Less is known about the mechanisms by which higher-skilled athletes are able to utilize anger in facilitative ways during competition. Perhaps the findings of the current 
study represent a foundation by which to help better understand the competitive aggressiveness and anger of athletes who compete in different NCAA divisions across the country. It could be beneficial to athletes of all levels to understand how to better manage emotions like anger and even potentially utilize anger in productive ways during competition.

\section{The Experience of Provocation in Sport}

Gender comparison. The results of the current study supported the view that the experience of provocation among male and female collegiate athletes varies. The first hypothesis regarding provocation was supported. Male athletes reported experiencing significantly more provocation, as well as more negative and intense responses to being provoked. Somewhat surprising, however, is the finding that female athletes reported higher levels of felt anger subsequent to competitor provocation. Therefore, it seems that male athletes in contact and collision sports may engage in more provocative behavior with each other, as well as more often reacting in a strong, negative manner. In comparison, female athletes actually become angrier when provoked by opponents.

It is unclear why male athletes in this study experienced more provocation. It may be in part due to the possibility that provocation itself seems to produce stronger reactions from male athletes than female athletes. In other words, using provocation is very effective at promoting a strong reaction with male athletes. While female athletes experienced higher anger levels, they scored significantly lower on the frequency of producing a negative response and the intensity of any response to being provoked. Simply put, female athletes seemed to manage being provoked better than male athletes (although it should be noted again that the overall amount of provocation in female contact and collisions sports was lower). 
One possible explanation for this phenomenon is that female collegiate athletes have more innate empathy, which has been shown to be a factor in inhibiting aggression (Stranger et al., 2016). In fact, research outside of athletics has pointed to the concept that females have greater empathy at birth and this gender difference continues throughout life (e.g., ChristovMoore et al., 2014). Research with adolescents has produced findings that females show a greater empathetic response (i.e., the ability to understand another person's situation and respond accordingly) than males of the same age (Mestre et al., 2009). Therefore, it is possible that female collegiate athletes may be more likely than male athletes to generate empathy towards a provocative opponent, preventing aggressive reactions. Other research aimed at helping to explain these gender differences would be welcome additions to the sport psychology literature base.

Sport type comparison. Being provoked is an important antecedent to aggressive behavior both in and out of athletic settings (e.g., Huang, Cheek, \& Lane, 1999; Stranger et al., 2016). Maxwell (2004) was one of the first researchers to focus on the exploration of provocation in sport. Unsurprisingly, he found that team sport athletes experienced more provocation than individual sport athletes. Maxwell, Moores, and Chow (2007) conducted similar research that supported the notion that contact sport male athletes experienced provocation at a greater frequency than male non-contact sport athletes. Although it was not a primary research question of this investigation, it does seem intuitive that team sport athletes likely experience more provocation than individual sport athletes, mainly due to the nature of team sport athletes being in closer proximity to their opponents and encountering more situations in competition that could cause conflict. For example, individual sport athletes generally compete without the presence of opponents that can physically or verbally affect their 
performance. In contact and collision sports, athletes are competing against one another at high speeds in an enclosed space, with the legality of some physical contact up to the discretion of officials.

The results of the current study partially supported the second hypothesis that collision sport athletes experience more provocation than contact sport athletes. Collision sport athletes in this study scored significantly higher on measures assessing the frequency of provocation, as well as the frequency of having a negative response to the provocative behavior. Collision and contact sport athletes did not differ significantly in reported felt anger from provocation or the intensity of responses to provocation. Ultimately, for contact and collision sport athletes, the differences in scores on the provocation questionnaire were not dependent on gender.

The current study is believed to be the first to investigate differences in the experience of provocation among contact and collision sport athletes. In general, little research in the area of applied sport psychology has investigated differences among athletes in these sport types. Related studies have investigated differences in the types of aggressive behavior or perceived legitimacy of aggression by sport type. For example, Keeler (2007) found that hostile and instrumental aggression levels did not differ between athletes in a collision sport (rugby) versus a contact sport (soccer). Gardner and Janelle (2002) found that male high school athletes rated video clips of aggressive and assertive behavior to be more legitimate and acceptable than female athletes, with no differences between the types of sport (high-contact, low-contact, or noncontact).

Overall, it appears that provocation likely occurs more frequently in collision sports, with athletes participating in these types of sports also producing more frequent negative responses to this type of behavior by opponents. It is possible that collision sport athletes are more likely to 
respond negatively to provocation because it is easier in a collision sport to get away with a physical act of "payback". It is also possible that the lines between legal and illegal competitive behavior are more blurred in collision sports, leaving the decision of whether an act is aggressive or harmful largely up to the officials. This means it is imperative that officials and coaches of these sports be even more aware of the potential for revenge-based aggressive behavior. To this end, researchers have explored specific criteria of competition that more likely to lead to aggression. This includes losing by a wide margin, playing poorly, and losing to an inferior opponent (Widmeyer et al., 2002). Game officials in collision sports should be trained to be hyper-aware of the potential for aggression to occur during these scenarios. In addition, stricter penalties may need to be introduced for athletes displaying provocative behavior, regardless of whether any aggressive behavior as occurred. This would be considered a proactive effort in attempting to keep games safe from violent behavior.

Division level comparison. Along with exploring gender and sport type differences for the experience of provocation, participants' NCAA division level was also explored. Although NCAA Division I athletes scored higher in competitive aggressiveness and anger than Division III athletes, the experience of provocation appears to be similar for both. In fact, there were no significant differences on any of the subscales of the sport provocation questionnaire. This would suggest that provocation is occurring at all levels of collegiate sport in comparable amounts, with similar responses produced.

There does not appear to be any prior research that compares personal or situational characteristics among athletes from different NCAA division levels. Therefore, it may be safe to assume that provocation occurs largely as a byproduct of interaction during competition in general, and is not necessarily more evident when the stakes and/or pressure are higher (i.e., at 
the Division I level). All sports involved in this study were team sports that involved physical contact between opponents. It seems that any sport that fits these criteria at the collegiate level may involve athletes that attempt to provoke each other.

\section{Future Research and Directions}

While this study was novel in its exploration of provocation in collegiate sport, the results are only a foundation for further research on the experience of provocation in collegiate sports, as well as the variables of competitive aggressiveness and anger. Unfortunately, little research currently exists in the sport psychology literature that explores these variables. Outside of sport, some research has begun to explore important personal characteristics in athletes that may help to understand aggressive behaviors. For example, some work has explored the phenomenon of "narcissistic rage", a state of heightened emotion that narcissistic individuals might feel when provoked (Krizan \& Johar, 2015). This state occurs when self-centered people feel their ego is being attacked and may include feelings of anger, sadness, and shame (Hart, Adams \& Tortoriello, 2016). Thus, one path for future research would be to begin to assess whether there may be a higher proportion of athletes with narcissistic traits that go into contact or collision sports, and whether these individuals are more susceptible to aggression and/or violence when being provoked.

Some researchers have focused on the idea of obsessive passion in athletes and how it may be associated with aggressive behavior. In particular, it was found that athletes having obsessive passion (passion that is connected to one's identity and self-esteem) were more likely to be aggressive than harmoniously-passionate athletes (Donahue, Rip, and Vallerand, 2009). The researchers suggested that to reduce aggressive behavior, it is more important to develop harmonious passion in sport, as this means individuals are passionate about an activity but don't 
let it affect their self-image. Again, research exploring the incidence of this trait in athletes may help to find more indicators of athletes that are predisposed to act out aggressively during competition. An example of this type of research would be utilizing regression analyses to investigate the impact of traits such as narcissistic rage and obsessive passion on competitive anger and aggressive behavior.

Research concerning the type of environment created by coaches could also help to explain some of the differences seen in competitive aggressiveness and anger among NCAA division levels and/or type of sport. The current study did not explore the role of coaches in creating an atmosphere that condones or prevents aggressive behavior. The role of the head coach is especially important because of the knowledge that a mastery climate focused on sportsmanship within a team is indicative of less hostile aggression (Chantal, Robin, Verna, \& Bernache-Assollant, 2005). It has also been suggested that coaches who emphasize winning and inter-team competition correlated with athletes with low moral reasoning (Miller, Roberts, \& Ommundsen, 2005). In other words, if a coach preaches the importance of sportsmanship and fair play, there appears to be less probability of hostile aggression by the athletes on that team.

Once it can be determined which athletes may struggle to manage competitive anger and aggressive tendencies, the second step is to have resources readily available for these individuals. Outside of sport, Howells (1998) observed two decades ago that a major issue in anger management interventions has been the failure to apply them to high-risk populations. It is obvious that athletes, especially at the collegiate level, should be considered high risk due to the high-stress, overtly physical, and oft-controversial nature of sports. Based on the findings of this study, males competing in collision sports are also at a high risk for aggressive behavior. 
Despite research that suggests the importance of psychological skills training to manage emotions and reduce aggressive behavior, very little research has focused on applied anger or aggression interventions. Helping athletes learn to self-regulate better could reduce instances of aggression on the field (Ciairano et al., 2007). For example, imagery, cognitive reframing, progressive muscle relaxation, and autogenic training have all been found to be helpful in reducing unhealthy emotions and improve sport performance (Carter, Forys, \& Oswald, 2008). Brunelle, Janelle, and Tennant (1999) were among the first researchers to examine anger and aggressive behavior using intervention methods. The researchers found that simply doing roleplaying helped to improve their ability to control anger and any subsequent aggressive behavior. A decade later, Lauer and Paiement (2009) conducted an aggression intervention using a singlesubject design to work with three youth hockey players. The researchers taught emotional regulation skills and how to react when provoked by opponents. Results revealed that all three participants decreased their aggression, with the largest reductions in hostile, retaliatory acts. Therefore, it is clear that interventions focused on reducing aggression have the potential to decrease potentially harmful behavior during competition.

So why has there been such a scarcity of published studies that utilized true anger or aggression intervention methods? The biggest reason may be the time and financial costs in conducting this type of research, in addition to issues with recruiting and attrition. Anger management typically requires anywhere from three to eight sessions (Thomas, 2001). Furthermore, it requires at least one trained researcher and resources such as worksheets, journals, and other materials. Another problem is recruiting athletes who would actually benefit from this type of work. An athlete that struggles to manage his/her anger is unlikely to actively attend an anger management workshop, either because he/she believes it to be unnecessary or are 
embarrassed to be labeled as someone who cannot control his/her emotions. Even if a researcher can get athletes to attend the first session, attrition is possible, as the demands of school and training become competing factors. It is unlikely that participating in one or two one-hour anger management workshops is enough to help athletes deal with anger in an effective manner.

\section{Study Strengths and Limitations}

This study is the first known study to identify differences in athletes competing in contact or collision sports in regards to levels of anger, aggressiveness, and the experience of provocation. This is important because contact and collision sport athletes are in frequent proximity to each other and the potential for aggressive behavior is higher than in non-contact or individual sports. Furthermore, it is one of the few studies to investigate differences in personal characteristics among athletes of different NCAA Division level. In addition, a strength of this study is that it furthers the understanding of provocation in college sports. No standardized measure exists to assess provocation in sport, and it is believed that the Sport Provocation Questionnaire created and utilized in this study is a first step in establishing this type of assessment.

A number of limitations were associated with this study. First, significant competitive anger and aggressiveness differences were found by NCAA division level, but gender and type of sport analyses grouped together athletes by division level. This was primarily because of the need for a larger sample size (for adequate statistical power). Ideally, a sample could be obtained that contained enough participants of each NCAA division level. Second, the Sport Provocation Questionnaire is an original assessment of provocation that has never been used before in sport psychology research. Although it is based on a now-extinct short scale that was once used to assess provocation, it has greatly expanded on this scale in depth and scope. It is probable that 
the Sport Provocation Questionnaire does not address all relevant aspects of the experience of provocation. It also remains to be seen whether it will withstand any future trials of rigorous psychometric testing. Third, although it was collected, the variable of race/ethnicity was not explored in this study in relation to competitive aggressiveness, anger, and provocation. It is possible that cultural differences in early socialization exist (such as appropriate methods of dealing with anger or reacting to provocation). Fourth, there exists the possibility of reporting bias within the study, as athletes may not want to be perceived as overly aggressive or angry on a self-report questionnaire. Finally, the recruitment process may have presented some bias among athletes, for example whether they were surveyed in the off-season or pre-season. This bias may lead athletes to underreport anger or aggression levels and provocation experiences, when the reality is that these scores might be higher if assessed during the competitive season. Alternatively, when coaches agreed to participate, they may have asked specific athletes to fill out the study survey that they deemed to have issues with anger or aggression. This could have led to a higher proportion of these athletes represented in the sample. 


\section{References}

Abrams, M. (2010). Anger management in sport: Understanding and controlling violence in athletes. Champaign, IL: Human Kinetics.

Bandura, A. (1973). Aggression: A social learning analysis. Englewood Cliffs, NJ: PrenticeHall.

Berkowitz, L. (1965). Aggressive cues in aggressive behavior and hostility catharsis. Psychological Review, 71, 104-122.

Berkowitz, L. (1989). Frustration-aggression hypothesis: Examination and reformulation. Psychological Bulletin, 106(1), 59-73.

Berkowitz, L. (1993). Aggression: Its causes, consequences, and control. New York. NY: McGraw-Hill.

Bolgar, M. R., Janelle, C., \& Giacobbi, P. R., Jr. (2008). Trait anger, appraisal, and coping differences among adolescent tennis players. Journal of Applied Sport Psychology, 20, 73-87.

Botterill, C., \& Brown, M. (2002). Emotion and perspective in sport. International Journal of Sport Psychology, 33, 38-60.

Bredemeier, B. (1994). Children's moral reasoning and their assertive, aggressive, and submissive tendencies in sport and daily life. Journal of Sport \& Exercise Psychology, $16,1-14$.

Bredemeier, B., Weiss, M., Shields, D., \& Cooper, B. (1986). The relationship of sport involvement with children's moral reasoning and aggression tendencies. Journal of Sport Psychology, 8, 304-318. 
Brunelle, J. P., Janelle, C. M., \& Tennant, K. (1999). Controlling competitive anger among male soccer players. Journal of Applied Sport Psychology, 11(2), 283-297.

Burton, J. M., \& Marshall, L. (2005). Protective factors for youth considered at risk for criminal behavior: Does participation in extracurricular activities help? Criminal Behaviour and Mental Health, 15(1), 46-64.

Bushman, B. J. (2002). Does venting anger feed or extinguish the flame? Catharsis, rumination, distraction, anger, and aggressive responding. Personality and Social Psychology Bulletin, 28(6), 724-731.

Buss, A. H., \& Perry, M. P. (1992). The aggression questionnaire. Journal of Personality and Social Psychology, 63, 452-459.

Carter, M. M., Forys, K. L., \& Oswald, J. C. (2008). The cognitive-behavioral model. In M. Hersen, \& A. M. Gross (Eds.), Handbook of clinical psychology (pp. 171-204). Hoboken, NJ: Wiley.

Chantel, Y., Robin, P., Vernat, J., \& Bernache-Assollant, I. (2005). Motivation, sportspersonship, and athletic aggression: A meditational analysis. Psychology of Sport \& Exercise, 6(2), 233-249.

Christov-Moore, L., Simpson, E. A., Coude, G., Grigaityte, K., Iacoboni, M., \& Ferrari, P. F. (2014). Empathy: Gender effects in brain and behavior. Neuroscience \& Biobehavioral Reviews, 46, 604-627. doi: 10.1016/j.neuobiorev.2014.09.001.

Ciairano, S., Rabaglietti, E., Roggero, A., Bonino, S., \& Beyers, W. (2007). Patterns of adolescent friendships, psychological adjustment and antisocial behavior: The moderating role of family stress and friendship reciprocity. International Journal of Behavioral Development, 31, 539-548. 
Coulomb-Cabagno, G., \& Rascle, O. (2006). Team sports players’ observed aggression as a function of gender, competitive level, and sport type. Journal of Applied Social Psychology, 36(8), 1980-2000. doi: 10.1111/j.0021-9029.2006.00090.

Creswell, J. W. (2014). Research design: Qualitative, quantitative, and mixed methods approaches $\left(4^{\text {th }}\right.$ Ed.). Thousand Oaks, California: SAGE Publications.

Dollard, J., Doob, L., Miller, N., Mowrer, O., \& Sears, R. (1939). Frustration and aggression. New Haven, CT: Yale University Press.

Donahue, E. G., Rip, B., \& Vallerand, R. J. (2009). When winning is everything: On passion, identity, and aggression in sport. Psychology of Sport and Exercise, 10(5), 526-534. doi: 10.1016/j.psychsport.2009.02.002.

Faul, F., Erdfelder, E., Lang, A. G., \& Buchner, A. (2007). G*Power 3.1: A flexible statistical power analysis program for the social, behavioral, and biomedical sciences. Behavior Research Methods, 39, 175-191.

Feindler, E. L., \& Ecton, R. B. (1994). Adolescent anger control: Cognitive behavioral techniques. Needham Heights, MA: Allyn \& Bacon.

Field, A. P. (2009). Discovering statistics using SPSS ( $3^{\text {rd }}$ ed.). London, England: SAGE Publications.

Gardner, R. E., \& Janelle, C. M. (2002). Legitimacy judgments of perceived aggression and assertion by contact and non-contact sport participants. International Journal of Sport Psychology, 33(3), 290-306.

Greene, A. F., Sears, Jr., S. F., \& Clark, J. E. (1993). Anger and sports participation. Psychological Reports, 72, 523-529. 
Hanin, Y. L. (2010). Coping in sport: Theories methods and related constructs (pp. 159-175). Hauppauge, NY: Nova Science Publishers, Inc.

Hanin, Y. L., \& Syrja, P. (1995). Performance affect in soccer players: An application of the IZOF model. International Journal of Sports Medicine, 16(4), 264-269.

Harris, M. B. (1993). How provoking! What makes men and women angry? Aggressive Behavior, 19(3), 199-211.

Hart, W., Adams, J., Burton, A., \& Tortoiello, G. (2017). Narcissism and self-presentation: Profiling grandiose and vulnerable narcissists' self-presentation tactic use. Personality and Individual Differences, 104, 48-57. doi:10.1016/j.paid.2016.06.062.

Howells, K. (1998). Cognitive-behavioral therapy for anger, aggression and violence. In N. Tarrier, \& A. Wells (Eds.), Complex cases in cognitive-behavioral therapy (pp. 295318). Chichester, NH: Wiley.

Huang, D. B, Cherek, D. R., \& Lane, S. D. (1999). Laboratory measurement of aggression in high school age athletes: Provocation in a nonsporting context. Psychological Reports, $85,1251-1262$.

Husman, B. F., \& Silva, J. M. (1984). Aggression in sport: Definitional and theoretical considerations. In J. M. Silva \& R. S. Weinberg (Eds.), Psychological foundations of sport (pp. 246-260). Champaign, IL: Human Kinetics.

IBM Corp. (2016). IBM SPSS Statistics for Macintosh, Version 24. Armonk, NY: IBM Corporation.

Kassinove, H., \& Tafrate, R. C. (2002). Anger management: The complete practitioner's guidebook for the treatment of anger. Atascadero, CA: Impact. 
Keeler, L. (2007). The differences in sport aggression, life aggression, and life assertion among adult male and female collision, contact, and non-contact sport athletes. Journal of Sport Behavior, 30(1), 57-76.

Kimble, N. B., Russo, S. A., Bergman, B. G., \& Galindo, V. H. (2010). Revealing an empirical understanding of aggression and violent behavior in athletics. Aggression and Violent Behavior, 15, 446-462.

Kirker, B., Tenenbaum, G., \& Mattson, J. (2000). An investigation of the dynamics of aggression: direct observation in ice hockey and basketball. Research Quarterly for Exercise and Sport, 71, 373-386.

Krizan, Z., \& Johar, O. (2015). Narcissistic rage revisited. Journal of Personality and Social Psychology, 108(5), 784-801.

Lane, A. M. (Ed.). (2007). Mood and human performance: Conceptual, measurement and applied issues. Hauppauge, NY: Nova Science Publishers, Inc.

Lane, A. M., Beedie, C. J., Jones, M. V., Uphill, M., \& Davenport, T. J. (2012). The BASES expert statement on emotion regulation in sport. Journal of Sport Sciences, 30(11), 11891195. doi: 10.1080/02640414.2012.693621.

Lauer, L., \& Paiement, C. (2009). The playing tough and clean hockey program. The Sport Psychologist, 23, 543-561.

Maxwell, J. P. (2004). Anger rumination: An antecedent of athlete aggression? Psychology of Sport \& Exercise, 5, 279-289. 
Maxwell, J. P., \& Moores, E. (2006). Development of a short scale measuring provocation in competitive athletes. Proceedings of the British Association of Sport and Exercise Sciences Annual Conference, September 2006, Wolverhampton, UK.

Maxwell, J. P., \& Moores, E. (2007). The development of a short scale measuring aggressiveness and anger in competitive athletes. Psychology of Sport and Exercise, 8, 179-193.

Maxwell, J. P., Moores, E., \& Chow, C. C. F. (2007). Anger rumination and self-reported aggression amongst British and Hong Kong Chinese athletes: A cross-cultural comparison. International Journal of Sport and Exercise Psychology, 5(1), 9-27.

Maxwell, J. P., Visek, A. J., \& Moores, E. (2009). The perceived legitimacy of aggression in male Hong Kong Chinese athletes: Effects of type of sport and level of competition. Psychology of Sport \& Exercise, 10, 289-296.

McNair, D. M., Lorr, M., \& Droppleman, L. F. (1971). Manual for the Profile of Mood States. San Diego, CA: Educational and Industrial Testing Service.

Mestre, M. V., Samper, P., Frias, M. D., \& Tur, A. M. (2009). Are women more empathetic than men? A longitudinal study in adolescence. Spanish Journal of Psychology, 12(1), 76-83.

Miller, B. W., Roberts, G. C., \& Ommundsen, Y. (2005). Effect of perceived motivational climate on moral functioning, team moral atmosphere perceptions, and the legitimacy of intentionally injurious acts among competitive youth football players. Psychology of Sport and Exercise, 6(4), 461-477. http://dx.doi.org/10.1016/j.psychsport.2004.04.003

Mohr, P., Howells, K., Gerace, A., Day, A., \& Wharton, M. (2007). The role of perspectivetaking in anger arousal. Personality and Individual Differences, 43, 507-517. doi: 3 10.1016.j.paid.2006.12.019. 
Nunnally, J. C., \& Bernstein, I. H. (1994). Psychometric theory ( $3^{\text {rd }}$ ed.). New York, NY: McGraw Hill.

Phillips, J. P., \& Giancola, P. R. (2007). The effects of contextual empathy on aggressive behavior in men and women. In A. M. Columbus (Ed.). Advances in psychology research, Vol. 49, (pp. 197-208). Hauppauge, NY: Nova Science Publishers, Inc.

Robazza, C., \& Bortoli, L. (2007). Perceived impact of anger and anxiety on sporting performance in rugby players. Psychology of Sport and Exercise, 8, 875-896,

Robazza, C., Bertoli, M., \& Bortoli, L. (2006). Frequency and direction of competitive anger in contact sports. The Journal of Sports Medicine and Physical Fitness, 46(3), 501-508.

Ruiz, C. N., \& Hanin, Y. L. (2011). Perceived impact of anger on performance of skilled karate athletes. Psychology of Sport \& Exercise Science, 12, 242-249.

Silva, J. M. (1983). The perceived legitimacy of rule violating behavior in sport. Journal of Sport Psychology, 5, 438-448.

Simpson, S., \& Newby, R. W. (1994). Scores on profile of mood states of college football players from nonscholarship and scholarship programs. Perceptual and Motor Skills, 78, $635-640$.

Sofia, R., \& Cruz, J. F. A. (2016). Exploring individual differences in the experience of anger in sport competition: The importance of cognitive, emotional, and motivational variables. Journal of Applied Sport Psychology, 28(3), 350-366, doi:10.1080/10413200.2015.1121170. 
Spielberger, C. D. (1988). State-Trait Anger Expression Inventory. Odessa, FL: Psychological Assessment Resources.

Spielberger, C. D., \& Reheiser, E. C. (2009). Assessment of emotions: Anxiety, anger, depression, and curiosity. Applied Psychology: Health and Well-Being, 1(3), 271-302.

Stranger, N., Kavussanu, M., McIntyre, D., \& Ring, C. (2016). Empathy inhibits aggression in competition: The role of provocation, emotion, and gender. Journal of Sport \& Exercise Psychology, 38, 4014.

Teclaw, R., Price, M., \& Osatuke, K. (2011). Demographic question placement: Effect on item response rates and means of a veterans health administration survey. Journal of Business and Psychology, 27, 281-290. doi: 10.1007/s10869-011-9249-y.

Thomas. S. P. (2001). Teaching healthy anger management. Perspectives in Psychiatric Care, $37(2), 41-48$.

Tucker, L., \& Parks, J. (2001). Effects of gender and sport type on intercollegiate athletes' perceptions of the legitimacy of aggressive behaviors in sport. Sociology of Sport Journal, 18, 403-413.

Vacha-Haase, T., \& Thompson, B. (2004). How to estimate and interpret various effect sizes. Journal of Counseling Psychology, 51(4) 473-481.

Vallance, J. K. H., Dunn, J. G. H., \& Dunn, J. L. C. (2006). Perfectionism, anger, and situation criticality in competitive youth ice hockey. Journal of Sport \& Exercise Psychology, 28, $383-406$.

Visek, A. J., Maxwell, J. P., Watson, J. C., Hurst, J. R. (2011). A cross-cultural evaluation of the factorial invariance of the competitive aggressiveness and anger scale. Journal of Sport Behavior, 33(2), 218-237. 
Wagstaff, C. R. D., \& Weston, N. J. V. (2014). Examining emotion regulation in an isolated performance team in Antarctica. Sport, Exercise, and Performance Psychology, 3(4), 273-287. DOI: 10.1037/spy0000022.

Widmeyer, W. N., Dorsch, K. D., Bray, S. R., \& McGuire, E. J. (2002). The nature, prevalence, and consequences of aggression in sport. In J. M. Silva \& D. E. Stevens (Eds.), Psychological foundations of sport (pp. 328-351). Boston: Allyn \& Bacon.

Woodcock, C., Cumming, J., Duda, J. L., \& Sharp, L. (2012). Working within an individual zone of optimal function (IZOF) framework: Consultant practice and athlete reflections on refining emotion regulation skills. Psychology of Sport and Exercise, 13, 291-302. 


\section{Appendix A: Data Tables}

\section{Demographics}

Table A1

Frequencies and Percentages for Participant Demographics

\begin{tabular}{|c|c|c|}
\hline Variable & $\mathrm{N}$ & Percent (\%) \\
\hline \multicolumn{3}{|l|}{ Gender } \\
\hline Male & 124 & 51.0 \\
\hline Female & 119 & 49.0 \\
\hline \multicolumn{3}{|l|}{ Age } \\
\hline $18-19$ & 128 & 52.7 \\
\hline $20-21$ & 93 & 38.3 \\
\hline $22-23$ & 22 & 9.0 \\
\hline \multicolumn{3}{|l|}{ Year in school } \\
\hline Freshmen & 93 & 38.3 \\
\hline Sophomore & 50 & 20.6 \\
\hline Junior & 51 & 21.0 \\
\hline Senior & 36 & 14.8 \\
\hline Fifth-year/Graduate & 13 & 5.3 \\
\hline \multicolumn{3}{|l|}{ NCAA Division } \\
\hline $\mathrm{I}$ & 64 & 26.3 \\
\hline II & 71 & 29.2 \\
\hline III & 108 & 44.4 \\
\hline \multicolumn{3}{|l|}{ Type of Sport } \\
\hline Contact & 126 & 52.7 \\
\hline Collision & 113 & 47.3 \\
\hline
\end{tabular}

Note: Overall $\mathrm{N}=243$. 


\section{Reliability Analysis}

Table B1

Internal Consistency Coefficients for the Sport Provocation Questionnaire and Competitive Aggressiveness and Anger Scale

\begin{tabular}{lccc}
\hline \multicolumn{1}{c}{ Subscale } & N of items & Valid N & Cronbach's Alpha $(\alpha)$ \\
Experience of provocation & 10 & 233 & .843 \\
Negative response to provocation & 10 & 221 & .875 \\
Anger level from provocation & 10 & 217 & .911 \\
Intensity of response to provocation & 10 & 212 & .896 \\
Aggressiveness & & & .850 \\
Anger & 6 & 239 & .829 \\
\hline
\end{tabular}

Note: Cronbach's alphas were calculated for all items in each subscale. 


\section{Inferential Statistics}

Table C1

One-way ANOVA of Total Competitive Aggressiveness and Anger Scale Score by Gender

\begin{tabular}{lcccccc}
\hline \multicolumn{1}{c}{ Source } & $\begin{array}{c}\text { Sum of } \\
\text { Squares }\end{array}$ & df & Mean Square & F & Sig. & $\eta^{2}$ \\
\hline Between Groups & 6301.76 & 1 & 6301.76 & 23.68 & $.000^{* *}$ & .091 \\
Within Groups & 63074.15 & 237 & 266.14 & & \\
Total & 69375.91 & 238 & & & \\
\hline
\end{tabular}

Note: $\eta^{2}=$ partial eta squared (used for effect size); $* \mathrm{p}<.05 * * \mathrm{p}<.001$ 
Table C2

One-Way ANOVA of Competitive Aggressive and Anger Scale Anger Subscale Score by Gender

\begin{tabular}{lcccccc}
\hline \multicolumn{1}{c}{ Source } & $\begin{array}{c}\text { Sum of } \\
\text { Squares }\end{array}$ & df & Mean Square & F & Sig. & $\eta^{2}$ \\
\hline Between Groups & 87.62 & 1 & 87.62 & 1.35 & .247 & .006 \\
Within Groups & 15668.21 & 241 & 65.01 & \\
Total & 15755.83 & 242 & & & \\
\hline
\end{tabular}

Note: $\eta^{2}=$ partial eta squared (used for effect size); $* \mathrm{p}<.05 * * \mathrm{p}<.001$ 
Table C3

One-Way ANOVA of Competitive Aggressive and Anger Scale Aggressiveness Subscale Score by Gender

\begin{tabular}{lccccccc}
\hline \multicolumn{1}{c}{ Source } & $\begin{array}{c}\text { Sum of } \\
\text { Squares }\end{array}$ & df & Mean Square & F & Sig. & $\eta^{2}$ \\
\hline Between Groups & 4911.64 & 1 & 4911.64 & 46.27 & $.000^{* *}$ & .163 \\
Within Groups & 25156.19 & 237 & 106.14 & & & \\
Total & 69375.91 & 238 & & & & \\
\hline Note: $: \eta^{2}=$ partial eta squared (used for effect size) $;{ }^{*} \mathrm{p}<.05 * * \mathrm{p}<.001$ &
\end{tabular}


Table C4

One-Way ANOVA of Total Sport Provocation Questionnaire Score by Gender

\begin{tabular}{|c|c|c|c|c|c|c|}
\hline Source & $\begin{array}{l}\text { Sum of } \\
\text { Squares }\end{array}$ & $\mathrm{df}$ & Mean Square & $\mathrm{F}$ & Sig. & $\eta^{2}$ \\
\hline Between Groups & .952 & 1 & .952 & 2.49 & .116 & .011 \\
\hline Within Groups & 82.92 & 217 & .382 & & & \\
\hline Total & 83.87 & 218 & & & & \\
\hline
\end{tabular}

Note: $\eta^{2}=$ partial eta squared (used for effect size); $* \mathrm{p}<.05 * * \mathrm{p}<.001$ 
Table C5

One-Way ANOVAs of Sport Provocation Questionnaire Subscales by Gender

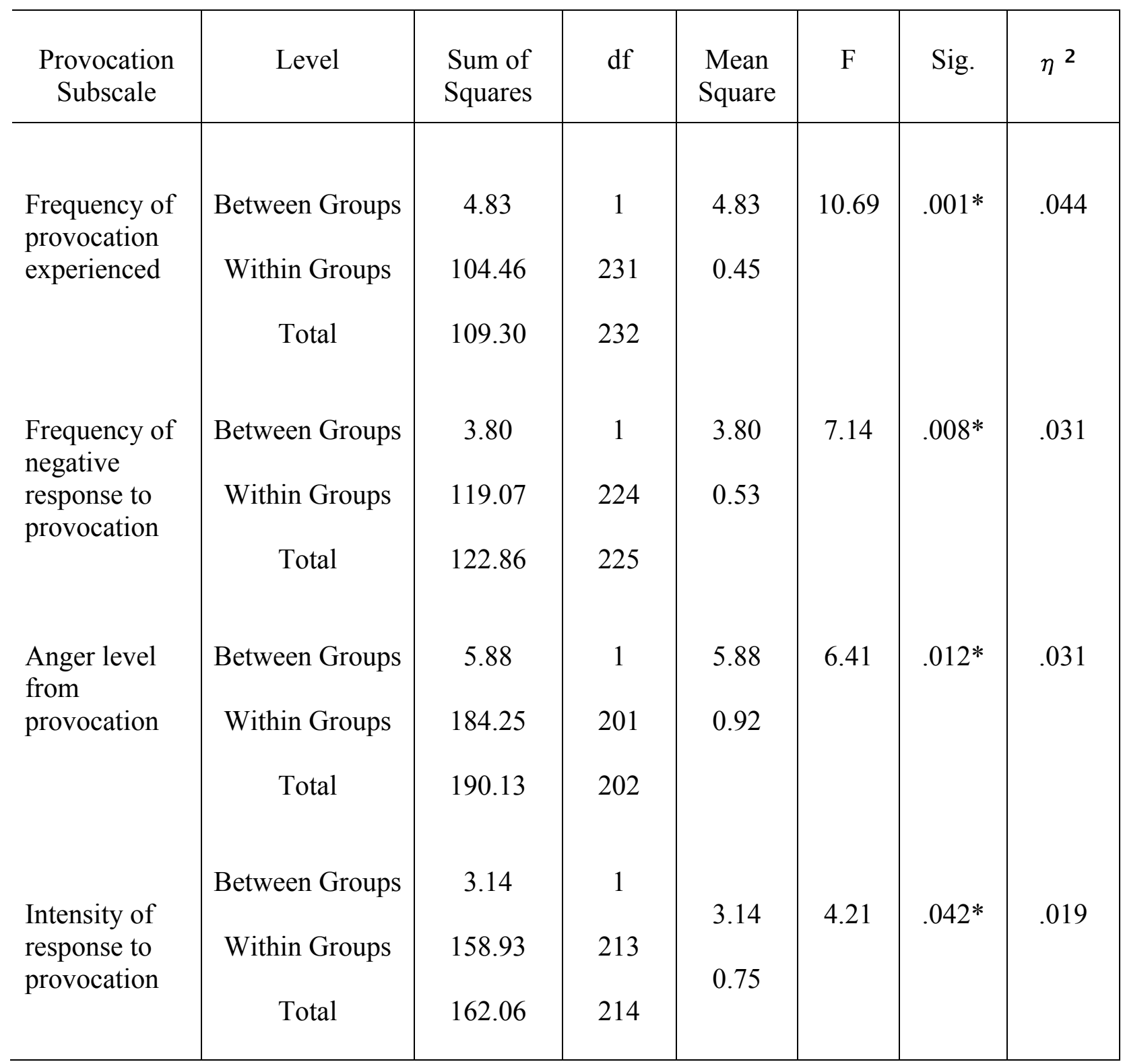

Note: $\eta^{2}=$ partial eta squared (used for effect size); $* \mathrm{p}<.05 * * \mathrm{p}<.001$ 
Table C6

One-Way ANOVA of Total Competitive Aggressiveness and Anger Scale Score by Type of Sport

\begin{tabular}{lcccccc}
\hline \multicolumn{1}{c}{ Source } & $\begin{array}{c}\text { Sum of } \\
\text { Squares }\end{array}$ & df & Mean Square & F & Sig. & $\eta^{2}$ \\
Between Groups & 8063.41 & 1 & 8063.41 & 31.17 & $.000^{* *}$ & .116 \\
Within Groups & 61312.50 & 237 & 258.70 & & \\
Total & 69375.91 & 238 & & & \\
\hline
\end{tabular}

Note: $\eta^{2}=$ partial eta squared (used for effect size); $* \mathrm{p}<.05 * * \mathrm{p}<.001$ 
Table C7

One-Way ANOVA of Competitive Aggressiveness and Anger Scale Anger Subscale Score by Type of Sport

\begin{tabular}{lcccccc}
\hline \multicolumn{1}{c}{ Source } & $\begin{array}{c}\text { Sum of } \\
\text { Squares }\end{array}$ & df & Mean Square & F & Sig. & $\eta^{2}$ \\
\hline Between Groups & 259.45 & 1 & 259.45 & 4.04 & $.046^{*}$ & .016 \\
Within Groups & 15496.38 & 241 & 64.30 & & & \\
Total & 83.87 & 242 & & & & \\
\hline
\end{tabular}

Note: $\eta^{2}=$ partial eta squared (used for effect size); $* \mathrm{p}<.05 * * \mathrm{p}<.001$ 
Table C8

One-Way ANOVA of Competitive Aggressiveness and Anger Scale Aggressiveness Subscale Score by Type of Sport

\begin{tabular}{lcccccc}
\hline \multicolumn{1}{c}{ Source } & $\begin{array}{c}\text { Sum of } \\
\text { Squares }\end{array}$ & df & Mean Square & F & Sig. & $\eta^{2}$ \\
\hline Between Groups & 5431.78 & 1 & 5431.78 & 52.25 & $.000^{* *}$ & .181 \\
Within Groups & 24636.05 & 237 & 103.95 & & \\
Total & 30067.83 & 238 & & \\
\hline
\end{tabular}

Note: $\eta^{2}=$ partial eta squared (used for effect size); $* \mathrm{p}<.05 * * \mathrm{p}<.001$ 
Table C9

One-Way ANOVA of Total Sport Provocation Questionnaire Score by Type of Sport

\begin{tabular}{lcccccc}
\hline \multicolumn{1}{c}{ Source } & $\begin{array}{c}\text { Sum of } \\
\text { Squares }\end{array}$ & df & Mean Square & F & Sig. & $\eta^{2}$ \\
\hline Between Groups & 2.76 & 1 & 2.76 & 7.39 & $.007^{*}$ & .033 \\
Within Groups & 81.12 & 217 & .374 & & \\
Total & 83.87 & 218 & & & \\
\hline
\end{tabular}

Note: $\eta^{2}=$ partial eta squared (used for effect size); ${ }^{*} \mathrm{p}<.05 * * \mathrm{p}<.001$ 
Table C10

One-Way ANOVAs of Sport Provocation Questionnaire Subscales by Type of Sport

\begin{tabular}{|c|c|c|c|c|c|c|c|}
\hline $\begin{array}{l}\text { Provocation } \\
\text { Subscale }\end{array}$ & Level & $\begin{array}{l}\text { Sum of } \\
\text { Squares }\end{array}$ & $\mathrm{df}$ & $\begin{array}{l}\text { Mean } \\
\text { Square }\end{array}$ & $\mathrm{F}$ & Sig. & $\eta^{2}$ \\
\hline $\begin{array}{l}\text { Frequency of } \\
\text { provocation } \\
\text { experienced }\end{array}$ & $\begin{array}{l}\text { Between Groups } \\
\text { Within Groups } \\
\text { Total }\end{array}$ & $\begin{array}{c}9.94 \\
99.35 \\
109.39\end{array}$ & $\begin{array}{c}1 \\
231 \\
232\end{array}$ & $\begin{array}{l}9.94 \\
0.43\end{array}$ & 23.12 & $.000^{* *}$ & .091 \\
\hline $\begin{array}{l}\text { Frequency of } \\
\text { negative } \\
\text { response to } \\
\text { provocation }\end{array}$ & $\begin{array}{l}\text { Between Groups } \\
\text { Within Groups } \\
\text { Total }\end{array}$ & $\begin{array}{c}5.65 \\
117.21 \\
122.86\end{array}$ & $\begin{array}{c}1 \\
224 \\
225\end{array}$ & $\begin{array}{l}5.65 \\
0.52\end{array}$ & 10.80 & $.001^{*}$ & .046 \\
\hline $\begin{array}{l}\text { Anger level } \\
\text { from } \\
\text { provocation }\end{array}$ & $\begin{array}{l}\text { Between Groups } \\
\text { Within Groups } \\
\text { Total }\end{array}$ & $\begin{array}{c}0.99 \\
189.14 \\
190.13\end{array}$ & $\begin{array}{c}1 \\
201 \\
202\end{array}$ & $\begin{array}{l}0.99 \\
0.94\end{array}$ & 1.05 & .306 & .005 \\
\hline $\begin{array}{l}\text { Intensity of } \\
\text { response to } \\
\text { provocation }\end{array}$ & $\begin{array}{l}\text { Between Groups } \\
\text { Within Groups } \\
\text { Total }\end{array}$ & $\begin{array}{c}2.11 \\
159.95 \\
162.06\end{array}$ & $\begin{array}{c}1 \\
213 \\
214\end{array}$ & $\begin{array}{l}2.11 \\
0.75\end{array}$ & 2.81 & .095 & .013 \\
\hline
\end{tabular}

Note: $\eta^{2}=$ partial eta squared (used for effect size); ${ }^{*} \mathrm{p}<.05 * * \mathrm{p}<.001$ 
Table C11

Two-Way ANOVA of Total Competitive Aggressiveness and Anger Scale Score by Gender and Type of Sport

\begin{tabular}{|c|c|c|c|c|c|c|}
\hline Source & $\begin{array}{l}\text { Sum of } \\
\text { Squares }\end{array}$ & $\mathrm{df}$ & Mean Square & $\mathrm{F}$ & Sig. & $\eta^{2}$ \\
\hline Gender & 973.78 & 1 & 973.78 & 3.79 & .053 & .016 \\
\hline Type of Sport & 2325.05 & 1 & 115.71 & 9.06 & $.003 *$ & .037 \\
\hline Gender x Type of Sport & 115.71 & 1 & 115.71 & .451 & .503 & .002 \\
\hline Within (Error) & 60318.19 & 235 & 256.67 & & & \\
\hline Total & 687335.11 & 239 & & & & \\
\hline
\end{tabular}


Table C12

Two-Way ANOVA of Total Sport Provocation Questionnaire Score by Gender and Type of Sport

\begin{tabular}{|c|c|c|c|c|c|c|}
\hline Source & $\begin{array}{l}\text { Sum of } \\
\text { Squares }\end{array}$ & df & Mean Square & $\mathrm{F}$ & Sig. & $\eta^{2}$ \\
\hline Gender & .011 & 1 & .011 & .030 & .862 & .000 \\
\hline Type of Sport & 1.41 & 1 & 1.41 & 3.77 & .054 & .017 \\
\hline $\begin{array}{l}\text { Gender x Type of } \\
\text { Sport }\end{array}$ & .751 & 1 & .751 & 2.01 & .158 & .009 \\
\hline Within (Error) & 80.35 & 215 & .374 & & & \\
\hline Total & 1256.56 & 219 & & & & \\
\hline
\end{tabular}




\section{Table D1}

One-Way ANOVA of Total Competitive Aggressiveness and Anger Scale Score by NCAA Division Level

\begin{tabular}{|c|c|c|c|c|c|c|}
\hline Source & $\begin{array}{l}\text { Sum of } \\
\text { Squares }\end{array}$ & $\mathrm{df}$ & Mean Square & $\mathrm{F}$ & Sig. & $\eta^{2}$ \\
\hline Between Groups & 2798.83 & 2 & 1399.42 & 4.96 & $.008 *$ & .040 \\
\hline Within Groups & 66577.07 & 236 & 282.11 & & & \\
\hline Total & 69375.91 & 238 & & & & \\
\hline
\end{tabular}


Table D2

Multiple Comparisons of One-Way ANOVA of Total Competitive Aggressiveness and Anger Scale Score by NCAA Division Level

\begin{tabular}{|c|c|c|c|c|c|c|}
\hline $\begin{array}{c}\text { Division } \\
\text { Level }\end{array}$ & $\begin{array}{c}\text { Division } \\
\text { Level }\end{array}$ & $\begin{array}{c}\text { Mean } \\
\text { Difference }\end{array}$ & $\begin{array}{l}\text { Std. } \\
\text { Error }\end{array}$ & $\begin{array}{l}\text { Lower } \\
\text { Bound }\end{array}$ & $\begin{array}{l}\text { Upper } \\
\text { Bound }\end{array}$ & Sig. \\
\hline \multirow[t]{2}{*}{ Division I } & Division II & 1.61 & 2.93 & -5.30 & 8.52 & .846 \\
\hline & Division III & 7.63 & 2.68 & 1.31 & 13.95 & $.013^{*}$ \\
\hline \multirow[t]{2}{*}{ Division II } & Division I & -1.61 & 2.93 & -8.52 & 5.30 & .846 \\
\hline & Division III & 6.02 & 2.58 & -.07 & 12.11 & .054 \\
\hline \multirow[t]{2}{*}{ Division III } & Division I & -7.63 & 2.68 & -13.95 & -1.31 & $.013^{*}$ \\
\hline & Division II & -6.02 & 2.58 & -12.11 & .07 & .054 \\
\hline
\end{tabular}

Note: $\mathrm{ANOVA}=$ analysis of variance; $* \mathrm{p}<.05 * * \mathrm{p}<.001$ 


\section{Table D3}

One-Way ANOVA of Competitive Aggressiveness and Anger Scale Anger Subscale Score by NCAA Division Level

\begin{tabular}{lcccccc}
\hline \multicolumn{1}{c}{ Source } & $\begin{array}{c}\text { Sum of } \\
\text { Squares }\end{array}$ & df & Mean Square & F & Sig. & $\eta^{2}$ \\
\hline Between Groups & 688.26 & 2 & 344.13 & 5.48 & $.005^{*}$ & .044 \\
Within Groups & 15067.57 & 240 & 62.78 & \\
Total & 15755.83 & 242 & & \\
\hline
\end{tabular}

Note: $\eta^{2}=$ partial eta squared (used for effect size); ${ }^{*} \mathrm{p}<.05 * * \mathrm{p}<.001$ 


\section{Table D4}

Multiple Comparisons Using Tukey's HSD of One-Way ANOVA of Competitive Aggressiveness and Anger Scale Anger Subscale Score by Division Level

\begin{tabular}{|c|c|c|c|c|c|c|}
\hline $\begin{array}{c}\text { Division } \\
\text { Level }\end{array}$ & $\begin{array}{c}\text { Division } \\
\text { Level }\end{array}$ & $\begin{array}{c}\text { Mean } \\
\text { Difference }\end{array}$ & Std. Error & $\begin{array}{l}\text { Lower } \\
\text { Bound }\end{array}$ & $\begin{array}{l}\text { Upper } \\
\text { Bound }\end{array}$ & Sig. \\
\hline \multirow[t]{2}{*}{ Division I } & Division II & 0.67 & 1.37 & -2.55 & 3.89 & .876 \\
\hline & Division III & 3.70 & 1.25 & 0.75 & 6.65 & $.009 *$ \\
\hline \multirow[t]{2}{*}{ Division II } & Division I & -0.67 & 1.37 & -3.89 & 2.55 & .876 \\
\hline & Division III & 3.03 & 1.21 & 0.18 & 5.89 & $.034^{*}$ \\
\hline \multirow[t]{2}{*}{ Division III } & Division I & -3.70 & 1.25 & -6.65 & -0.75 & $.009^{*}$ \\
\hline & Division II & -3.03 & 1.21 & -5.89 & -0.18 & $.034 *$ \\
\hline
\end{tabular}

Note: ANOVA $=$ analysis of variance; $* \mathrm{p}<.05 * * \mathrm{p}<.001$ 
Table D5

One-Way ANOVA of Competitive Aggressiveness and Anger Scale Aggressiveness Subscale Score by NCAA Division Level

\begin{tabular}{|c|c|c|c|c|c|c|}
\hline Source & $\begin{array}{l}\text { Sum of } \\
\text { Squares }\end{array}$ & df & Mean Square & $\mathrm{F}$ & Sig. & $\eta^{2}$ \\
\hline Between Groups & 773.69 & 2 & 386.84 & 3.12 & $.046^{*}$ & .026 \\
\hline Within Groups & 29294.14 & 236 & 124.13 & & & \\
\hline Total & 30067.83 & 238 & & & & \\
\hline
\end{tabular}

Note: $\eta^{2}=$ partial eta squared (used for effect size); ${ }^{*} \mathrm{p}<.05 * * \mathrm{p}<.001$ 
Table D6

Multiple Comparisons using Fisher's LSD of One-Way ANOVA of Competitive Aggressiveness and Anger Scale Aggressiveness Subscale Score by Division Level

\begin{tabular}{c|c|c|c|c|c|c}
\hline Division Level & Division Level & $\begin{array}{c}\text { Mean } \\
\text { Difference }\end{array}$ & Std. Error & $\begin{array}{c}\text { Lower } \\
\text { Bound }\end{array}$ & $\begin{array}{c}\text { Upper } \\
\text { Bound }\end{array}$ & Sig. \\
\hline \multirow{2}{*}{ Division I } & Division II & 1.11 & 1.94 & -2.71 & 4.94 & .567 \\
& Division III & 4.11 & 1.78 & 0.61 & 7.62 & $.022^{*}$ \\
& Division I & -1.11 & 1.94 & -4.94 & 2.71 & .567 \\
& Division III & 3.00 & 1.71 & -0.38 & 6.37 & .081 \\
& & & & & & \\
& & & & & & \\
Division II & Division I & -4.11 & 1.78 & -7.62 & -0.61 & $.022^{*}$ \\
& Division II & -3.00 & 1.71 & -6.37 & 0.38 & .081 \\
\hline
\end{tabular}

Note: $\mathrm{ANOVA}=$ analysis of variance; ${ }^{*} \mathrm{p}<.05 * * \mathrm{p}<.001$ 
Table D7

One-Way ANOVA of Total Sport Provocation Questionnaire Score by NCAA Division Level

\begin{tabular}{lcccccc}
\hline \multicolumn{1}{c}{ Source } & $\begin{array}{c}\text { Sum of } \\
\text { Squares }\end{array}$ & $\mathrm{df}$ & Mean Square & F & Sig. & $\eta^{2}$ \\
\hline Between Groups & 0.44 & 1 & 0.22 & 0.57 & .564 & .005 \\
Within Groups & 83.42 & 216 & 0.39 & & & \\
Total & 83.87 & 218 & & & & \\
\hline
\end{tabular}

Note: $\eta^{2}=$ partial eta squared (used for effect size); ${ }^{*} \mathrm{p}<.05 * * \mathrm{p}<.001$ 
Table D8

One-Way ANOVAs of Sport Provocation Questionnaire Subscales by Division Level

\begin{tabular}{|c|c|c|c|c|c|c|}
\hline $\begin{array}{l}\text { Provocation } \\
\text { Subscale }\end{array}$ & Level & $\begin{array}{l}\text { Sum of } \\
\text { Squares }\end{array}$ & $\mathrm{df}$ & $\begin{array}{l}\text { Mean } \\
\text { Square }\end{array}$ & $\mathrm{F}$ & Sig. \\
\hline $\begin{array}{l}\text { Frequency of } \\
\text { provocation } \\
\text { experienced }\end{array}$ & $\begin{array}{l}\text { Between Groups } \\
\text { Within Groups } \\
\text { Total }\end{array}$ & $\begin{array}{c}0.14 \\
109.16 \\
109.30\end{array}$ & $\begin{array}{c}2 \\
230 \\
232\end{array}$ & $\begin{array}{l}0.07 \\
0.48\end{array}$ & 0.15 & 0.86 \\
\hline $\begin{array}{l}\text { Frequency of } \\
\text { negative } \\
\text { response to } \\
\text { provocation }\end{array}$ & $\begin{array}{l}\text { Between Groups } \\
\text { Within Groups } \\
\text { Total }\end{array}$ & $\begin{array}{c}0.73 \\
122.14 \\
122.86\end{array}$ & $\begin{array}{c}2 \\
223 \\
225\end{array}$ & $\begin{array}{l}0.36 \\
0.55\end{array}$ & 0.66 & .517 \\
\hline $\begin{array}{l}\text { Anger level } \\
\text { from } \\
\text { provocation }\end{array}$ & $\begin{array}{l}\text { Between Groups } \\
\text { Within Groups } \\
\text { Total }\end{array}$ & $\begin{array}{c}0.89 \\
189.24 \\
190.13\end{array}$ & $\begin{array}{c}2 \\
200 \\
202\end{array}$ & $\begin{array}{l}0.44 \\
0.95\end{array}$ & 0.47 & .627 \\
\hline $\begin{array}{l}\text { Intensity of } \\
\text { response to } \\
\text { provocation }\end{array}$ & $\begin{array}{l}\text { Between Groups } \\
\text { Within Groups } \\
\text { Total }\end{array}$ & $\begin{array}{c}0.53 \\
161.54 \\
162.06\end{array}$ & $\begin{array}{c}2 \\
212 \\
214\end{array}$ & $\begin{array}{l}0.26 \\
0.76\end{array}$ & 0.34 & .709 \\
\hline
\end{tabular}

Note: $\mathrm{ANOVA}=$ analysis of variance; ${ }^{*} \mathrm{p}<.05 * * \mathrm{p}<.001$ 


\section{Appendix B: Extended Review of Literature \\ Part 1: Competitive Anger in Sport}

\section{The Nature of Emotion}

In the realm of sports, controlling one's emotions is a necessary skill for effective performance. In fact, Taylor (1996) once suggested intensity level is the most important factor in determining whether athletes will perform their best, regardless of physical or technical preparation. It is therefore understandable that studying emotions and the ability to regulate them has been a principal focus of research in the realm of sports (Hanin, 2000).

All individuals, whether athletes or not, experience emotions. However, defining one is not a simple task. One comprehensive definition that has been utilized in a sport context is from Deci (1980), who suggested emotion is, “... a reaction to a stimulus event (either actual or imagined). It involves change in the viscera and musculature of the person, is experienced subjectively in characteristic ways, is expressed through such means as facial changes and action tendencies, and may mediate and energize subsequent behaviors" (p. 85). One prominent characteristic of emotion in this regard is that it must be a response to a preceding stimulus; otherwise, it is simply a mood that tends to be longer lasting (Jones, 2003). Furthermore, emotions tend to bring about physiological changes such as increases in heart rate or changes in arousal level.

There is no question based on both strong anecdotal and empirical evidence that emotions experienced by athletes have a major influence on performance (Hanin, 2000; Lane, 2007). A number of ideas have been put forth to help explain how emotions affect sport performance, but most researchers agree it occurs by influencing motivation and physical, as well as cognitive performance (Botterill \& Brown, 2002). Other explanations stem from findings of research 
focused on the influence of emotions on performance in sport. For example, research with national-level softball players found that the emotions of both anger and dejection in competition have a significant negative correlate with concentration, suggesting focus becomes too narrow with increased levels of anger (Vast, Young, \& Thomas, 2010). These negative emotions, along with anxiety, were found to have a larger impact on concentration and performance than more positive ones. Interestingly, there was a negative correlation between anger and self-rated performance, but this was not a significant result (Vast, Young, \& Thomas, 2010).

\section{Measuring and Improving Emotion}

Whether or not an athlete were to feel, for example, shame or fear after making a mistake constitutes the subjective nature of emotions. Jones (2003) noted that this is most commonly captured in sport psychology research through the use of self-report measures. While it is intuitive that the most accurate way to measure one's emotion levels is during competition, this can be costly and intrusive. Competition tends to be when emotions run highest for athletes, but it is also when the stakes are highest.

Alternatively, a number of researchers have suggested using retrospective self-report measures with collegiate athletes to report levels of emotions (e.g., anxiety) as a valid technique. Utilizing self-report measures is inexpensive, convenient for both researchers and athletes, and perhaps most importantly, not invasive. Even more promising is that athletes' accuracy in recalling emotions has been labeled as precise whether or not they actually met their performance expectations (Harger \& Raglin, 1994). While certainly not perfect, utilizing retrospective self-report inventories are among the best ways available to assess one's recollection of experienced emotions both before and during competition. One of the more common self-report questionnaires used in sport is the Competitive State Anxiety Inventory 2 
(CSAI-2; Martens, Burton, Vealey, Bump, \& Smith, 1990) which includes scales to measure somatic and cognitive state anxiety, as well as fear of physical harm. Another scale widely used in sports is the Physical Activity Enjoyment Scale (PACES; Kendzierski \& DeCarlo, 1991), which has been featured in a wide range of studies to assess enjoyment and participation in sport. The emotion of anger is also commonly experienced in sport, especially when the competition level is high and pressure is felt. To date, few measures exist to measure anger in an athletic setting.

To help improve one's emotion and therefore increase performance, a number of both cognitive and arousal-based techniques have been outlined prominently in the literature. For example, imagery, cognitive reframing, progressive muscle relaxation, and autogenic training have all been found to helpful in reducing unhelp emotions and improve sport performance (Carter, Forys, \& Oswald, 2008). Over a decade ago, Jones (2003) suggested that, "future applied research should evaluate the effectiveness of the proposed techniques in controlling a range of emotions..." (p. 483). Since then, a range of applied research is available to help individuals in the field of sport psychology understand and manage common emotions in sport such as anxiety, fear, and depression. However, anger has been seemingly overlooked in the literature, with few instruments created to measure the emotion and even fewer available empirical management techniques.

\section{The Emotion of Anger}

Novaco (1975), a frontrunner in anger management techniques, discussed the emotion of anger as an affective stress reaction to provocation involving physiological and cognitive components. More recently, Spielberger and Reheiser (2009) referred to anger as, "an emotional state that consists of feelings that vary in intensity, with associated activation or arousal of the 
autonomic nervous system" (p. 281). A key component of both of these definitions is the lack of appraisal concerning anger being a "good" or "bad" thing, but rather a normal, human emotion. Deffenbacher (2011) has claimed that anger is a natural experience and, "the human nervous system is hard-wired for the experience of anger" (p. 212). Abrams and Hale (2005) summed up this notion by saying, "It is a normal emotion that requires no judgment be made of it. It is neither good nor bad to be angry; it is as normal as being happy" (p. 96). Whether anger becomes problematic is less about the fact that it is present and more about the nature and severity of behavioral outcomes (Kassinove \& Tafrate, 2002).

Somewhat unique to anger, however, is it resulting from some type of provocation, causing a change in one's physiological functioning and mental processes. What are these events that can elicit angry responses from an individual? Deffenbacher (2011) defined three major sources of anger that arises in individuals. These include: 1) specific, identifiable external events (e.g., offensive comments from others or unresponsive technology), 2) a combination of external events and anger-related memories and images (e.g., heightened reaction of a war veteran with PTSD), and 3) internal stimuli (e.g., ruminating about being divorced or thinking about a coworker who embarrassed you).

Based on this early definition, how can an athlete play well and think straight if they are too overcome with anger? It holds true that some athletes are simply unable to control anger, which inevitably leads to debilitative performance. The key appears to understand how to be able to successfully control one's anger and use it to facilitate performance in a positive manner. Furthermore, it seems that while anger is an emotion expressed by almost all athletes, differences may exist among gender, competition level, and sport type (Maxwell, Visek, \& Moores, 2009). The individual nature of anger expression was echoed years ago by Novaco (1995), who stated, 
“anger may be viewed as a customary feature of a personality style that takes a combative orientation to perceived threats and challenges" (p. 325). Some researchers investigating perfectionism in athletes reported that higher scores of perfectionism correlated with higher trait anger (Vallance, Dunn, \& Dunn, 2006). Athletes in this study also reported higher anger following personal mistakes in situations deemed more critical. Evidently, athletes that have more of a perfectionist orientation are at a greater risk for experiencing anger, especially when the pressure is on.

Other researchers have published findings that further this theme, but also pointed to some similarities in how athletes cope with anger. For example, a study conducted by Bolgar, Janelle, and Giacobbi (2008) suggested that adolescent tennis players who scored higher in trait anger were more likely to use problem and emotion-focused coping techniques than athletes with low trait anger. Using a scale to rate adolescent anger, athletes that scored higher on the reactive anger scale experienced more eruptions of anger during practice and competition than those who scored lower on that subscale. Interestingly, no differences were found between male and female tennis players, suggesting male and females cope with anger in a similar fashion (Bolgar, Janelle, \& Giacobbi, 2008).

\section{Assessing Anger}

As mentioned above, a prominent issue that has been identified in the study of anger is the lack of a sport specific measure of anger during competition (Maxwell \& Moores, 2007). This is despite long-established scales used in sport to measure general mood such as the Profile of Mood States. The POMS can be used to assess a state measure of anger, but it is not a comprehensive instrument to assess or quantify the anger that can arise during sporting competition. 
Outside of sport, the State Trait Anger Expression Inventory (STAXI; Spielberger, 1988) was constructed to help assess the experience, expression, and control of anger in individuals. The most recent version, the STAXI-2 (Spielberger, 1999) is a revised version of the original STAXI, which was a combination of two original scales, one measuring state and trait anger and the other measuring expression and control of anger. The STAXI-2 consists of 57 items across six primary subscales- trait anger, state anger, anger expression-out, anger expression-in, anger control-out, and anger-control in. The trait anger scale is divided into two types: anger/T (temperament) to assess disposition to experience anger without provocation, and anger/R (reaction) to assess the occurrence of experiencing anger while being treated badly. There is also an overall Anger Expression Index, which is intended to serve as an overall index of anger expression. This score is obtained by adding the anger control subscales and subtracting the anger control subscales.

Spielberger (1999) presented norms for high school and college students, psychiatric and medical patients, working adults, and others in the test manual. Norms for the original STAXI are also available in the manual for general medical and surgical patients, prison inmates, and military recruits. As stipulated by Spielberger and Reheiser (2009), persons who have high anger scores (i.e., score above the $75^{\text {th }}$ percentile) are more likely to be debilitated by the angry feelings. Furthermore, individuals who have high anger-in or anger-out subscale scores may have issues in relationships and acquire psychology and/or medical disorders. Overall, the STAXI-2 has been utilized extensively in studies assessing anger expression, experience, and control, and it seems to be one of the best, psychometrically validated instruments available for these purposes. Unfortunately, published norms for the STAXI-2 or the original form are not yet available for athletes. 
The STAXI is considered a valid and reliable assessment of anger level, expression, and control. However, its use with competitive athletes is limited because it has not been normed in an athletic population and is not sport specific in structure. In fact, it appears the STAXI has been used with athletic populations only twice. The first was a modified sport-specific version in a study looking at anger in Italian combat sports (Robazza, Bertolo, \& Bortoli, 2006) and another time in a study investigating anger in Spanish karate athletes (Ruiz \& Hanin, 2011). Therefore, in 2007, Maxwell and Moores sought to establish a valid and reliable instrument to measure anger and aggressiveness in the sporting context. They established the Competitive Anger and Aggressiveness Scale (CAAS; Maxwell \& Moores, 2007). This 12-item instrument assesses anger (e.g., frustration from missed calls from referees) and aggressiveness, or the tolerance of aggression and inclination to aggress.

Despite being one of the few scales to assess anger and aggressiveness, the CAAS has several limitations (i.e., severity ratings across items, no social desirability check, non-elite sample) and has come under criticism for a number of issues including the foundational definition of aggression and the nature of the items (Kerr, 2008). Visek, Maxwell, Watson, \& Hurst (2011) later investigated the factor structure of the CAAS and found it to be replicable with Americans and English-speaking Chinese athletes. With only slight modifications, they supported the use of the CAAS across different cultures as a satisfactory tool to assess anger and aggressiveness. Little research has utilized the CAAS since its inception, but it is a promising instrument to use in the exploration of anger and aggressiveness in athletes.

\section{Anger in Athletes vs. Non-Athletes}

It is unclear whether or not athletes have more anger than non-athletes, as this is understandably difficult to accurately assess. The media seems to report mainly negative press 
regarding athletes' behavior, in particular when anger is uncontrolled. For example, athletes engaging in locker room fights, domestic abuse, unnecessary roughness, and late hits all get plenty of coverage in the press due to the high profile nature of the transgressors. But do athletes really have more anger than non-athletes, and if so, why is this the case? Unfortunately, the little research on this subject is ambiguous at best, and these important questions currently stand unanswered.

In one of the first studies that attempted to explore this topic, Newby and Simpson (1991) reported notable findings in their research on non-scholarship collegiate athletes. Using the Profile of Mood States (POMS), the researchers found that a sample of 120 athletes did not follow the typical "iceberg profile" for elite athletes. This controversial profile by Morgan (1980) suggested that one could predict elite athletes because of their regularity to score below average on tension, anger, fatigue, depression, and confusion, and higher on vigor. In contrast to the iceberg profile, Newby \& Simpson (1991) found that the athletes scored higher than the norm for college students on tension, anger, depression, and fatigue. Furthermore, varsity athletes had higher levels of anger than junior varsity players, pointing to the possibility of anger as necessary for athletic success. The higher overall scores in anger and tension were attributed to being athletes. This study was important because it shed light on the possibility that athletes have higher levels of anger than non-athletes, and this difference may widen as competition level increases (Newby \& Simpson, 1991).

Three years later, the same authors compared both scholarship and non-scholarship athletes from three different sized-schools. Using the POMS, they found that athletes at all three schools scored significantly higher on the anger subscale than the general population of college students (Simpson \& Newby, 1994). Interestingly, when looking at scholarship athletes 
compared to non-scholarship athletes, the latter group scored higher on anger than the former. It is unclear why this is the case, with the authors only offering the possibility that scholarship athletes play more and are able to release their anger more often on the field (Simpson \& Newby, 1994).

However, other researchers have suggested that athletes do not necessarily have higher levels of anger than non-athletes (Greene, Sears Jr., \& Clark, 1993). In fact, intramural and varsity athletes were even found to have similar levels of trait anger as well. Other research has suggested no significant differences exist in how athletes and non-athletes respond aggressively. Looking at the startle response to aversive and non-aversive stimuli, Collins, Hale, and Loomis (1995) found no significant difference between athletes and non-athletes. This also held true when looking at aggressive tendencies in the response to hypothetical vignettes involving frustration and the possibility of an aggressive response. The researchers suggested, "these results indicate that the extreme suggestions of psychopathic tendency in contact sports participants should be dismissed as pure speculation" (p. 11). As suggested previously, the media almost certainly plays a role in society's view of the "violent athlete", but this notion has not been a primary focus of research. At this time no empirical evidence is available to truly establish a link between being an athlete and having more anger.

Within athletes, there seems to be some evidence of differences among gender and competition level when it comes to anger levels. For example, Bebetsos, Zouboulias, Antoniou, and Kourtesis (2013) recently found that among elite Greek water polo athletes, women scored significantly lower than men in both anger and aggression as measured by the CAAS. The idea of variations in the amount of anger experienced by athletes of different gender and competition level has been suggested before (e.g., Maxwell, Visek, \& Moores, 2009), but this is still an area 
of anger research still ripe for investigation. Ultimately, like much of the research focused on anger and aggression in sport, the question of whether athletes are more aggressive than nonathletes in unclear. As Kimble, Russo, Bergman, \& Galindo (2010) noted in one of the only meta-analyses available on aggression and violent behavior in sport, "until the methodological approach to this area of aggression research improves, answering questions such as whether athletes are, indeed, an inherently more violent population will remain a difficult endeavor" (p. 460).

\section{Effects of Anger on Performance}

In sport, negative emotions such as anger have historically been regarded as being highly detrimental to performance, causing some researchers to propose interventions to help decrease these symptoms (e.g., Gould, Greenleaf, \& Krane, 2002; Williams \& Harris, 2001). However, not all research on anger has produced findings that suggest anger is disadvantageous for all athletes (e.g., Botterill \& Patrick, 2003). In fact, the studies that have explored whether anger helps or hurts performance in sport seem to present mixed results. In research utilizing soccer players, track and field athletes, and figure skaters, results indicated that anger as an emotion, and potentially aggression as the behavioral, can be either beneficial or detrimental to performance depending on how it is interpreted and utilized by the athlete (Hanin and Syrja, 1995; Robazza, Bortoli, \& Nougier, 1998). Research on low and high-level rugby players confirmed this finding and indicated that these athletes typically report a moderate level of anger symptoms, and due to the overtly physical nature of the sport, tended to interpret the anger as facilitative to performance on the field (Robazza \& Bortoli, 2007).

Another recent study explored the impact of anger and other anger-related symptoms on performance in twenty national team-level male Spanish karate athletes (Ruiz \& Hanin, 2011). 
These athletes were asked to assess anger during situations prior to, during, and after their best and worst performances. The researchers found various levels of anger intensity related to athletes' best and worst performances. In the best ones, anger was perceived to be helpful in increasing energy reserves. In poor performances, anger was perceived to be ineffectively using important resources. Based on this study, it seems anger can be both harmful and helpful to performance depending on the ability of the athlete to interpret and successfully control the anger.

In research with male Italian contact sport athletes, Robazza, Bertolo, \& Bortoli (2006) found using the STAXI that team sport athletes (i.e., rugby players) were more likely to interpret their angry as helpful to performance, a possible side product of the social environment that places a heavy value on being angry and displaying aggression. When comparing the highly skilled athletes with novice ones, the highly skilled athletes more often reported the beneficial aspects of anger on performance, even among individual sport athletes. This suggested that regardless of sport type, elite athletes have better skills to manage anger and use it in a positive manner (Robazza et al., 2006). This finding was substantiated by McCarthy, Allen, and Jones (2012), who found that anger had a greater negative association with the cognitive thought processes of younger athletes compared to older ones. The authors suggested that older athletes more likely learn through experience to better control emotions and concentration during tough situations, which younger, more inexperienced athletes cannot do as well. The authors gave credence to the notion of providing more opportunities to manage anger for younger athletes by claiming, "interventions targeted towards younger athletes should also look to identify techniques that help regulate the occurrence of anger..." (p. 513). 
Ruiz and Hanin (2004) have helped to understand how skilled athletes manage to do this. They investigated differences in how high-level karate athletes described feeling states before, during, and after best and worst performances. They reported that athletes tended to use more positive descriptors of anger in best performances as opposed to negatively toned descriptions during worst performances. When facilitative, anger produced confidence and increased motivation; alternatively, when debilitative, anger was related to tension, a dearth of confidence, and an inability to feel able to handle the situation at hand (Ruiz \& Hanin, 2004).

Evidently, being angry in sport is not necessarily the same as being out of control, and also not necessarily harmful to performance. When uncontrolled, anger has certainly been shown to lead to a number of negative performance outcomes such misuse of energy, a decrease in achievement, and the potential for violent behavior (Robazza et al., 2006). However, whether this occurs depends largely on the ability of the athlete to interpret and successfully control and harness the anger. Robazza and colleagues (2006) suggested that a moderate amount of anger is seen as useful, but only to athletes that feel able to control the emotion. It seems it may be detrimental to try and reduce anger for all athletes, whereas it may be more beneficial to help them utilize it effectively to improve performance.

More recently, research studied how specific emotions such as happiness, hope, and anger influenced performance on basic cognitive and physical tasks (Woodman et al., 2009). The emotion of anger was viewed as a negative emotion and measured using State-Trait Anger Scale (STAS; Spielberger, Jacobs, Russell, \& Crane, 1983). A cognitive task involved grammatical reasoning, while the physical one involved a muscular peak force task. The three different emotions were induced through the use of mental imagery on 15 physically active male and female university students in the UK. Results showed that performance on the physical task was 
significantly greater in the anger condition compared to both happiness and emotion-neutral. The findings of this study only add more credibility to the idea that the emotion of anger is not always debilitative and may actually improve performance, especially on physical tasks (Woodman et al., 2009). The authors of this study suggested that the facilitative effect of anger is more likely when the skill involved is similar to anger's action tendency, an idea originally postulated by Lazarus (2000). In other words, if the physical skill involves a movement similar to lashing out, anger can improve performance on a skill analogous to lashing out (e.g., throwing a ball).

Similar research conducted by Rathschlag and Memmert (2013) investigated how selfinduced emotions, including anger, would impact performance on three physical tasks in university athletes. When compared to a neutral state, individuals who evoked anger or happy emotions performed significantly better on the physical tasks. These results were in agreement with results reported by Woodman et al. (2009), suggesting that feeling angry can be facilitative to performance on physical tasks, especially if the task is similar to anger's action tendency. Furthermore, Rathschlag and Memmert (2013) put forth the possibility that tasks involving more coordination could be less likely to be enhanced by a negative emotion like anger, as opposed to a positive emotion like happiness. In fact, the researchers commented that, "where positive effects of emotions on performance are observed, performance may be attenuated when there are high coordinative demands" (p. 11). This suggests that for physical tasks involving a high degree of coordination, anger is much less likely to be facilitative to performance.

In their book on managing anger, Abrams and Hale (2005) have commented on the inconclusiveness of whether or not anger helps or hurts performances in athletes. They noted, "we need to develop sport-specific state and trait measures of anger and embark on qualitative 
research to better understand how anger benefits or detracts from performance" (p. 112). This may be the best avenue to better understand the emotion of anger from the athletes' points of view, and gain a clearer picture of how anger can be both facilitative and debilitative for athletes of different backgrounds and competition level.

\section{Part 2: Aggressive Behavior in Sport}

\section{Anger As A Precursor to Aggressive Behavior}

As noted previously, anger itself is simply an emotion, not a behavior. Aggression, as opposed to anger, is a behavior that can be viewed. Anger and aggression are therefore not equivalent in nature. However, while anger does not have to be followed by aggressive behavior, it has been known for some time that aggression often follows anger, especially anger which is uncontrolled (Berkowitz, 1993; Feindler \& Ecton, 1994). What determines the type of response that results from anger? Feindler and Guttman (1993), early pioneers of cognitive behavioral anger management treatment, suggested it was cognitive deficiencies or distortions that cause hostility (or what might be characterized as overly-aggressive behavior). In other words, how an individual interprets aggressive cues determines whether anger becomes aggression. It has long been suggested that these same cognitive processes can also help decrease hostility by restraining aggressive acts (Berkowitz, 1983).

Spielberger (1988), a pioneer of anger research, put forth his state-trait anger theory nearly two decades ago that suggested individuals high in trait anger were more likely to experience anger and be triggered by anger-provoking events. These individuals would also be more likely to act aggressively when angry and initiate negative conflict for extended periods of time. This theory formed the basis for the STAXI instrument, considered one of the gold standard measurements of anger and anger expression (Spielberger, 1988). Unfortunately, the 
STAXI has rarely been used empirically in sport research, and the STAXI has not been normed in athletes. Future research could benefit from investigating if high trait anger athletes are more likely to aggress than low-trait anger athletes.

Other research has suggested that anger is commonly expressed through aggressive behavior in sports, and simply ruminating about past experiences that provoked anger can increase the propensity of aggression (Maxwell, 2004). This aggressive behavior was higher in UK male athletes than females, and higher in team sport than individual athletes. A follow-up to this study comparing British and Chinese athletes found similar results, suggesting being provoked and having thoughts of revenge were significantly related to self-reported aggression (Maxwell, Moores, \& Chow, 2007). A cultural difference was suggested, with Chinese athletes more often inhibiting their aggressive responses, even when the chance to react aggressively was prevalent. These are important findings because they suggest that the emotion of anger, even if not present at the moment, can potentially increased one's aggressive behavior (Maxwell, 2004).

While it is unclear the precise link between anger and aggression, it is evident that aggression is often a byproduct of uncontrolled anger. However, when and how often this occurs seems to be based more on the individual. Years ago in a position statement on aggression and violence in sport, Tenenbaum, Stewart, Singer, \& Duda (1997) put forth nine recommendations to help curtail incidents of violence in sport. The final recommendation noted, "athletes should take part in programs aimed at helping them reduce behavioral tendencies toward aggression" (p.

5). Unfortunately, only a few studies have actually attempted to satisfy this recommendation in an applied setting (e.g., Brunelle et al., 1999).

\section{Defining Aggression}

To better understand the relationship between anger and aggression, it is necessary to 
define and explore exactly what it means to be "aggressive" in sports, and how it is different than assertive behavior. It is also important to establish when these behaviors cross the line into violence, and what constitutes behavior that is acceptable or justified within the realm of sports. Unfortunately, a simple glance into the aggression research in the field of sport and exercise psychology sheds light on one of the primary issues: the inability to come to a consensus on an operational definition (e.g., Abrams, 2010; Kirker, Tenenbaum, \& Matteson, 2000; Stephens, 1998). Silva (1978) was one of the first to characterize forms of heightened physical behavior seen as goal-oriented and within the rules of sport as assertive. This type of behavior "requires unusual energy and effort, which in most other social settings would appear to be aggressive behavior. These assertive behaviors must be exhibited with no intent to harm or injure another person" (Husman \& Silva, 1984, p. 249).

Connelly (1998) noted that assertive behavior in sport is not only acceptable but also widely appreciated and sought after by coaches. To distinguish between assertive and aggressive actions requires a subjective view and a more complex understanding of an athlete's intent (and not force or result of one's actions). The author goes on to suggest that a nonassertive athleteone who lacks vigor and conviction and lets opponents dictate play- can be just as problematic as the aggressive one. The assertive athlete is a more effective leader, more strategic, more satisfied with one's performance, and plays more confidently within the rules of the game (Connelly, 1998). Issues with the use of the word "assertive" have been brought up by some authors, who suggest it is inappropriate to use in sports. For example, Abrams and Hale (2005) suggest to be assertive is to insist on one's rights, and in sport, there is no right to outright win; instead, you have to compete to gain victory. The example provided by the authors was that you wouldn't say a running back "assertively" went through three defenders on his way to the end zone. Therefore, 
"aggression" is a better way to characterize this type of behaviors often used in sport to ensure success.

The term aggression is more commonly associated with negative, antagonistic behavior, but must also be looked at in terms of the true motive behind such behavior. Independent of the sport setting, many scholars have attempted to define the word aggression. For example,

Berkowitz (1993) suggested that for a behavior to be considered aggressive it had to both be an attempt directed at another human with the intent of harming them and include the expectation that this attempt would be effective. Baron and Richardson (1994) similarly defined aggression as, "any form of behavior directed toward the goal of harming or injuring another living being who is motivated to avoid such treatment" (p. 7). However, the authors of this second definition expanded it to include living beings, as well as the notion that the other living being would not want to be a recipient of the aggressive behavior.

In accordance with these two definitions and several other similar ones, the following four conditions of aggression were more recently delineated by Gill and Williams (2008): 1) it is a behavior (not an attitude or emotion); 2) it involves intent (accidental injury is not considered aggressive); 3) it involves harm or injury (can be physical or psychological); and 4) it is directed towards another living organism (damage to equipment or a building is technically not considered aggressive). Therefore, based on this definition aggression can clearly be seen, felt, or heard and is not simply an attitude or feeling one portrays.

With this comprehensive definition of aggression, it would seem easy to identify any aggressive acts witnessed on the playing field. When it comes to athletics, however, it is near impossible to come to a consensus over whether an aggressive sport act is "good" or "bad" because it is largely in the eye of the beholder. For example, is it good or bad aggression if a 
lacrosse player lowers his shoulder while going for a ground ball, slamming into his opponent? Does this change if the opposing player breaks his collarbone, effectively ending his season? To help separate this ambiguity, Gill (2000) suggested that when it comes to aggressive acts, it is best to avoid looking at it as a black and white (i.e., good or bad) phenomenon because of the various emotions and instinctive associations we have for such behavior. Furthermore, viewing aggression as an objective behavior to be assessed and understood is both simpler and more productive (Gill \& Williams, 2008).

\section{Hostile vs. Instrumental Aggression}

With a comprehensive definition of aggression in hand, it is easier to differentiate between a behavior based on whether it is purely aggressive or nonaggressive. For example, a basketball player kicking a trash can near the locker room after being ejected cannot be considered aggressive, but a soccer forward kicking a defender in the shins away from the ball is certainly aggressive. This works well until we consider the case of an athlete who must inflict injury to an opponent to score points or win a game, but is not necessarily attempting to injury the opponent. These actions are not harm-oriented by nature but are required for success within the context of the sport.

To help with the distinction between these scenarios, Buss (1961) was the first to propose two types of aggression. The first was labeled hostile aggression, in which the main goal was to hurt another person either physically or psychological. This first type of aggressive behavior encompasses anger and is thought of commonly as violence (Cox, 2007). The second was termed instrumental aggression, in which the primary goal was nonaggressive (such as scoring extra points), but injury or harm must be inflicted to achieve this goal (Husman \& Silva, 1984).

With these distinctions made, it is clear that hostile aggression should not only be 
avoided but also reprimanded within a sport context due to the high possibility of injury. Actions with the sole person to hurt another individual have no place in the realm of sports (and beyond). Instrumental aggression, on the other hand, can still cause injury but is more of a necessity in certain athletic settings. Injury caused by this type of behavior is unfortunate but a natural part of participation in sports. Research in the physical sports of ice hockey and basketball has suggested that aggressive behavior in these sports is instrumental approximately two-thirds of the time (Kirker et al., 2000). These findings were produced by filming and subsequently analyzing aggressive behaviors in two full games of each sport.

Other research investigating perceptions of aggression in youth hockey leagues found a younger level of play was more likely to approve of instrumental aggression (Loughead \& Leith, 2001). Youth players' views of aggression were not related to coaches' views among three different levels of play. Interestingly, while players viewed instrumental aggression as more acceptable, observation of actual behavior proved otherwise, with more hostile-type penalties occurring (Loughead \& Leith, 2001). It seems from this study that even when athletes believe certain actions in the rink are more acceptable than others, this is not always displayed once the puck drops and play begins.

It should be noted that not all researchers agree on using the traditional instrumental vs. hostile aggression dichotomy. In particular, Kerr $(1999 ; 2002 ; 2005)$ has suggested that the main distinction lies in whether displayed aggression is outside of the rules of sport (unsanctioned) or not (sanctioned). Kerr argues that trying to remove aggression from sport just based on the harmful and potentially problematic aspects is unnecessary, due to some sports like rugby or American football requiring aggressive behavior for enjoyment, survival, and success. 
Taking it one step further (and based on Apter's Reversal Theory) Kerr (2005) has proposed four types of aggression: "play", "power", "anger", and "thrill” that relate to one's motivation to aggress. The "play" type is accepted within the rules of sport and not seen as problematic. However, the "power", “anger", and "thrill” types are unsanctioned and unwarranted from a sporting perspective. Kerr remarks that unsanctioned aggression is not only detrimental to individual athletes but also the team. This type of aggressive behavior is usually based on provocation or revenge, and can be pre-planned. It is important to note that within this framework, aggression does not always have to occur with anger. This is indicated by the possibility of the thrill of aggressing on an opponent generating feelings of pleasure rather than produced by strong feelings of anger (Kerr \& Grange, 2015).

\section{Violent Behavior in Sport}

It is clear that the sole intent to injure or harm is the profound difference between sanctioned (or similarly, instrumental) aggression and unsanctioned (or similarly, hostile) behavior. Then there is the need to account for violent behavior. What exactly is violence and how is it different from hostile aggression? Terry and Jackson (1985) provided a useful sportsspecific definition of violence in their paper assessing factors fueling sport violence. In this paper, the authors stated, "violence is defined as harm-inducing behavior bearing no direct relationship to the competitive goals of sport, and relates, therefore, to incidents of uncontrolled aggression outside the rules of sport, rather than highly competitive behavior within the rule boundaries" (p. 27). From this definition it can be assumed that violence has the sole intent of injury to another individual and disregards any rules of the sport. Kerr $(2005 ; 2015)$ has suggested violence is simply the most extreme form of unsanctioned aggression. 
More recently, Abrams (2010) formulated a model of sport violence in an attempt to differentiate violence from merely another form of hostile aggression. In this model, violence can be broken down into incidental or hostile violence. Incidental violence is more similar to instrumental aggression in that the overall goal is sports-related, not harm-related. Abrams (2010) suggested that this type of behavior, while sometimes resulting in injury, is more acceptable in sports (e.g., board-checking in hockey). Hostile violence, on the other hand, has the end goal to hurt another person. This type of violence is usually penalized harshly in sport.

A key component of the model of sport violence is the division of hostile violence into spontaneous and planned violence. Spontaneous hostile violence is usually as a result of provocation, an extreme response of anger that occurs when a player is frustrated from being goaded one too many times. Abrams (2010) noted that spontaneous violence is, "directly related to anger" and "anger management programs specifically target reducing this type of behavior" (p. 6). While this type of violence is unacceptable, it can at least be understood as someone "losing their cool" after being deliberately provoked. The final type of hostile violence, planned, is the worst type. It represents intentional and violent behavior to hurt another player. Calling it “complete system failure" (p. 6), Abrams (2010) noted that this type of behavior is not necessarily due to anger, and athletes or coaches who display planned violence should be legally prosecuted and immediately removed from the playing field.

\section{Exploring Theories of Aggression}

Certainly the experience of feeling frustration and anger can lead to aggressive behavior. However, it is clear that simply feeling angry does not automatically cause one to lash out aggressively. In the many years since research began on the phenomenon of aggression, a number of pertinent theories have been put forth to help understand the potential causes of 
aggression. Other research has been conducted in an attempt to help predict or modify aggressive behavior. It should be noted that most theories do not directly discuss the emotion of anger being an antecedent to aggression; however, as discussed previously it is assumed that a considerable degree of aggressive acts are the result of frustration that leads to poorly managed anger.

The majority of major aggression theories has not necessarily been formulated from sport research but have been adapted in the sport and exercise psychology literature and utilized to help explain aggressive acts in the athletic setting. Many studies have investigated aggression and violence through the lens of the following theories which will be discussed below: instinct theory, social learning theory, theory of moral reasoning and aggression, frustration-aggression (or drive) theory, revised frustration-aggression theory, and the general aggression model. Relevant research in support of these theories will also be explored.

Instinct theory. The instinct theory of aggression stems from the work of famous Austrian psychologists Sigmund Freud and Konrad Lorenz. Freud (as cited in Cox, 2007) proposed that aggression was an innate instinct that all humans have and builds up until it must be expressed. The way this can be achieved is either through direct release or from release through a socially acceptable means such as sport (this is known as "catharsis"). In regards to this phenomenon, Sloan (1979) wrote, "Catharsis or reduction of aggression level will occur either by participating in an aggressive act or vicariously through watching acts of aggression by others. Thus, they [pent up emotions] must be relieved periodically or erupt, producing catharsis in either case" (p. 23).

An early, foundational theory, Stephens (1998) suggested that instinct theory has had mixed support throughout the years, but recent twin research conducted at the University of Southern California may show some truth to the idea that, "aggressive tendencies may have a 
strong genetic component" (p. 278). Bushman (2002) investigated angered individuals who hit a punching bag and then either used rumination (thought bout the person who angered them) or distraction (thought about getting fit). He found that rumination increased anger and aggression over distraction or doing neither. In fact, venting one's anger (i.e., catharsis) was less effective than doing nothing, which disagreed strongly with the tenants of instinct theory.

Frustration-aggression theory. The frustration-aggression theory, sometimes referred to as the drive theory, was originally postulated by a group of Yale University psychologists who suggested that aggression was a result of goal obstruction or failure (Dollard, Doob, Miller, Mowrer, \& Sears, 1939). In other words, if a goal-directed behavior is obstructed, frustration occurs which eventually leads to acting out aggressively. An example of this could be provoking behavior by an opponent that could eventually lead to frustration. Early research on factors leading to aggression found that hot temperatures could lead to increased hostile affect and cognitions, which could lead to aggressive behavior (Anderson, Deuser, \& DeNeve, 1995). This finding has led to research suggesting that even words associated with hot temperatures can increase aggressive cognitions in male and female college students (DeWall \& Bushman, 2009). Maxwell (2004), found in research on male and female collegiate athletes that being provoked and ruminating on past experiences that led to anger were positively correlated with the predisposition to subsequently aggress. For example, thinking about a past experience that led to frustration could foster thoughts of revenge and lead to ensuing aggressive acts. Maxwell (2004) also reported that female athletes and individual sport athletes self-reported lower levels of aggression than male or team-sport athletes. It should be pointed out that one major limitation of this study was that aggression was not differentiated between hostile and instrumental types. 
While this theory seemed intuitive and some circumstantial evidence could point to frustration leading to aggression, it did not explain the situations in which frustration did not lead to aggressive acts. For example, research in men's professional hockey found after analyzing game videos that unsuccessful actions such as losing possession were not found more often to be followed by aggressive behavior (Sheldon \& Aimar, 2001). This would suggest that frustration from poor performance or provocation does not necessarily cause aggressive behavior. Even taking into account this aggression being released cathartically in other ways, Gill and Williams (2008) found minimal evidence that frustrated participants in contact sports release their frustration through the socially acceptable means of sport participation. Additionally, research pointed to watching aggressive behavior (e.g., in hockey and wrestling) as contributing to increased spectator hostility, which would negate the notion of catharsis through observation/participation in aggressive sport (Arms, Russell, \& Sandilands, 1979). The frustration-aggression theory was influential in considering frustration as a source of aggression, but by itself was not sufficient to explain aggressive acts. Berkowitz $(1965 ; 1993)$ later reformulated the original frustration-aggression theory to include the importance of learned behavior.

Social learning theory. Based on the influential work of Albert Bandura, social learning theory explains aggression as behavior that is primarily learned through observation. Bandura (1973) suggested that aggressive behavior that is reinforced and modeled in one's environment is likely to be repeated if not penalized. Bandura's theory was generated in part from his famous research with children who committed violent acts towards blow-up dolls more often if they had previously seen adults carry out the acts. This type of modeling behavior was even stronger if the children were positively reinforced for their behavior. 
In the realm of sports, a multitude of research has supported the social learning theory as a way to understand aggression. Early research by Silva (1983) suggested that athletes might learn aggressive behavior though in-sport socialization by important groups such as coaches or teammates. For example, his research found that males in collision, contact, and non-contact sports were more likely to accept and approve of illegal, aggressive sporting behavior than females. This trend continued as the level of physicality, years in sport, and level of sport increased.

In the sport of ice hockey, Sheldon and Aimar (2001) found that many illegal aggressive behaviors, such as crosschecking, are not penalized. This led to athletes being reinforced by athletic success for these acts. Other research found that aggressive acts were largely predicted by participants' perceptions of teammates' behavior in those situations (Stephens, 2001; Tucker \& Parks, 2001), along with readiness to injure another athlete based on a coach's request (Stephens, 2001). This latter research on girl's basketball players suggested that behavior modeled by a team was likely to be reinforced by individual athletes.

More recent research has continued to support social learning theory, with one study supporting the notion that in professional hockey, aggressive behaviors are learned and not a result of frustration on the ice. In this study, Gee and Leith (2007) used existing penalty records to show that North American-born players were more likely to commit aggressive acts than European-born players, a byproduct of early socialization and modeling. Furthermore, the researchers found that as European players spent more time in the league, they became equally as aggressive as North American players, compared with the amount of aggressive behavior displayed as rookies (Gee \& Leith, 2007). Social learning as a way to understand the cause of 
aggression is one of the more widely accepted theories of aggression and continues to be an important concept in helping to understand sources of aggression.

Theory of moral reasoning and aggression. Centered around the influential work of famous child development psychologist Jean Piaget, Brenda Bredemeier postulated that a person's inclination to aggress depends largely on his/her stage of moral reasoning. This theory was developed after research found that grade school children's self-reported moral reasoning levels were positively associated with assertive behavior, but negatively related with aggressive behavior (Bredemeier, 1994). In this study, male children scored higher on aggression scales even though no gender differences were found among moral reasoning scale scores. In addition to these findings, earlier research on moral reasoning by Bredemeier, Shields, Weiss, and Cooper (1986) suggested that participation in contact sports (e.g., football or wrestling) for grade-school boys was positively correlated with less mature moral reasoning and therefore a greater likelihood to both physically and non-physically aggress in sport and daily life.

Not all research has agreed with the association between contact sports and moral reasoning. Keeler (2007) reported that sport hostile and instrumental aggression did not differ between sport type and gender for adult club athletes in soccer, volleyball, and rugby. Her findings disagreed with the findings of Bredemeier et al. (1986) and suggested additionally that life aggression and sport hostile/instrumental aggression did not vary among different levels of contact sport (collision, contact, and non-contact). Whether or not participation in contact or collision types of sport is related to decreased moral reasoning is still debatable.

Since seminal studies on the relationship between moral reasoning and aggression, more research has continued to explore this theory. Tucker and Parks (2001) conducted a study with Division 1-A collegiate athletes and found that among athletes in collision and contact sports, the 
in-sport moral atmosphere created by the team and coaches may be favorable in creating the inclination to aggress among athletes. Another study on children and adolescent athletes found that aggressive sport behavior was perceived as being more legitimate as level of competition increased (Conroy, Silva, Newcomer, Walker, \& Johnson, 2001). Older participants also perceived aggressive behavior as legitimate than younger participants. These results were supported in a study by Visek and Watson (2005), where it was found in the sport of ice hockey that as player age and competitive level increased, athletes were more likely to perceive aggressive behavior as appropriate. Older athletes in a higher competition level also held more professionalized attitudes towards sport.

It seems that as competitive level increases in sport, team norms and role expectations may help to create a moral atmosphere that can have a significant influence on whether or not athletes aggress during competition. Unfortunately, this is particularly troubling because more recent research has found comparable results at the youth sport level (Chow, Murray, \& Feltz, 2009). Looking at the self-reported attitudes and behaviors of youth athletes, parents, spectators, and coaches, Shields, Bredemeier, LaVoi, and Power (2005) reported that ethical issues are in abundance in youth sport. While the authors pointed out that results showed most people involved in youth sport believe in good sportsmanship and want to teach it, they also suggested that, "it is clear that the concept of 'good sport' is lacking sufficient behavioral specificity" (p. 57). Clearly, the accepted norms and moral atmosphere established on sport teams at all levels can have a drastic impact whether or not athletes choose to act out aggressively. At the youth level, it is imperative that a positive social atmosphere and appropriate team norms are created and maintained by coaches and parents (Shields et al., 2005).

Revised frustration-aggression theory. Combining the original frustration-aggression 
theory with parts of social learning theory, Berkowitz $(1965 ; 1993)$ proposed the widely held theory that frustration does not always lead to aggression, but does increase the likelihood. This increased likelihood for aggressive behave occurs as a result of increases in anger, arousal, and other emotions (Baron \& Richardson, 1994). For a frustrated person, certain stimuli can generate the capacity for aggression, similar to the red flag for an aggravated bull (Anderson et al., 1995). The revised frustration-aggression theory would suggest that this would only turn to aggression if one also encompasses the social cues that indicate the appropriateness of displaying aggression in a particular situation. As Cox (2007) notes, "The development of aggressive tendencies is complex, but certainly learning from parents, peers, and other aggressors is a paramount factor" (p. 353). While there seems to hold a large degree of anecdotal evidence to endorse this theory, Stephens (1998) suggests that the results of empirical research on the revised frustrationaggression theory are ambiguous at best.

General aggression model. While the previously discussed theories all contributed a key piece of understanding aggression and its causes (i.e., the importance frustration, modeling), more recent research has focused on aggression as more comprehensive and multifaceted. Anderson and Bushman (2002) proposed the general aggression model (GAM) to account for personal and situational factors leading to changes in one's internal state that may ultimately lead to aggressive behavior. Essentially, the GAM proposes that it is a mix of personal factors (e.g., personality or beliefs) and situational factors (e.g., frustrating conditions or opponent provocation) that lead to a change in one's internal state (e.g., mood or arousal level). How the individual interprets this change will determine if and how aggressive or violent behavior is then displayed (Anderson \& Bushman, 2002). 
The strength of the GAM is in the ability to combine various aggression theories related to social, biological, cognitive, and personal development (Anderson \& Bushman, 2002). GAM is fairly new and untested, although it has been researched using laboratory-setting aggression. More recently, the GAM has been suggested to be effective in helping to comprehend other forms of violence such as domestic, intergroup, and suicide (DeWall, Anderson, \& Bushman, 2009). A search of literature on research utilizing the GAM specifically in sport turned up no results. The GAM is considerably harder to test because of its multifaceted nature, but more future research using this modern, inclusive model is certainly warranted.

\section{Measuring Aggression in Sport}

To date, there exists no standard method to assessing aggressive acts in sport. Intuitively, being able to utilize trained observers to identify aggression would be ideal. This would help identify the antecedents or build up, the act itself, and the resulting consequence. However, this is a long, potentially expensive process, especially because aggressive acts are not always frequent in sports (Maxwell \& Moores, 2007). Self-report questionnaires have traditionally been the most common method to assess aggression in sport (see Stephens, 1998 for a review of these instruments). While all of the questionnaires have been developed to assess aggressive behavior, only a few were developed to use in sport, and even these are problematic. As Maxwell \& Moores (2007) noted, the scales most utilized in sport have lacked reliability, consistency with subscale constructs, sport specificity, and a measure of severity. Therefore, they attempted to develop a sport-specific instrument to measure both anger and aggressiveness. The Competitive Anger and Aggressiveness Scale (CAAS) is divided into an Anger and Aggressiveness parts, with 6 items in each subscale. In establishing the scale, the authors found differences in gender 
and type of sport, with males and contact sport athletes reporting a higher tendency to aggress than females and non-contact athletes, respectively.

\section{Antecedents to Aggressive Behavior}

While research has suggested it is plausible that anger does not always produce aggressive behavior, it is clear there is a high likelihood of aggressive behavior when anger is unable to be controlled (Abrams, 2010; Berkowitz, 1993; Feindler \& Ecton, 1994). Spielberger (1988) also suggested that individuals with high trait anger were more likely to be triggered and experience anger more frequently and for longer durations. Consequently, these individuals are more likely to express their anger in aggressive behaviors and other maladaptive ways. In addition, Maxwell (2004) has even claimed that thinking about past experiences that provoked anger can increase the propensity of aggression. A follow-up to this study comparing British and Chinese athletes found similar results, suggesting being provoked and having thoughts of revenge were significantly related to self-reported aggression (Maxwell, Moores, \& Chow, 2007).

Provocation has also been identified as one of the clearest antecedents of aggression in both non-sporting (e.g., Harris, 1993) and sporting (e.g., Huang, Cherek, \& Lane, 1999) environments. In fact, in seminal work on his Frustration-Aggression Hypothesis, Berkowitz (1989) suggested that provocation, along with frustration and aversive stimuli leads to aggression through the generation of negative affect that is interpreted by the individual as anger. Research has suggested that provocation itself is commonly interpreted as an offense and has been consistently linked to an increase in anger (Mohr, Howells, Gerace, Day, \& Wharton, 2007). So what determines whether a behavior is considered provocation and what else is known about its influence on anger and aggressive behavior? 
According to Maxwell, Moores, and Chow (2007), provocation is "any behavior that is judged by the victim as aversive or unpleasant, normally with intent on the part of the perpetrator implicitly assumed, and rousing feelings of anger, frustration, or fear" (p. 11). More recently, Stranger, Kavusannu, McIntyre, and Ring (2016) defined provocation similarly, explaining it "refers to any action judged to be aversive, eliciting negative emotions such as anger" (p. 5). While these two definitions are nearly equivocal, Maxwell and colleagues identified that provocation is usually assumed to involve intent by the perpetrator. This seems a key distinction, as it should not be considered provocation if an athlete frustrates or angers an opponent to the point of him/her lashing out, when the athlete acted entirely without harmful intent or ill will.

Despite being a common antecedent of aggressive sporting behavior, little research has investigated provocation in sport. Zillmann and Bryant (1974) were among the first researchers to explore the effect of provocation on both athletes and non-athletes. He found no significant differences in aggressiveness between non-athletes and athletes when not provoked. When provoked, non-athletes were actually found to be more aggressive than athletes. Interestingly, Zillmann and Bryant reported non-contact athletes were significantly less aggressive than both non-athletes and contact sport athletes. It should be noted that this study was conducted decades ago with questionable methods used to collect data. However, it was one of the first studies to look at provocation as an important predictor of aggressive behavior.

Little published research has focused on provocation in sport in the last three decades. Outside of the sport setting, researchers have suggested that provocation may potentially negate the inhibitory effects that empathy can have on aggression (Phillips \& Giancola, 2007; Stranger et al., 2016). The late John Maxwell was one of the few researchers to investigate provocation in athletics. In 2004, Maxwell reported that provocation has been positively associated with 
aggression in athletes. This mirrored similar findings of research on norm-breaking behaviors in sport, in which Kirker, Tenenbaum, \& Matteson (2000) observed that mild aggressive acts often followed provocation acts in a tit-for-tat manner. In the worst cases, this sometimes resulted in more severely violent aggression.

Maxwell (2004) also claimed athletes from team sports report greater frequency of provocation than athletes who compete in individual sports. A few years later, Maxwell and Moores (2006) suggested that males experience provocation at a greater frequency than females, suggesting that males may perceive more incidences as provoking in sport. Maxwell, Visek, \& Moores (2009) found that athletes who compete in high contact team sports tend to experience higher provocation while playing sport. Findings of this study suggested that provocation is seen as a justification for retaliatory aggression, but not always between the original combatants, at least in team sports. Importantly, it was also found that it is possible that individuals with high trait anger are more likely to perceive others as provocative and endorse aggressive act (Maxwell, Visek, \& Moores, 2009).

\section{Assessing Provocation in Sport}

Ideally, as with aggressive behavior, provocation is most accurately assessed by observation. However, this method is timely and unpredictable, in addition to somewhat subjective. An act perceived as provocative to one athlete may not necessarily be perceived the same way by others. Furthermore, sometimes provocation is verbal by nature, which can be difficult to assess by outside observers. It would seem that a self-report assessment of provocation is needed, focused on a sport context.

Back in 2006, Maxwell \& Moores tried to fulfill this need by presenting the Provocation in Sport Questionnaire (PSQ), which included six statements representing incidences of 
provocation that are common in many sports. The scale measured the frequency that respondents experienced each provocation and the corresponding intensity of associated anger on five point Likert scales. An example is: "How often, during your competitive matches do opponents use offensive gestures?" (where $1=$ never to $5=$ almost always) and corresponding intensity of associated anger (e.g., '"How angry did you feel when opponents use offensive gestures?'” $1=$ not at all angry to $5=$ extremely angry). Scale scores were calculated by summing responses (scores could range from 6 to 30 for both subscales). Higher scores represented greater frequency of provocation and more intense anger in response to provocation. Internal reliability was high for both scales (provocation frequency $=0.78$; anger intensity $=0.82$ ).

Unfortunately, the PSQ was only published in one study in which it was translated and used in Chinese. It appears that, besides the PSQ, only one other basic method has ever been used to assess provocation. Maxwell (2004) and Maxwell et al. (2007) assessed provocation by asking one question to assess the experience of aggressive acts (Provocation; "I am the victim of verbal or physical abuse from opponents"). Clearly, a need exists to assess the type and frequency of provocation commonly experienced by athletes, in addition to the intensity of one's reaction to the provocation. Furthermore, more research is needed to assess the frequency and response characteristics to differing types of provocation set within various settings.

\section{Part 3: Managing Anger and Aggressive Behavior in Sport}

\section{Structure of anger management}

The structure of anger management programs can differ greatly in size and scope. However, they are typically offered in a group setting, range from three to eight sessions, depending on the type of participants and resources available (Thomas, 2001). While three to four weeks seems like a small time frame, precedent for running brief group interventions is 
outlined by Yalom (1985). Thomas (2001) also suggested sex-specific interventions for men and women, mainly because men and women tend to have different perceptions of the experiences and meanings of their anger. Significant decreases in self-reported anger have been found in just three sessions of anger management workshops for female inmates (Smith, Smith, \& Beckner, 1994). The sessions focused on symptoms and reasons for anger, how to effectively manage anger, and ways to incorporate techniques into personal lives.

\section{Anger Management Training in General Population}

While anger is neither a good or bad emotion, people often associate anger with a distressing and unpleasant emotion, sometimes coupled with anxiety and guilt (Thomas, 1993). Unfortunately, research has suggested that people often have fewer working strategies for controlling anger than most other emotional states, including fear and sadness (Tice \& Baumeister, 1993).

The most effective anger management treatment would ideally target individuals who have the highest levels of trait (or innate) anger. It is unclear (and likely difficult to assess) the number of these individuals in the general population that are high in trait anger. Some research has studied those individuals who are on both ends of the spectrum in terms of trait anger. Tafrate, Kassinove, and Dundin (2002) conducted this type of research on adults in the general population with low and high trait anger, as measured by the Trait-Anger Scale (Spielberger, 1988; TAS). This 10-item scale assesses an individual's likelihood of expressing anger across a number of different situations.

The findings of the study suggested that individuals with high trait anger more often experienced anger that was also more intense and long lasting. Furthermore, these individuals reported more negative consequences than the low trait anger individuals such as drug use and 
physical aggression. It seems that individuals that are unable to manage anger suffer more consequences than those individuals who have learned the necessary skills.

The effectiveness of anger management training in non-sport settings has been studied somewhat extensively. While a number of different methods have been implemented for anger treatment, cognitive behavioral therapy (CBT) seems to be the method of choice in the last few decades. The best support for the effectiveness of CBT in the treatment of anger is a metaanalysis covering 50 studies conducted by Beck and Fernandez (1998), who found that CBT studies had a grand mean weight effect size of .70. As the authors suggested, “... it can be inferred that the average subject in the CBT condition was better off than $76 \%$ of control subjects." (p.70). Even more favorable is that this reported effect size was found to be more or less homogenous across studies with a variety of populations such as school children, juvenile offenders, and inmates (Beck \& Fernandez, 1998). Sukhodolsky, Kassinove, and Gorman (2003) also found empirical support for CBT-based treatment utilizing multimodal interventions and skills training for anger in children and adolescents, with a medium effect size.

More recently, Del Vecchio \& O’Leary (2004) conducted a meta-analysis on controlled studies of anger treatment for various anger properties. They found CBT to be the best treatment of anger compared to relaxation and cognitive therapy (CT). Participants who had difficulty with anger control also responded best to CBT. While CBT is not the only available treatment of anger, it seems to be among the most popular forms of treatment and, in addition, have some the best empirical support. Deffenbacher (2011) outlined the following four characteristics of CBT anger interventions. First, individuals with anger issues that undergo CBT treatment fare better than untreated individuals. Second, as mentioned above, treatment effect sizes indicate, consequential positive change. Third, treatment effects appear to remain after both short and 
long-term follow up efforts. Finally, different types of interventions appear equally effective, suggesting that there is no one "best" intervention in helping to control anger (Deffenbacher, 2011). It seems it is more important to work to tailor interventions to an individual's experience with anger.

Researchers have suggested that anger management training can be effective for the treatment of some behavior problems in children, two examples being the Anger Coping and Coping Power programs (Lochman, Boxmeyer, Powell, Barry, \& Pardini, 2010). These programs are based on providing cognitive-behavioral strategies and coping mechanisms to use when dealing with anger. Examples of the various skills taught are goal setting, relaxation, and emotional awareness. These programs have been found to decrease reported anger and also increase prosocial behaviors, even a year after post-intervention (Lochman et al., 2009).

While anger management can no doubt be effective, there are certain instances where it is not recommended. For example, anger management training is not appropriate for individuals with neurological conditions, acute psychosis, or severe personality disorders that include violent tendencies (Thomas, 2001). It is far more important for these individuals to engage in consistent individual psychotherapy before starting anger management training in a group setting.

\section{Other Anger Management Techniques}

In addition to traditional CBT-based treatments, it has been suggested that exercise may reduce anger in the short term. Using a sample of college students, McGown, Pierce, and Jordan (1991) used the Profile of Mood States (POMS; McNair, Lorr, \& Droppleman, 1971) to assess mood after only a single bout of exercise. The researchers suggested that, when compared to a control group of students who just participated in an exercise science lecture, participants in the activity classes reduced their mood disturbance, tension, depression, confusion, and anger. This 
study hinted at the importance of physical activity in an immediate reduction of anger, although long-term effects are unknown (McGown, Pierce, \& Jordan, 1991). No research has compared the effectiveness of exercise interventions and traditional anger management.

\section{Anger Management Training in Sport}

Outside of sport, Howells (1998) identified years ago that one of the limitations in anger management interventions has been the failure to apply them to high-risk populations. Despite some athletes being at a heightened risk of anger due to the competitive, physical and often controversial nature of sports, very little research has explored the effectiveness of anger management training in athletics. Researchers have even suggested that anger management practices such as emotional regulation, cognitive restructuring, and relaxation techniques can be beneficial to individual athletes (Deffenbacher \& McKay, 2000). Despite this, anger management interventions are noticeably lacking in the literature, even over a decade after the first anger intervention was conducted in a sport setting. Researchers have noted this issue, stating, "applied researchers and practitioners who wish to develop interventions to alleviate the impact of anger on sports participants lack adequate empirical data to guide their efforts" (Bolgar, Janelle, \& Giacobbi, p.73).

Brunelle, Janelle, \& Tennant (1999) were among the first and only researchers to examine anger and aggressive behavior using intervention methods. In their study, the purpose was to examine the effectiveness of anger awareness training and role-playing interventions in reducing angry on-field behavior and feelings of anger assessed using self-reported measures. Participants were 57 male college students enrolled in a soccer course, the majority of whom had played at least at the high school level. Although participants from the anger awareness, roleplaying and control groups initially exhibited equivalent anger scores, the researchers found that 
the role-playing group participants showed improved ability to control angry behavior than the other two groups. Interestingly, angry feelings remained somewhat constant throughout the study, but role-playing was found to be the most effective method in reducing these feelings and any resultant behavior.

The findings of this study pointed to the potential performance and enjoyment benefits of having athletes model and rehearse more effective ways to deal with anger. It seems that anger management training can have a positive impact on reducing feelings of anger and potentially aggressive behavior (Brunelle, Janelle, \& Tennant, 1999). Unfortunately, little sport-specific research utilizing intervention methods has been published in the area of anger management/control. Intervention methods seem to be vastly underutilized in the field of sport psychology, despite the more natural, applied nature of this type of work. This is unfortunate since it has been suggested recently that interventions can be successful, even with youth athletes, if they provide a holistic skills package, involve other important members such as teammates and coaches, and support a focus on the enduring benefits (Henriksen, Larsen, Storm, \& Ryom, 2014). Researchers have also pointed out that if psychological skills training (PST) are delivered as early as possible to athletes, they are more likely than older, elite athletes to actually utilize them (Blom, Hardy, Burke, \& Joyner, 2003).

Robazza and Bortoli (2007) suggested that sport psychology professionals could help athletes (especially in combat sports) be more aware of the cognitive and somatic symptoms of anger and how they can help or hurt their performances. They even directly proposed the benefit of applied anger management methods, suggesting that, "cognitive restructuring or selfregulation of emotional levels might be proposed separately or in combination to help athletes 
attain control over their anger" (p. 893). Since then, a review of the sport psychology literature reveals there are no empirically validated anger management programs available for athletes.

Understanding and studying the emotion of anger is important in sport for a number of reasons. First, anger can be facilitative to performance, but the inability to control one's anger can lead to decreased performance. Second, teammates and coaches that don't understand anger will attempt to psych up athletes by tapping into his/her anger. This is dangerous if anger management has not been learned. Third, if anger goes unhindered for too long, there can be devastating consequences for athletes (and spectators) both on and off the field of play (Abrams, 2010).

\section{Aggression Management Training}

Information on applied interventions focused on managing aggressive behavior is difficult to find. While a number of studies (e.g., Cox, 2011) have explored the effectiveness of mental skills and CBT-based interventions on stress and anxiety, few have focused on helping athletes prone to unsanctioned aggressive behavior. In fact, Kerr and Grange (2015) suggested only three published studies and one unpublished dissertation have investigated the used of aggression-based interventions in the past three decades. A brief discussion of the four studies follows, and if nothing else, this lack of empirically based aggression interventions points to the need for more research on the characteristics of individuals most likely to engage in aggressive behavior.

Silva (1982) was the first to apply aggression management training in sport. He worked with a Division I male ice hockey player who tended to lash out at opponents when outplayed or made to look bad. This type of behavior was seen both in practice and games, seemingly as a result of frustration and subsequently losing confidence, self-esteem, and bringing about feelings 
of social competence. Silva's basic aggression intervention involved two stages, with the first focusing on the athlete restructuring his view of aggression to help understand that it was unnecessary and could be prevented. The second stage focused more on using concentration cues and imagery of both good and bad plays to help reinforcement more positive on-ice behavior. Silva reported that, although playing time increased by only two minutes per game, a $57 \%$ reduction in aggressive penalties over the final ten games of the competitive season.

Several years later, Connelly (1998) applied an intervention with a Division I female basketball player who was using unsanctioned aggression to retaliate against opponents she believed were actively provoking her during games. Connelly helped teach the athlete relaxation techniques and the athlete's coach reinforced good behavior while punishing bad behavior (e.g., removal from practice or game). Connelly reported that post-intervention, the athlete had retained her starting position, had averaged fewer fouls, and was avoiding fouling out of games completely.

As part of their Playing Tough and Clean Hockey Program design to teach "clean" (or sanctioned) aggression and use cognitive techniques to decrease unsanctioned aggression, Lauer \& Paiement (2009) worked with three male youth hockey players who had been prone to receiving penalties for unsanctioned aggressive behavior. The program consisted of ten total sessions that focused on relaxation and refocusing techniques. Specifically, the youth hockey players were taught how to react when provoked or in situations that typically produce negative thoughts and emotions such as anger or frustration. Lauer \& Paiement claimed that postintervention, improvements in the hockey players' behavior were prevalent, most notably reductions in the number of unsanctioned, retaliatory aggression. 
In his unpublished dissertation, Matessi (2002) conducted an aggression management training program designed to reduce penalty minutes of three male university hockey players. These players had incurred the highest number of penalty minutes. Matessi's program included teaching psychological skills techniques such as positive self-talk, deep breathing, and coping imagery focusing on positive results. The aggression management program was found to reduce penalty minutes and decrease the likelihood of penalties from aggressive behavior. Matessi also reported that the hockey players were able to better control anger and arousal levels and cope more appropriately from a relaxed state.

\section{Significance of Study}

It is clear that certain types of aggressive behavior in sport, particularly behavior that is goal-directed and not intended to produce harm (i.e., sanctioned aggression), is acceptable and even necessary for success. However, the line is often small between this type of instrumental aggression and violent behavior that can cause injuries or worse. What are the characteristics of athletes that might struggle with anger and are more likely to engage in this type of harmful behavior? At the present time, there is no good way to determine this, and it is not even fully understood whether athletes are inherently more angry or aggressive than non-athletes. In addition, it is not clear from the research the type and frequency of provocation athletes experience, both from opponents and other prominent sport personnel (e.g., referees or passionate fans). Furthermore, do gender differences exist in the anger-aggression-provocation relationship? Does the type (i.e., non-contact vs. contact) and level of sport somehow influence this relationship?

The present study aims to investigate these questions and provide some insight into the area of aggression and violent behavior that can inform better practices moving forward. It seems 
logical to begin being proactive about identifying characteristics of athletes that may struggle with managing high levels of intrinsic anger and aggressive behavior. Understanding the emotion of anger is important in sport for a number of reasons. First, anger can be facilitative to performance, but the inability to control one's anger can be debilitative to performance. Second, teammates and coaches that don't understand anger will attempt to psych up athletes by tapping into their anger. This is dangerous if anger management has not been learned or practiced. Third, if anger goes unhindered for too long, there can lead to devastating consequences for athletes (and spectators) both on and off the field of play (Abrams, 2010).

Even though the presence of anger does not have to be followed by aggressive behavior, it has been known for some time that aggression often follows anger, especially anger which is uncontrolled (Berkowitz, 1993; Feindler \& Ecton, 1994). Maxwell (2004) claimed that anger was commonly expressed through aggressive behavior in sports, and simply ruminating about past experiences that provoked anger can increase the propensity of aggression. Maxwell found aggressive behavior was higher in British male athletes than female athletes, and higher in team sport athletes than individual sport athletes. A follow-up to this study comparing British and Chinese athletes found similar results, suggesting being provoked and having thoughts of revenge were significantly related to self-reported aggression (Maxwell, Moores, \& Chow, 2007). The authors suggested a cultural difference could be at play, with Chinese athletes more often inhibiting their aggressive responses, even when the chance to react aggressively was prevalent. These are important findings because they suggest that the emotion of anger, even if not present at the moment, can potentially increased one's aggressive behavior (Maxwell, 2004).

It is evident that aggressive behavior is often a byproduct of uncontrolled anger. Years ago in a position statement on aggression and violence in sport, Tenenbaum and colleagues 
(1997) put forth nine recommendations to help curtail incidents of violence in sport. The final recommendation noted, "athletes should take part in programs aimed at helping them reduce behavioral tendencies toward aggression" (p. 5). Unfortunately, only a few studies have actually attempted to satisfy this recommendation in an applied setting (e.g., Brunelle et al., 1999). Despite some athletes being at a heightened risk of anger due to the competitive and overtly physical nature of sports, in addition to the influence of personality traits, very little research has explored the effectiveness of anger management training in athletics.

Robazza and Bortoli (2007) suggested that sport psychology professionals could help athletes (especially in combat sports) be more aware of the cognitive and somatic symptoms of anger and how they can help or hurt their performances. They even directly proposed the benefit of applied anger management methods, suggesting that, "cognitive restructuring or selfregulation of emotional levels might be proposed separately or in combination to help athletes attain control over their anger" (p. 893). Other researchers have suggested that anger management practices such as emotional regulation, cognitive restructuring, and relaxation techniques can be beneficial to individual athletes (Deffenbacher \& McKay, 2000). Since then, a review of the sport psychology literature reveals there are no empirically validated anger management programs available for athletes, well over a decade after the first anger intervention (Brunelle et al., 1999) was conducted in a sport setting. Other researchers have noted this issue, stating, "applied researchers and practitioners who wish to develop interventions to alleviate the impact of anger on sports participants lack adequate empirical data to guide their efforts" (Bolgar, Janelle, \& Giacobbi, 2008, p.73).

It is expected that the results of the current study will help promote the creation of more applied interventions focusing on anger and aggression management with high-risk athletes. The 
first step is to identify characteristics of these high-risk individuals and determine how provocation influences the likelihood of aggressive behavior. A number of studies have suggested that male athletes are more aggressive than their female counterparts, both on and off the field (e.g., Burton \& Marshall, 2005; Coulomb-Cabagno \& Rascle, 2006), and perceive aggression to be more legitimate than females (e.g., Bredemeier, 1985; Gardner \& Janelle, 2002; Tucker \& Parks, 2001). These findings may be influenced by the notion of male athletes clinging to traditional beliefs about masculine behavior (Sheldon \& Aimar, 2001). However, other studies have refuted these results and suggested that, contrary to previous research, men and women do not differ in levels of instrumental aggression (e.g., Keeler, 2007). Ultimately, aggression studies that focused on gender have revealed conflicting findings, with no significant differences being reported between males and females (Kimble et al., 2010).

As a counselor, sport psychologist, or other service provider, the information obtained from this study can be crucial in identifying the characteristics of athletes that could benefit most from anger and aggression interventions. Recently, Kerr and Grange (2015) suggested the importance of establishing theory-based aggression management interventions. These types of interventions are more reactive, in that they focus on individuals who have already shown to be likely to act out aggressively in his/her sport. Unfortunately, only four known studies have been conducted that utilized applied interventions to work with athletes prone to unsanctioned aggressive behavior. These studies were all significant in establishing the importance of applied interventions with aggressive athletes. Importantly, the results help confirm the notion that helping athletes learn to self-regulate better can reduce instances of aggression (Ciairano et al., 2007). However, they also represent a general gap in the literature focused on anger and aggressiveness in athletes. 
Other stakeholders can benefit from the current research as well. As a college athletic director, the success of the university's sport teams is priority number one. For these individuals it is feasible that a better understanding of the anger levels of athletes and the subsequent connection to aggressive behavior will help keep violent transgressions down and both fans and players safe. Players that are more likely to engage in violent behavior only hurt the team with penalties and suspensions that keeps them off the playing surface.

College coaches can also benefit greatly from the results of this study. As mentioned previously, players that are unable to manage their anger and frequently aggress cannot help the team be successful, and often times hurt the team's chances at success. It is imperative to understand who the at-risk athletes may be to provide better education and management materials to these individuals. Furthermore, research suggests that coaches in a variety of sport contexts are very influential of incidences of aggressive athlete behavior and ones that emphasize winning and inter-team competition can lead to low moral reasoning (Miller, Roberts, \& Ommundsen, 2005). This can be dangerous because of the knowledge that a mastery climate focused on sportsmanship within a team is indicative of less hostile aggression (Chantal, Robin, Vernat, \& Bernache-Assollant, 2005). It is possible that coaches in certain sporting contexts (e.g., male teams or high-contact sports) need better information, education, and programming to help promote an environment more conducive to safe, sanctioned play.

From athletes and coaches on the field to athletic directors and stakeholders off of it, uncontrolled anger and aggressive behavior can lead to devastating consequences for athletes. The investigation of these topics, in addition to provocative behavior that often leads to them, is ripe for investigation and in serious need of more foundational research. Currently, it is difficult to assess anger and aggressive behavior in athletes, and little is known about the characteristics 
of athletes that may be more likely to respond aggressively to provocative acts. This study is important in establishing information about the levels of anger and aggressiveness in college athletes, as well as increasing the understanding of the experience of provocation in sport. Hopefully, the results of this study and future similar studies will help promote the creation of more empirically-based anger and aggression management programs (like some described previously) with the goal to help athletes deal more effectively with their emotions and provocative behavior both on and off the field. 


\section{References}

Abrams, M. (2010). Anger management in sport: Understanding and controlling violence in athletes. Champaign, IL: Human Kinetics.

Abrams, M., \& Hale, B. (2005). Anger: How to moderate hot buttons. In Murphy, S. (Ed.). The sport psych handbook (pp. 93-112). Champaign, IL: Human Kinetics.

Anderson, C. A., \& Bushman, B. J. (2002). Human Aggression. Annual Review of Psychology, $53,27-51$.

Anderson, C. A., Deuser, W. E., DeNeve, K. M. (1995). Hot temperatures, hostile affect, hostile cognition, and arousal: Tests of a general model of affective aggression. Personality and Social Psychological Bulletin, 21, 434-448.

Bandura, A. (1973). Aggression: A social learning analysis. Englewood Cliffs, NJ: PrenticeHall.

Baron, R. A., \& Richardson, D. R. (1994). Human aggression. New York, NY: Plenum Press.

Bebetsos, E., Zouboulias, S., Antoniou, P., \& Kourtesis, T. (2013). Do anxiety, anger and aggression differentiate elite water-polo players? Journal of Physical Education and Sport, 13(2), 209-212.

Beck, R., \& Fernandez, E. (1998). Cognitive-behavioral therapy in the treatment of anger: A meta-analysis. Cognitive Therapy and Research, 1, 63-74.

Berkowitz, L. (1965). Aggressive cues in aggressive behavior and hostility catharsis. Psychological Review, 71, 104-122.

Berkowitz, L. (1983). Aversively stimulated aggression: Some parallels and differences in research with animals and humans. American Psychologist, 38, 1135-1144. 
Berkowitz, L. (1989). Frustration-aggression hypothesis: Examination and reformulation. Psychological Bulletin, 106(1), 59-73.

Berkowitz, L. (1993). Aggression: Its causes, consequences, and control. New York. NY: McGraw-Hill.

Blom, L., Hardy, C., Burke, K., \& Joyner, A. (2003). High school athletes’ perceptions about sport psychology and preferences for service. International Sports Journal, 7, 18-24.

Bolgar, M. R., Janelle, C., \& Giacobbi, P. R., Jr. (2008). Trait anger, appraisal, and coping differences among adolescent tennis players. Journal of Applied Sport Psychology, 20, 73-87.

Botterill, C., \& Brown, M. (2002). Emotion and perspective in sport. International Journal of Sport Psychology, 33, 38-60.

Botterill, C., \& Patrick, T. (2003). Understanding and managing emotions in team sports. In R. Lidor \& K.P. Henschen (Eds.), The psychology of team sports (pp. 115-130). Morgantown, WV: Fitness Information Technology.

Bredemeier, B. (1985). Moral reasoning and the perceived legitimacy of intentionally injurious sport acts. Journal of Sport Psychology, 7, 110-124.

Bredemeier, B. (1994). Children's moral reasoning and their assertive, aggressive, and submissive tendencies in sport and daily life. Journal of Sport \& Exercise Psychology, $16,1-14$.

Bredemeier, B., Weiss, M., Shields, D., \& Cooper, B. (1986). The relationship of sport involvement with children's moral reasoning and aggression tendencies. Journal of Sport Psychology, 8, 304-318. 
Brunelle, J. P., Janelle, C. M., \& Tennant, K. (1999). Controlling competitive anger among male soccer players. Journal of Applied Sport Psychology, 11(2), 283-297.

Burton, J. M., \& Marshall, L. (2005). Protective factors for youth considered at risk for criminal behavior: Does participation in extracurricular activities help? Criminal Behaviour and Mental Health, 15(1), 46-64.

Bushman, B. J. (2002). Does venting anger feed or extinguish the flame? Catharsis, rumination, distraction, anger, and aggressive responding. Personality and Social Psychology Bulletin, 28(6), 724-731.

Buss, A. H. (1961). The psychology of aggression. New York, NY: Wiley.

Buss, A. H., \& Perry, M. P. (1992). The aggression questionnaire. Journal of Personality and Social Psychology, 63, 452-459.

Carter, M. M., Forys, K. L., \& Oswald, J. C. (2008). The cognitive-behavioral model. In M. Hersen, \& A. M. Gross (Eds.), Handbook of clinical psychology (pp. 171-204). Hoboken, NJ: Wiley.

Chantel, Y., Robin, P., Vernat, J., \& Bernache-Assollant, I. (2005). Motivation, sportspersonship, and athletic aggression: A meditational analysis. Psychology of Sport \& Exercise, 6(2), 233-249.

Chow, G. M., Murray, K. E., \& Feltz, D. L. (2009). Individual, team, and coach predictors of players' likelihood to aggress in youth soccer. Journal of Sport \& Exercise Psychology, $31(4), 425-443$.

Christov-Moore, L., Simpson, E. A., Coude, G., Grigaityte, K., Iacoboni, M., \& Ferrari, P. F. (2014). Empathy: Gender effects in brain and behavior. Neuroscience \& Biobehavioral Reviews, 46, 604-627. doi: 10.1016/j.neuobiorev.2014.09.001. 
Ciairano, S., Rabaglietti, E., Roggero, A., Bonino, S., \& Beyers, W. (2007). Patterns of adolescent friendships, psychological adjustment and antisocial behavior: The moderating role of family stress and friendship reciprocity. International Journal of Behavioral Development, 31, 539-548.

Collins, D. Hale, B., \& Loomis, J. (1995). Differences in emotional responsivity and anger in athletes and nonathletes: Startle reflex modulation and attributional response. Journal of Sport \& Exercise Psychology, 17, 171-184.

Connelly, D. (1998). Increasing intensity of play of non-assertive athletes. The Sport Psychologist, 2, 255-265.

Conroy, D. E., Silva, J. M., Newcomer, R. R., Walker, B. W., \& Johnson, M. S. (2001). Personal and participatory socializers of the perceived legitimacy of aggressive behavior in sport. Aggressive Behavior, 27(6), 405-418. http://dx.doi.org/10.1002/ab.1026.

Coulomb-Cabagno, G., \& Rascle, O. (2006). Team sports players' observed aggression as a function of gender, competitive level, and sport type. Journal of Applied Social Psychology, 36(8), 1980-2000. doi: 10.1111/j.0021-9029.2006.00090.

Cox, R. H. (2007). Sport psychology: Concepts and applications, (6th ed.). New York, NY: McGraw-Hill.

Cox, R. H. (2011). Sport psychology: Applications and developments (7th ed.). Madison, WI: Brown \& Benchmark Publishers.

Creswell, J. W. (2014). Research design: Qualitative, quantitative, and mixed methods approaches $\left(4^{\text {th }}\right.$ Ed.). Thousand Oaks, California: SAGE Publications. 
Culhane, S. E., \& Morea, O. F. (2010). Reliability and validity of the Novaco Anger Scale and Provocation Inventory (NAS-PI) and State-Trait Anger Expression Inventory-2 (STAXIII) in Hispanic and non-Hispanic White student samples. Hispanic Journal of Behavioral Sciences, 32(4), 586-606.

Deci, E. L. (1980). The psychology of self-determination. Lexington, MA: Heath.

Deffenbacher, J. L. (2011). Cognitive-behavioral conceptualization and treatment of anger. Cognitive and Behavioral Practice, 18, 212-221.

Deffenbacher, J. L., \& McKay, M. (2000). Overcoming situational and general anger. Oakland, CA: New Harbinger Publications.

Del Vecchio, T., \& O’Leary, D. (2004). Effectiveness of anger treatments for specific anger problems: A meta-analytic review. Clinical Psychology Review, 24, 15-34.

DeWall, N. C., \& Bushman, B. J. (2009). Hot under the collar in a lukewarm environment: Words associated with hot temperature increase aggressive thoughts and hostile perceptions. Journal of Experimental Psychology, 45, 1045-1047.

Dollard, J., Doob, L., Miller, N., Mowrer, O., \& Sears, R. (1939). Frustration and aggression. New Haven, CT: Yale University Press.

Donahue, E. G., Rip, B., \& Vallerand, R. J. (2009). When winning is everything: On passion, identity, and aggression in sport. Psychology of Sport and Exercise, 10(5), 526-534. doi: 10.1016/j.psychsport.2009.02.002.

Faul, F., Erdfelder, E., Lang, A. G., \& Buchner, A. (2007). G*Power 3.1: A flexible statistical power analysis program for the social, behavioral, and biomedical sciences. Behavior Research Methods, 39, 175-191. 
Feindler, E. L., \& Ecton, R. B. (1994). Adolescent anger control: Cognitive behavioral techniques. Needham Heights, MA: Allyn \& Bacon.

Feindler, E. L., \& Guttman, J. (1993). Cognitive-behavioral anger control training for groups of adolescents: A treatment manual. In C. W. LeCroix (Ed.), Handbook of child and adolescent treatment manuals. New York, NY: Lexington Books.

Field, A. P. (2009). Discovering statistics using SPSS ( $3^{\text {rd }}$ ed.). London, England: SAGE Publications.

Garcia-Leon, A., Reyes, G. A., Vila, J., Perez, N., Robles, H., \& Ramos, M. M. (2002). The aggression questionnaire: A validation study in student samples. The Spanish Journal of Psychology, 5(1), 45-53.

Gardner, R. E., \& Janelle, C. M. (2002). Legitimacy judgments of perceived aggression and assertion by contact and non-contact sport participants. International Journal of Sport Psychology, 33(3), 290-306.

Gee, C. J., \& Leith, L. M. (2007). Aggressive behavior in professional ice hockey: A crosscultural comparison of North American and European born NHL players. Psychology of Sport \& Exercise, 8, 567-583.

Gill, D. (2000). Psychological dynamics of sport and exercise. Champaign, IL: Human Kinetics.

Gill, D., \& Williams, L. (2008). Psychological dynamics of sport and exercise ( $3^{\text {rd }}$ Ed.). Champaign, IL: Human Kinetics.

Gould, D., Greenleaf, C., \& Krane, V. (2002). Arousal-anxiety and sport behavior. In Horn, T.S. (Ed.). Advances in sport psychology (2 ${ }^{\text {nd }}$ ed.). Champaign, IL: Human Kinetics.

Greene, A. F., Sears, Jr., S. F., \& Clark, J. E. (1993). Anger and sports participation. Psychological Reports, 72, 523-529. 
Hanin, Y. L. (2000). Emotions in sport. Champaign, IL: Human Kinetics.

Hanin, Y. L. (2010). Coping in sport: Theories methods and related constructs (pp. 159-175). Hauppauge, NY: Nova Science Publishers, Inc.

Hanin, Y. L., \& Syrja, P. (1995). Performance affect in soccer players: An application of the IZOF model. International Journal of Sports Medicine, 16(4), 264-269.

Harger, G. J., \& Raglin, J. S. (1994). Correspondence between actual and recalled precompetition anxiety in collegiate track and field athletes. Journal of Sport \& Exercise Psychology, 16, 206-211.

Harris, M. B. (1993). How provoking! What makes men and women angry? Aggressive Behavior, 19(3), 199-211.

Hart, W., Adams, J., Burton, A., \& Tortoiello, G. (2017). Narcissism and self-presentation: Profiling grandiose and vulnerable narcissists' self-presentation tactic use. Personality and Individual Differences, 104, 48-57. doi:10.1016/j.paid.2016.06.062.

Henriksen, K., Larsen, C. H., Storm, L. K., \& Ryom, K. (2014). Sport psychology interventions with young athletes: The perspective of the sport psychology practitioner. Journal of Clinical Sport Psychology, 8, 245-260.

Howells, K. (1998). Cognitive-behavioral therapy for anger, aggression and violence. In N. Tarrier, \& A. Wells (Eds.), Complex cases in cognitive-behavioral therapy (pp. 295318). Chichester, NH: Wiley.

Huang, D. B, Cherek, D. R., \& Lane, S. D. (1999). Laboratory measurement of aggression in high school age athletes: Provocation in a nonsporting context. Psychological Reports, $85,1251-1262$. 
Husman, B. F., \& Silva, J. M. (1984). Aggression in sport: Definitional and theoretical considerations. In J. M. Silva \& R. S. Weinberg (Eds.), Psychological foundations of sport (pp. 246-260). Champaign, IL: Human Kinetics.

IBM Corp. (2016). IBM SPSS Statistics for Macintosh, Version 24. Armonk, NY: IBM Corporation.

Jones, M. V. (2003). Controlling emotions in sport. The Sport Psychologist, 17, 471-486.

Kassinove, H., \& Tafrate, R. C. (2002). Anger management: The complete practitioner's guidebook for the treatment of anger. Atascadero, CA: Impact.

Keeler, L. (2007). The differences in sport aggression, life aggression, and life assertion among adult male and female collision, contact, and non-contact sport athletes. Journal of Sport Behavior, 30(1), 57-76.

Kendzierski, D., \& DeCarlo K. J. (1991). Physical Activity Enjoyment Scale (PACES): Two validation studies. Journal of Sport \& Exercise Psychology, 13(1), 50-64.

Kerr, J. H. (1999). The role of aggression and violence in sport: A rejoinder to the ISSP position stand. The Sport Psychologist, 13, 83-88.

Kerr, J. H. (2002). Issues in aggression and violence in sport: The ISSP position stand revisited. The Sport Psychologist, 16, 68-78.

Kerr, J. H. (2005). Rethinking aggression and violence in sport. London, UK: Routledge.

Kerr, J.H . (2008). A critique of the development of the Competitive Aggressiveness and Anger Scale. Psychology of Sport and Exercise, 9(6), 721-728. 
Kerr, J. H., \& Grange, P. (2015). Proposed intervention strategies for unsanctioned aggression management: Anger, power and thrill aggression. The Sport Psychologist, 30, 179-188.

Kimble, N. B., Russo, S. A., Bergman, B. G., \& Galindo, V. H. (2010). Revealing an empirical understanding of aggression and violent behavior in athletics. Aggression and Violent Behavior, 15, 446-462.

Kirker, B., Tenenbaum, G., \& Mattson, J. (2000). An investigation of the dynamics of aggression: direct observation in ice hockey and basketball. Research Quarterly for Exercise and Sport, 71, 373-386.

Krizan, Z., \& Johar, O. (2015). Narcissistic rage revisited. Journal of Personality and Social Psychology, 108(5), 784-801.

Lane, A. M. (Ed.). (2007). Mood and human performance: Conceptual, measurement and applied issues. Hauppauge, NY: Nova Science Publishers, Inc.

Lane, A. M., Beedie, C. J., Jones, M. V., Uphill, M., \& Davenport, T. J. (2012). The BASES expert statement on emotion regulation in sport. Journal of Sport Sciences, 30(11), 11891195. doi: 10.1080/02640414.2012.693621.

Lauer, L., \& Paiement, C. (2009). The playing tough and clean hockey program. The Sport Psychologist, 23, 543-561.

Lazarus, R. S. (2000). Cognitive-motivational-relational theory of emotion. In Y. L. Hanin (Ed.), Emotions in sport (pp. 39-63). Champaign, IL: Human Kinetics. 
Lochman, J. E., Boxmeyer, C., Powell, N., Barry, T. D., \& Pardini, D. A. (2010). Anger control for aggressive youth. In J. Weisz \& A. Kazdin (Eds.), Evidence-based psychotherapies for children and adolescents (2nd ed., pp. 227-242). New York, NY: Guilford Press.

Lochman, J. E., Boxmeyer, C., Powell, N., Qu, L., Wells, K., \& Windle, M. (2009).

Dissemination of the Coping Power program: Importance of intensity of counselor training. Journal of Consulting and Clinical Psychology, 77, 397-409.

Loughead, T. M., \& Leith, L. M. (2001). Hockey coaches' and players' perceptions of aggression and the aggressive behavior of players. Journal of Sport Behavior, 24(4), 394408.

Martens, R., Vealey, R. S., Burton, D., Bump, L., \& Smith, D. E. (1990). Development and validation of the Competitive State Anxiety Inventory-2. In R. Martens, R. S. Vealey, \& D. Burton (Eds.), Competitive anxiety in sport (pp. 117-178). Champaign, IL: Human Kinetics.

Matessi, M. A. (2002). The effects of an aggression-management training intervention program on controlling ice hockey player penalty minutes. Unpublished doctoral dissertation, West Virginia University, Morgantown, WV.

Maxwell, J. P. (2004). Anger rumination: An antecedent of athlete aggression? Psychology of Sport \& Exercise, 5, 279-289.

Maxwell, J. P., \& Moores, E. (2006). Development of a short scale measuring provocation in competitive athletes. Proceedings of the British Association of Sport and Exercise Sciences Annual Conference, September 2006, Wolverhampton, UK.

Maxwell, J. P., \& Moores, E. (2007). The development of a short scale measuring aggressiveness and anger in competitive athletes. Psychology of Sport and Exercise, 8, 179-193. 
Maxwell, J. P., Moores, E., \& Chow, C. C. F. (2007). Anger rumination and self-reported aggression amongst British and Hong Kong Chinese athletes: A cross-cultural comparison. International Journal of Sport and Exercise Psychology, 5(1), 9-27.

Maxwell, J. P., Visek, A. J., \& Moores, E. (2009). The perceived legitimacy of aggression in male Hong Kong Chinese athletes: Effects of type of sport and level of competition. Psychology of Sport \& Exercise, 10, 289-296.

McCarthy, P. J., Allen, M. S., \& Jones, M. V. (2012). Emotions, cognitive interference, and concentration disruption in youth sport. Journal of Sports Sciences, 31(5), 505-515.

McGown, R. W., Pierce, E. F., \& Jordan, D. (1991). Mood alterations with a single bout of physical activity. Perceptual and Motor Skills, 72, 1203-1209.

McNair, D. M., Lorr, M., \& Droppleman, L. F. (1971). Manual for the Profile of Mood States. San Diego, CA: Educational and Industrial Testing Service.

McNair, D. M., Lorr, M., \& Droppleman, L. F. (1992). Revised manual for the Profile of Mood States. San Diego, CA: Educational and Industrial Testing Service.

Mestre, M. V., Samper, P., Frias, M. D., \& Tur, A. M. (2009). Are women more empathetic than men? A longitudinal study in adolescence. Spanish Journal of Psychology, 12(1), 76-83.

Miller, B. W., Roberts, G. C., \& Ommundsen, Y. (2005). Effect of perceived motivational climate on moral functioning, team moral atmosphere perceptions, and the legitimacy of intentionally injurious acts among competitive youth football players. Psychology of Sport and Exercise, 6(4), 461-477. http://dx.doi.org/10.1016/j.psychsport.2004.04.003

Mohr, P., Howells, K., Gerace, A., Day, A., \& Wharton, M. (2007). The role of perspectivetaking in anger arousal. Personality and Individual Differences, 43, 507-517. doi: 3 10.1016.j.paid.2006.12.019. 
Morgan, W. P. (1980) Tests of champions: The iceberg profile. Psychology Today, 14(4), 92108.

Newby, R. W., \& Simpson, S. (1991). Personality profile of non-scholarship college football players. Perceptual Motor Skills, 73, 1083-1089.

Novaco, R. W. (1975) Anger control: The development and evaluation of an experimental treatment. Lexington, MA: Heath.

Novaco, R. W. (1995). Clinical problems of anger and its assessment and regulations through a stress coping skills approach. In W. O’Donohue, \& L. Krasner (Eds.), Handbook of psychological skills training: Clinical techniques and applications (pp. 320-338). Needham Heights, MA: Allyn \& Bacon.

Nunnally, J. C., \& Bernstein, I. H. (1994). Psychometric theory ( $3^{\text {rd }}$ ed.). New York, NY: McGraw Hill.

Phillips, J. P., \& Giancola, P. R. (2007). The effects of contextual empathy on aggressive behavior in men and women. In A. M. Columbus (Ed.). Advances in psychology research, Vol. 49, (pp. 197-208). Hauppauge, NY: Nova Science Publishers, Inc.

Rathschlag, M., \& Memmert, D. (2013). The influence of self-generated emotions on physical performance: An investigation of happiness, anger, anxiety, and sadness. Journal of Sport \& Exercise Psychology, 35(2), 197-210.

Robazza, C. (2006). Emotion in sport: an IZOF perspective. In S. Hanton, \& S. D. Mellalieu (Eds.), Literature reviews in sport psychology (pp. 127-158). New York, NY: Nova Science. 
Robazza, C., \& Bortoli, L. (2007). Perceived impact of anger and anxiety on sporting performance in rugby players. Psychology of Sport and Exercise, 8, 875-896,

Robazza, C., Bertoli, M., \& Bortoli, L. (2006). Frequency and direction of competitive anger in contact sports. The Journal of Sports Medicine and Physical Fitness, 46(3), 501-508.

Robazza, C., Bortoli, L., \& Nougier, V. (1998). Performance-related emotions in skilled athletes: Hedonic tone and functional impact. Perceptual and Motor Skills, 87, 547-564.

Ruiz, C. N., \& Hanin, Y. L. (2004). Metaphoric description and individualized emotion profiling of performance states in top karate athletes. Journal of Applied Sport Psychology, 16(3)$258-273$.

Ruiz, C. N., \& Hanin, Y. L. (2011). Perceived impact of anger on performance of skilled karate athletes. Psychology of Sport \& Exercise Science, 12, 242-249.

Sheldon, J. P., \& Aimar, C. M. (2001). The role aggression plays in successful and unsuccessful ice hockey behaviors. Research Quarterly for Exercise and Sport, 72(3), 304-309.

Shields, D., Bredemeier, B., LaVoi, N., \& Power, F. (2005). The sport behavior of youth, parents, and coaches: The good, the bad, and the ugly. Journal of Research in Character Education, 3(1), 43-59.

Silva, J. M. (1978). Assertive and aggressive behavior in sport: A definitional clarification. In Naedau, C. H. et al. (Eds.), Psychology of motor behavior and sport (pp. 199-208). Champaign, IL: Human Kinetics.

Silva, J. M. (1982). Competitive sport environments: Performance enhancement through cognitive intervention. Behavior Modification, 6, 443-463. doi:10.1177/01454455820064001. 
Silva, J. M. (1983). The perceived legitimacy of rule violating behavior in sport. Journal of Sport Psychology, 5, 438-448.

Simpson, S., \& Newby, R. W. (1994). Scores on profile of mood states of college football players from nonscholarship and scholarship programs. Perceptual and Motor Skills, 78, $635-640$.

Sofia, R., \& Cruz, J. F. A. (2016). Exploring individual differences in the experience of anger in sport competition: The importance of cognitive, emotional, and motivational variables. Journal of Applied Sport Psychology, 28(3), 350-366, doi:10.1080/10413200.2015.1121170.

Smith, L. L., Smith, J. N., \& Beckner, B. M. (1994). An anger-management workshop for women inmates. Families in Society: The Journal of Contemporary Human Services, 75, 172-175.

Spielberger, C. D. (1988). State-Trait Anger Expression Inventory. Odessa, FL: Psychological Assessment Resources.

Spielberger, C. D. (1999). Professional manual for the State-Trait Anger Expression Inventory-2 (STAXI-2). Odessa, FL: Psychological Assessment Resources.

Spielberger, C. D., Jacobs, G., Russell, S., \& Crane, R. S. (1983). Assessment of anger: The state-trait anger scale. In J. N. Butcher, \& C. D. Spielberger (Eds.), Advances in personality assessment (Vol. 2, pp. 159-187). Hillsdale, NJ: Erlbaum.

Spielberger, C. D., \& Reheiser, E. C. (2009). Assessment of emotions: Anxiety, anger, depression, and curiosity. Applied Psychology: Health and Well-Being, 1(3), 271-302. 
Stephens, D. E. (1998) Aggression. In: Duda, J.L. (Ed.), Advancements in sport and exercise psychology measurement. Morgantown, WV: Fitness Information Technology.

Stephens, D. E. (2001). Predictors of likelihood to aggress in youth soccer: An examination of coed and all-girls teams. Journal of Sport Behavior, 23(3), 311- 325.

Stranger, N., Kavussanu, M., McIntyre, D., \& Ring, C. (2016). Empathy inhibits aggression in competition: The role of provocation, emotion, and gender. Journal of Sport \& Exercise Psychology, 38, 4014.

Sukhodolsky, D. G., Kassinove, H., \& Gorman, B. S. (2003). Cognitive-behavioral therapy for anger in children and adolescents: A meta-analysis. Aggression and Violent Behavior, 9, 247-269.

Tafrate, R. C., Kassinove, H., \& Dundin, L. (2002). Anger episodes in high-and low-trait anger community adults. Journal of Clinical Psychology, 58, 1573-1590.

Taylor, J. (1996). Intensity regulation and athletic performance. In J.L. Van Raalte \& B. W. Brewer (Eds.), Exploring sport and exercise psychology. Washington, DC: American Psychological Association.

Teclaw, R., Price, M., \& Osatuke, K. (2011). Demographic question placement: Effect on item response rates and means of a veterans health administration survey. Journal of Business and Psychology, 27, 281-290. doi: 10.1007/s10869-011-9249-y.

Tenenbaum, G., Stewart, E., Singer, R. N., \& Duda, J. (1997). Aggression and violence in sport: An ISSP position stand. The Sport Psychologist, 11, 1-7.

Terry, P. C., \& Jackson, J. J. (1985). The determinants and control of violence in sport. Quest, $37(1), 27-37$. 
Terry, P. C., Lane, A. M., \& Fogarty, G. (2003). Construct validity of the Profile of Mood StatesA for use with adults. Psychology of Sport and Exercise, 4, 125-139.

Terry, P. C., Lane, A. M., Lane, H. J., \& Keohane, L. (1999). Development and validation of a mood measure for adolescents: POMS-A. Journal of Sports Sciences, 17, 861-872.

Thomas, S. P. (Ed.) (1993). Women and anger. New York, NY: Springer.

Thomas. S. P. (2001). Teaching healthy anger management. Perspectives in Psychiatric Care, $37(2), 41-48$.

Tice, D. M., \& Baumeister, R. F. (1993). Controlling anger: Self-induced emotion change. In D. M. Wegner \& J. W. Pennebaker (Eds.), Handbook of mental control (pp. 393-409). Englewood Cliffs, NJ: Prentice Hall.

Tucker, L., \& Parks, J. (2001). Effects of gender and sport type on intercollegiate athletes' perceptions of the legitimacy of aggressive behaviors in sport. Sociology of Sport Journal, 18, 403-413.

Vacha-Haase, T., \& Thompson, B. (2004). How to estimate and interpret various effect sizes. Journal of Counseling Psychology, 51(4) 473-481.

Vallance, J. K. H., Dunn, J. G. H., \& Dunn, J. L. C. (2006). Perfectionism, anger, and situation criticality in competitive youth ice hockey. Journal of Sport \& Exercise Psychology, 28, 383-406.

Vast, R. L., Young, R. L., Thomas, P. R. (2010). Emotions in sport: Perceived effects on attention, concentration, and performance. Australian Psychologist, 45(2), 132-140. 
Visek, A. J., Maxwell, J. P., Watson, J. C., Hurst, J. R. (2011). A cross-cultural evaluation of the factorial invariance of the competitive aggressiveness and anger scale. Journal of Sport Behavior, 33(2), 218-237.

Visek, A. J., \& Watson, J. W. (2005). Ice hockey players' legitimacy of aggression and professionalization of attitudes. The Sport Psychologist, 19(2), 178-192.

Wagstaff, C. R. D., \& Weston, N. J. V. (2014). Examining emotion regulation in an isolated performance team in Antarctica. Sport, Exercise, and Performance Psychology, 3(4), 273-287. DOI: $10.1037 /$ spy0000022.

Watson, D., \& Clark, L. A. (1994). Emotions, moods, traits, and temperaments: Conceptual distinctions and empirical findings. In P. Ekman \& R. J. Davidson (Eds.). The nature of emotion: Fundamental questions (pp. 89-93). New York, NY: Oxford University Press.

Widmeyer, W. N., Dorsch, K. D., Bray, S. R., \& McGuire, E. J. (2002). The nature, prevalence, and consequences of aggression in sport. In J. M. Silva \& D. E. Stevens (Eds.), Psychological foundations of sport (pp. 328-351). Boston: Allyn \& Bacon.

Williams, J. M., \& Harris, D. V. (2001). Relaxation and energizing techniques for regulation of arousal. In Williams, J. M. (Ed.). Applied sport psychology: Personal growth to peak performance $\left(4^{\text {th }}\right.$ ed.). Mountain View, CA: Mayfield.

Wongtongkam, N., Ward, P. R., Day, A., \& Winefield, A. H. (2013). Reliability and validity of self-reported questionnaires related to adolescent violence and consequences, Thailand. International Journal of Social Science Studies, 1(2), 82-92.

Woodcock, C., Cumming, J., Duda, J. L., \& Sharp, L. (2012). Working within an individual zone of optimal function (IZOF) framework: Consultant practice and athlete reflections on refining emotion regulation skills. Psychology of Sport and Exercise, 13, 291-302. 
Woodman, T., Davis, P. A., Hardy, L., Callow, N., Glasscock, I., \& Yuill-Proctor, J. (2009). Emotions and sport performance: An exploration of happiness, hope, and anger. Journal of Sport \& Exercise Psychology, 31, 169-188.

Yalom, I. D. (1985). The theory and practice of group psychotherapy. New York, NY: Basic Books.

Zillmann, D., \& Bryant, J. (1974). Effect of residual excitation on the emotional response to provocation and delayed aggressive behavior. Journal of Personality and Social Psychology, 30(6), 782-791. http://dx.doi.org/10.1037/h0037541. 


\section{Appendix C: Assistant and Head Coach Recruitment Letter}

$\mathrm{Hi}$, my name is Michael Berrebi, and I am a doctoral candidate in the Sport \& Exercise Psychology program at West Virginia University. I am writing to ask for your voluntary assistance in my dissertation study. In this study, I plan to investigate the relationship between competitive anger, aggressiveness, and the experience of provocation in NCAA sports. I am also interested in how these variables may differ based on gender and type of sport.

If you would be willing to participate, I am hoping you will take a minute to pass along my Study link to the student-athletes on your team. If they also agree to participate, the athletes can proceed to fill out a brief questionnaire regarding competitive anger, aggressiveness, and provocation.

I want to emphasize that all information received will be kept confidential, and in no way will any of the collected information be identifiable. Therefore, any presented or published data from this study will not include names, year on team, or any other true identifiable information. I also want to stress that there are no known risks or harm associated with participation in the study. West Virginia University's Institutional Review Board acknowledgment of this project is on file.

Please consider this opportunity to assist in my study and help advance the knowledge of anger, aggression, and provocation in both athletics and the field of sport \& exercise psychology. For your assistance, I will be sending all participating coaches the complete findings of the study.

Thank you for your consideration, and if you agree to participate please let me know by email that you have passed along the Study link.

Sincerely,

Michael Berrebi, M.S.

$============$

Michael E. Berrebi, M.S.

Doctoral Candidate

Sport \& Exercise Psychology

West Virginia University

Phone: (304)-276-9580

Email: mberrebi@mix.wvu.edu

Study link
Dr. Edward Etzel

Principal Investigator

Sport \& Exercise Psychology

West Virginia University

Phone: (304)-293-7062

Email: Edward.etzel@mail.wvu.edu 


\section{Appendix D: Participant Cover Page}

\section{Dear Participant,}

This letter is a request for you to take part in a research project to assess the relationship between competitive anger, aggressiveness, and the experience of provocation in sport. This project is being conducted by Michael E. Berrebi, M.S., under the supervision of Dr. Edward Etzel, professor in the WVU College of Physical Activity and Sport Sciences for a Doctoral degree in Sport \& Exercise Psychology. Your participation in this survey study is greatly appreciated and will take approximately 15 minutes to fill out the following questionnaires.

Your involvement in this project will be kept as confidential as legally possible. All data will be reported in the aggregate. You must be a NCAA collegiate athlete and 18 years of age or older to participate. I will not ask any information that should lead back to your specific identity as a participant. Your participation is completely voluntary. You may skip any question that you do not wish to answer and you may discontinue your participation at any time. Your class standing will not be affected if you decide either not to participate or withdraw. West Virginia University's Institutional Review Board acknowledgment of this project is on file.

I hope that you will participate in this research project, as it could be beneficial in helping to understand the experience of provocation in collegiate sport, and how it relates to competitive anger and aggressive behavior. Thank you very much for your time. Should you have any questions about this letter or the research project, please feel free to contact either Dr. Edward Etzel at (304)-293-7062 or by email at Edward.Etzel@mail.wvu.edu or Michael Berrebi at (304)-276-9580 or by email at mberrebi@mix.wvu.edu.

Thank you for your time and help with this project.

Sincerely, 


\section{Appendix E: Demographic Questionnaire}

\section{University/College:}

NCAA Division Level: I () $\quad$ II $\quad() \quad$ III $\quad() \quad$ Other $\quad()$

Sport:

Gender: Male () Female ()

Age:

Year in School: Freshman () Sophomore () Junior () Senior () Other ()

Race or Ethnicity: Black/African American () White/Caucasian ()

American Indian/Alaskan Native () Hispanic or Latino () Asian or Asian American ()

Other: 


\section{Appendix F: Competitive Aggressiveness and Anger Scale (CAAS)}

Table 1

Competitive Aggressiveness and Anger Scale items, exploratory factor loadings, mean intensity of aggression and mean rating ${ }^{\mathrm{a}}$ from all athletes

\begin{tabular}{llll}
\hline Factor Items & Factor loading & Mean intensity & Mean rating \\
\hline Anger & & & 2.71 \\
I become irritable if I am disadvantaged during a match & .73 & 1.45 & 2.23 \\
I feel bitter towards my opponent if I lose & .42 & 1.58 & 3.39 \\
I get mad when I lose points & .74 & 1.63 & 2.54 \\
I show my irritation when frustrated during a game & .73 & 1.55 & 1.88 \\
I find it difficult to control my temper during a match & .66 & 2.01 & 3.12 \\
Official's mistakes make me angry & .70 & 1.65 & 1.49 \\
Aggressiveness & & 1.66 \\
Violent behaviour, directed towards an opponent, is acceptable & .73 & 2.61 & 1.98 \\
It is acceptable to use illegal physical force to gain an advantage & .86 & 2.67 & 1.78 \\
I taunt my opponents to make them lose concentration & .62 & 1.87 & 1.77 \\
I use excessive force to gain an advantage & .79 & 2.52 & 2.37 \\
I verbally insult opponents to distract them & .77 & 2.02 & 1.78 \\
Opponents accept a certain degree of abuse & & \\
\hline
\end{tabular}

${ }^{a}$ Mean rating calculated using combined data from EFA and CFA.

A primary author of this scale has granted full permission to use it in its entirety. The current version is the latest. Each question is rated by participants on a scale from 1 to 5 on the following Likert-type scale:

$1=$ almost never

2 = occasionally

$3=$ sometimes

$4=$ quite often

$5=$ almost always

For scoring, each question has a particular item severity associated with it (i.e., mean intensity) and item scores should be multiplied by this intensity to create a CAAS total. 


\section{Appendix G: Sport Provocation Questionnaire (SPQ)}

Frequency of provocation experienced

Using the following scale, please choose a number from 1-5 to indicate the frequency of your experience with each type of provocation.

$$
1=\text { never, } 2=\text { very rarely, } 3=\text { sometimes, } 4=\text { often, } 5=\text { always }
$$

1) In competitive sports, how often do you experience the following types of verbal provocation from opponents?
A) the use of curse words or verbal abuse
B) the use of racial/ethnic slurs
C) the use of violent threats

2) In competitive sports, how often do you experience the following types of provocative gestures from opponents?
A) threatening stares or looks
B) being given the finger or aggressive body or hand gestures
C) an opponent faking a hit or kick at you, or charging at you

3) In competitive sports, how often do you experience the following types of physical provocation from opponents?
A) constant or inappropriate touching
B) being purposefully shoved or tripped
C) being punched or kicked
D) being purposefully struck with an instrument (like a helmet or stick)

Frequency of negative response to provocation

Using the following scale, please choose a number from 1-5 to indicate the frequency of your negative response to each type of provocation.

$$
1=\text { never, } 2=\text { very rarely, } 3=\text { sometimes, } 4=\text { often, } 5=\text { always }
$$

4) In competitive sports, how often have you responded negatively to the following types of verbal provocation?
A) curse words or verbal abuse
B) racial/ethnic slurs
C) violent threats 
5) In competitive sports, how often have you responded negatively to the following types of provocative gestures?
A) a threatening stare or look
B) an opponent giving you the finger or aggressive body or hand gestures
C) an opponent faking a hit or kick at you, or charging at you

6) In competitive sports, how often have you responded negatively to the following types of physical provocation?
A) constant or inappropriate touching
B) purposeful shoving or tripping
C) punching or kicking
D) purposefully being struck with an instrument (like a helmet or stick)

\section{Anger level after provocation}

Using the following scale, please choose a number from 1-5 to indicate your level of anger regarding each type of provocation.

\section{$1=$ not at all angry, $2=$ slightly angry, $3=$ moderately angry, $4=$ very angry, $5=$ extremely angry, $6=\mathrm{N} / \mathrm{A}$ (have not experienced)}

7) In competitive sports, what is your level of anger when an opponent:
A) uses curse words or verbal abuse at you
B) uses racial/ethnic slurs at you
C) uses violent threats against you

8) In competitive sports, what is your level of anger when an opponent:
A) looks or stares at you in a threatening way
B) gives you the finger or aggressive body or hand gestures
C) fakes hitting, kicking, or charging at you

9) In competitive sports, what is your level of anger when an opponent:
A) constant or inappropriately touches you
B) purposefully shoves or trips you
C) punches or kicks you
D) purposefully strikes you with an instrument (like a helmet or stick) 
Intensity of response to provocation

Using the following options, please choose a number from 1-5 to indicate the intensity of your response to each type of provocation

$1=$ no response, $2=$ display mild disapproval, $3=$ verbally aggressive response, $4=$ respond with an aggressive gesture, $5=$ physically aggressive response

10) How would you respond to each of the following types of verbal provocation?
A) curse words or verbal abuse
B) racial/ethnic slurs
C) violent threats

11) How would you respond to each of the following types of provocative gestures?
A) a threatening stare or look
B) being given the finger or aggressive body or hand gestures
C) faking a hit or kick, or being charged

12) How would you respond to each of the following types of physical provocation?
A) constant or inappropriate touching
B) purposefully shoved or tripped
C) being punched or kicked
D) purposefully being struck with an instrument (like a helmet or stick) 


\section{Appendix H: Sport Provocation Questionnaire Pilot Data and Feedback}

\section{Statistical Analyses}

Table 1

Descriptive Statistics for Sport Provocation Questionnaire Subscales

\begin{tabular}{lcccccc}
\hline & $\mathrm{N}$ & Range & Min & Max & Mean & SD \\
\hline $\begin{array}{l}\text { Experience of provocation } \\
\text { Negative response to }\end{array}$ & 22 & 2.20 & 1.20 & 3.40 & 2.18 & 0.56 \\
$\begin{array}{l}\text { provocation } \\
\begin{array}{l}\text { Anger level from } \\
\text { provocation }\end{array}\end{array}$ & 22 & 3.30 & 1.00 & 4.30 & 2.15 & 1.0 \\
$\begin{array}{l}\text { Intensity of response to } \\
\text { provocation }\end{array}$ & 22 & 2.60 & 1.40 & 4.30 & 2.6 & 0.66 \\
\hline
\end{tabular}

Note: all scales except the intensity of response to provocation were measured on a 5-point Likert-type scale. 
Table 2

Correlations Among the Sport Provocation Questionnaire Subscales
1.
2.
3.
4.

1. Exp. of prov.

$--$

2. Neg. response to prov

$.738 * *$

$--$

3. Anger level from prov $.457 *$

$.773 * *$

$--$

4. Int. of response to prov $.440^{*}$

$.569 * *$

$.676^{* *}$

$--$

Note: $* \mathrm{p}<.05$, two-tailed, $* * \mathrm{p}<.01$, two-tailed 
Table 3

Internal Consistency Coefficients of the Sport Provocation Questionnaire Subscales

$\mathrm{N}$ items $\quad$ Cronbach's Alpha

Experience of provocation

10

.843

Negative response to provocation

10

.926

Anger level from provocation

10

.955

Intensity of response to provocation

10

.890

Note: Cronbach's alphas were calculated for all items in each subscale. The overall $\mathrm{N}$ in the pilot study $=22$. 


\section{Pilot Data Open Feedback}

- A total of twenty-two former high school and collegiate athletes completed the pilot survey.

- Over half (55\%) of participants had no major feedback and felt the survey covered the important aspects of provocation in competitive sports.

- One participant suggested being clear in the "response to provocation" section that the questionnaire is asking about your negative or harmful response to provocation. This edit was made, as this type of response is the most likely to produce aggressive behaviors.

- One participant suggested being clear about an opponent purposefully striking you with an instrument (like a stick). This change was also made. It is possible to be accidentally hit by an opponent's instrument, who may have no harmful intent in his/her actions.

- One participant mentioned the possibility of provocation following social media use. While the use of social media is a novel way to potentially provoke opponents, this study is focused on direct provocation occurring on the playing field.

- One participant who played a collision sport said that some coaches encouraged players to provoke his/her opponents in order to "gain an edge". Coach behavior can certainly play an impact in athlete aggressiveness, although this study is focused on athlete-toathlete provocation and how it relates to competitive anger and aggression. 
- Two participants disclosed that provocation could come from parents, fans, and coaches. While this is certainly true, it is outside the scope of this study to look at spectator influence or parent/coach behaviors.

- Two participants claimed that sometimes when opponents provoked their teammates it actually provoked him/her to get angry. This is important to note, but it is also outside the scope of the athlete-athlete provocation experience that can lead to anger and aggressive acts.

- Four participants indicated the possibility of a positive response to provocation (i.e., laughing it off or talking calmly with the referee). While these responses are the most beneficial to athlete, they would likely not produce high levels of competitive anger or aggressive behavior. 